\title{
A taxonomic review of the family Trachipteridae (Acanthomorpha: Lampridiformes), with an emphasis on taxa distributed in the western Pacific Ocean
}

\author{
JENNIFER M. MARTIN ${ }^{1,2^{*}}$ \& ERIC J. HILTON ${ }^{1,3}$ \\ ${ }^{1}$ Department of Fisheries Science, Virginia Institute of Marine Science, College of William \& Mary, Gloucester Point, VA, 23062, USA \\ ${ }^{2}$ Current address: Thomas Nelson Community College, Hampton, VA, 23666, USA \\ ${ }^{3}$ ๑ $h$ https://orcid.org/0000-0003-1742-3467 \\ *Corresponding author. martinj@tncc.edu; @ ittps://orcid.org/0000-0001-7417-9435
}

\begin{abstract}
The family Trachipteridae - the Ribbonfishes, Dealfishes, and their relatives - has a circumglobal distribution, with at least 10 species in three genera ( $\mathrm{Zu}$ Walters \& Fitch 1960, Desmodema Walters \& Fitch 1960, and Trachipterus Goüan 1770) that are characterized by elongate, extremely laterally compressed bodies, large eyes, absence of ribs, spines on lateral-line scales, greatly protrusible mouths, and a lack of pelvic fins in adults. They are also known for the drastic morphological changes that occur during ontogeny. Trachipterids are poorly represented in collections due to the fragile nature of their bodies. Most studies of the Trachipteridae have been limited by the numbers, developmental stages, and the completeness of the specimens that were examined. Along with the lack of available material, incomplete and conflicting character information compounds the taxonomic confusion of Trachipteridae. Despite the body of regional revisions that have examined trachipterid taxonomy, none have synthesized a suite of morphological characters across ontogeny. The goals of this paper are to (1) revise the family Trachipteridae, (2) revise the genera Trachipterus, Zu, and Desmodema, including information regarding ontogeny and biogeography, and 3) address the alpha taxonomy of Zu, Desmodema, and Trachipterus from the western Pacific Ocean. We recognize possibly five species of Trachipterus as being present in the western Pacific, as well as two species of both $Z u$ and Desmodema. Despite additions to the specimen base that allows refinement of taxonomy and diagnoses, there are still large knowledge gaps associated with the taxonomic review of Trachipteridae. These reflect incomplete understanding of geographic distribution of taxa which may mask unrecognized taxonomic variability. The genus Trachipterus specifically remains problematic and will require greater detailed global study. Early life history stages remain unknown for several taxa which hinders full interpretation of ontogenetic transitions. Protracted transitions, some of which are clarified here, further confuse stage-based diagnoses and must be considered in future analyses of this family.
\end{abstract}

Key words: ribbonfishes, Trachipterus, Desmodema, Zu, ontogenetic characters

"So little is known about the life history of the fishes belonging to this family that any new facts, however apparently trivial in themselves, which relate to their appearance and distribution acquire exceptional value, and should be recorded in full; especially should the changes which are now known to take place during the progress of the fish towards maturity be carefully noted and the results tabulated. For it is only by the collection and collation of these scattered references that we may in time hope to gain some insight into the economy of the strange denizens of the ocean depths."

J. Douglas Ogilby, 1898, regarding Trachipteridae

\section{Introduction}

The family Trachipteridae - the Ribbonfishes, Dealfishes, and their relatives - has a circumglobal distribution, with at least 10 species in three genera ( $Z u$ Walters \& Fitch 1960, Desmodema Walters \& Fitch 1960, and Trachipterus 
Goüan 1770; Fig. 1A). These fishes (Figs.1-3) are characterized by elongate, extremely laterally compressed bodies, large eyes, the absence of ribs, and spines on the lateral line scales (Olney et al. 1993), greatly protrusible mouths (Ferry et al. 2019), and a lack of pelvic fins in adults. They are also known for drastic morphological changes that occur during ontogeny (Hubbs 1925). Much of the work on the taxonomy and biogeography of Trachipteridae has relied on regional descriptions (e.g., southwestern Pacific, Ogilby 1898; New Zealand, Hamilton 1916; Mediterranean and northeast Atlantic, Palmer 1961, Lipej et al. 2018, Macali et al. 2020); northwest Atlantic, Purchase 2017; East Pacific, Fitch 1964, Angulo \& López-Sánchez 2017; Tasmania, Scott 1983; South African waters, Heemstra \& Kannemeyer 1984; Japan, Hayashi 2002; Korea, Ji et al. 2009; North Pacific, Savinykh \& Baitalyuk 2011) with limited morphological data and incomplete analysis. Although these localized reviews benefit biodiversity assessments of specific areas, such descriptions may not account for population-level differences in those species suggested to have wide-ranging or even circumglobal distributions.

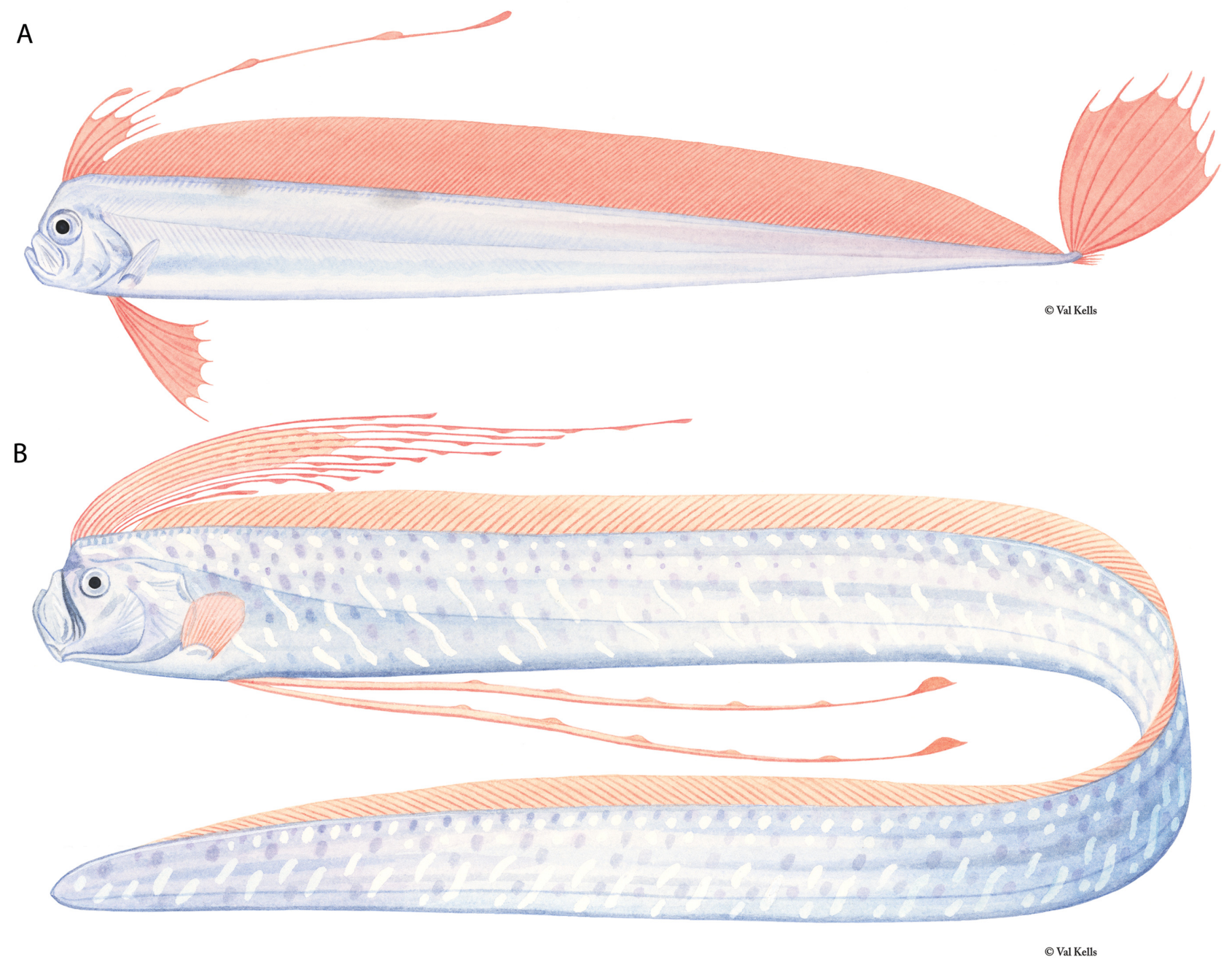

FIGURE 1. Illustrations of a representative A, Trachipteridae (Trachipterus altivelis) and B, Regalecidae (Regalecus glesne). Illustrations (C) Val Kells, used with permission. The trachipterid shown here is a large juvenile with pelvic fins and elongate dorsal rays. Regalecids retain these characters into the adult stage as shown here.

Like their sister group the oarfishes (Regalecidae, Olney et al., 1993; Fig. 1B), trachipterids are poorly represented in collections due to the fragile nature of their bodies (i.e., they are often damaged during collection). Most studies of Trachipteridae have been limited by the numbers, developmental stages, and the completeness of the specimens that were examined. Relative to the adult stages, juvenile trachipterids are more common in ichthyological collections. This is likely due to their greater abundance and the near shore habitats they occupy (vs. the open pelagic, often deep-water habitats of adults). Additionally, the distinct morphology of juvenile specimens allows for proper identification at the family level, but not at a finer scale. It is not uncommon for taxonomic reviews and identification keys for Trachipteridae to compare and base species descriptions on adult specimens of Trachipterus 
and Desmodema and juvenile specimens of $Z u$ (e.g., Walters \& Fitch 1960; Palmer 1961; Fitch 1964; Ji et al. 2009). To complicate comparisons further, the drastic morphological changes that trachipterids undergo during ontogeny are not directly correlated with size. The length at which juvenile characters are lost in trachipterid fishes is variable and can occur relatively late in $Z u$, in which specimens up to $800 \mathrm{~mm}$ SL retain juvenile characters, such as elongate dorsal- and pelvic-fin rays and a scalloped ventral body margin (Heemstra \& Kannemeyer 1984; JMM, pers. obs.). Juvenile characters, including elongate fin-rays and spotted pigmentation patterns, can be retained in Trachipterus specimens up to $600 \mathrm{~mm}$ SL (JMM, pers. obs.). Based on generic descriptions provided by Walters \& Fitch (1960), Palmer (1961), and Fitch (1964), the species diagnoses in these studies were based solely on subadult $Z u$, for example. Limited species descriptions, in part, are a likely reason for misidentifications of adult specimens in many collections. More recent studies, such as that of Heemstra \& Kannemeyer (1984), acknowledge the rarity of adult specimens in collections but their diagnoses remain limited and include data from only one adult specimen of Z. cristatus Bonelli 1820 and two adult specimens of Z. elongatus Heemstra \& Kannemeyer 1984, all from South African waters.
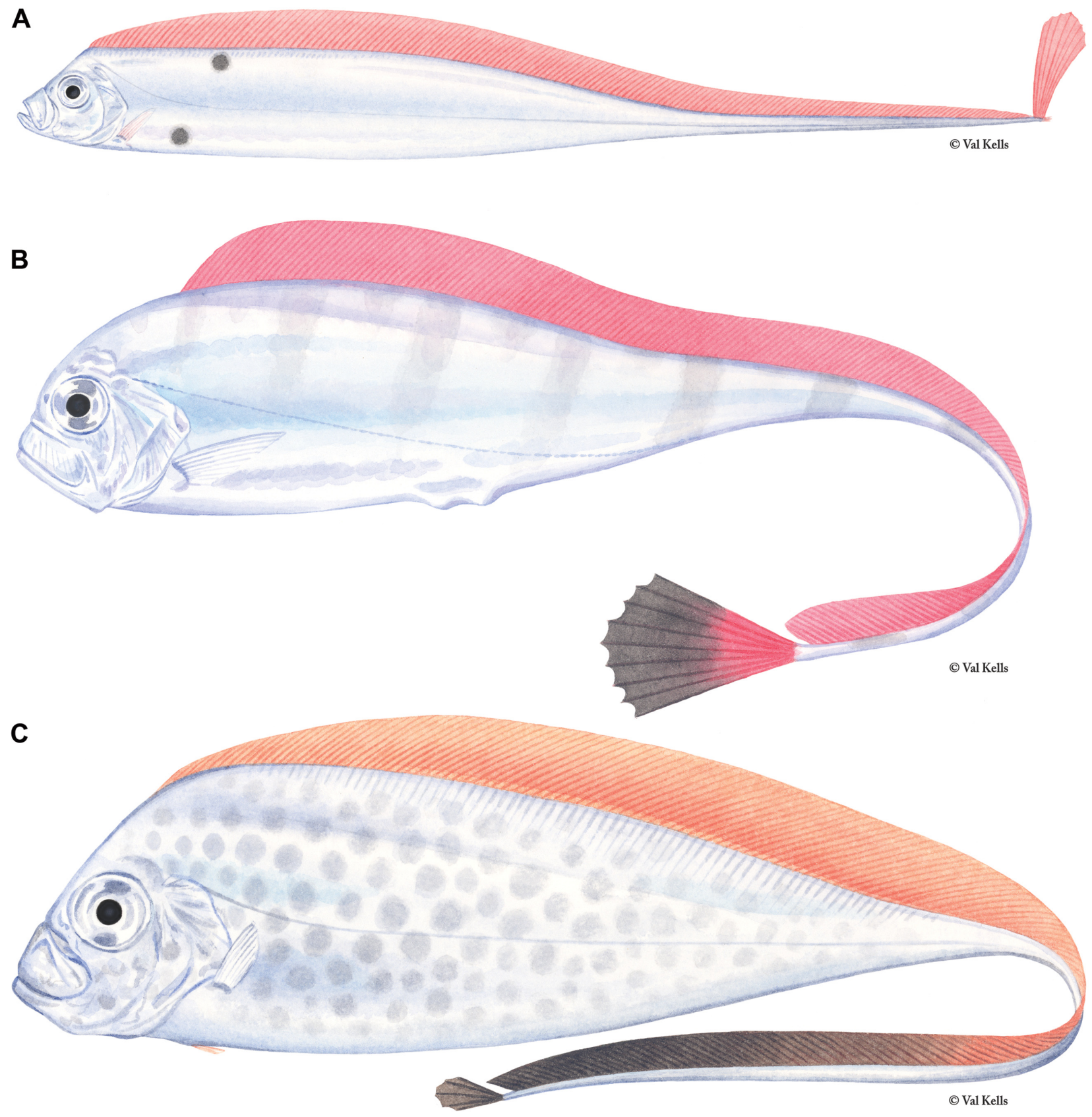

FIGURE 2. Illustrations of representatives of the three genera of Trachipteridae. A, Trachipterus fukuzakii (large juvenile). B, Zu cristatus (large juvenile). C, Desmodema polystictum (juvenile). Illustrations (C Val Kells, used with permission. 


\section{A}

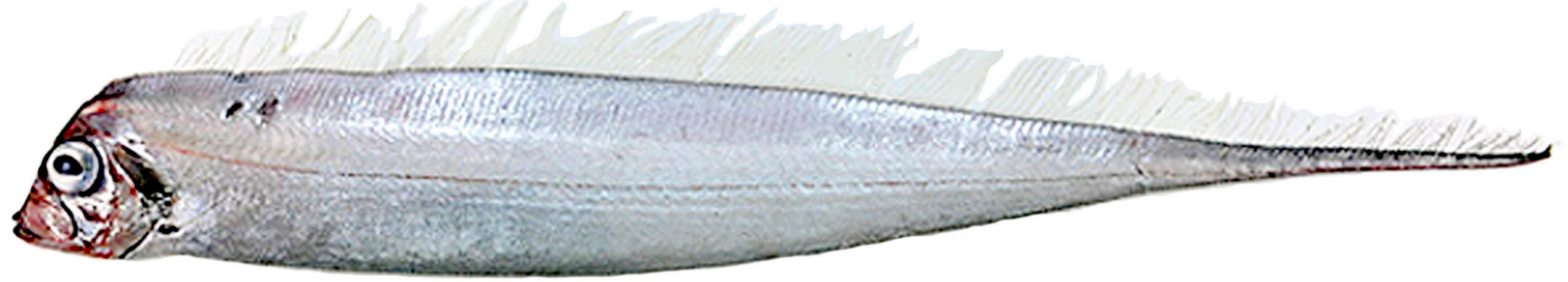

B
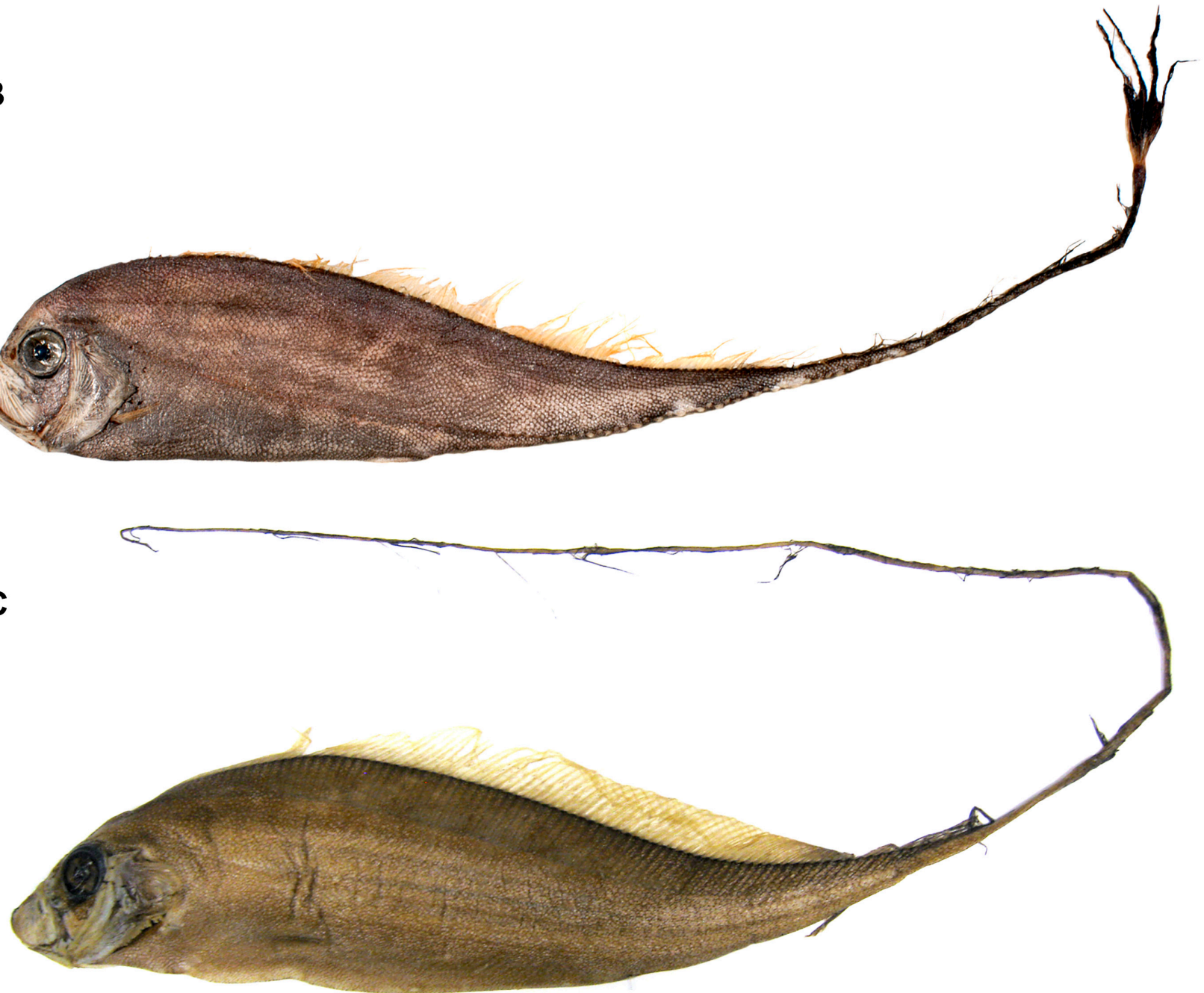

C

FIGURE 3. Photographs of adult representatives of the three genera of Trachipteridae. A, Trachipterus ishikawae Jordan \& Snyder, 1901; KPM-NI 48485; C Hiroshi Senou; obtained from http://fishpix.kahaku.go.jp. B, Zu cristatus (Bonelli, 1820); CSIRO H-6325-01; 1142 mm SL. C, Desmodema lorum Rosenblatt \& Butler 1977. Holotype; USNM 216726; 1098 mm SL.

Along with the lack of available material, incomplete and conflicting character information compounds the taxonomic confusion of Trachipteridae. For example, Walters \& Fitch (1960), Palmer (1961), Fitch (1964), Scott (1983) and Heemstra \& Kannemeyer (1984) all noted the absence of scales at all life stages as a diagnostic character for Trachipterus, which in turn has been used to distinguish Trachipterus from $\mathrm{Zu}$, and according to some authors, Trachipterus from Desmodema (Rosenblatt \& Butler 1977). However, scales are present in adult specimens of Trachipterus examined in the present study. The putative absence of scales is therefore an artifact of the condition 
of the specimens being examined, and cannot be used to diagnose the genus. Taxonomic revisions, including a synthesis of global data partitioned by ontogenetic stages, are clearly needed for the genera in Trachipteridae. As these fishes are relatively rare in collections, limited research material has impeded a comprehensive review (in terms of geography and ontogeny) of the family. As material in collections accumulates and new geographic regions of the ocean are sampled, the number of specimens, particularly of adult stages, that are available for examination increases. There are now more specimens available to fill in the gaps of both the ontogenetic and geographic continua in the studies by previous authors, therefore making this review timely.

Despite the regional revisions that have examined trachipterid taxonomy, none have synthesized a suite of morphological characters across ontogeny. Also, no recent taxonomic studies have focused on a comprehensive review of ribbonfishes from the western Pacific. Confusion in the literature regarding the ontogeny, biogeography, and taxonomy of the family prompted the examination of newly collected material and museum specimens of trachipterid genera from all over the globe. The objectives of the study are to 1) revise the family Trachipteridae, 2) revise the genera Trachipterus, $Z u$, and Desmodema and incorporate information regarding ontogeny and biogeography, and 3) discuss the alpha taxonomy of Zu, Desmodema, and Trachipterus from the western Pacific Ocean (with a focus on waters surrounding Japan, Australia, and New Zealand).

\section{Methods}

Body measurements and fin-ray counts follow Heemstra \& Kannemeyer (1984) and Ji et al. (2009), with minor modifications as noted below in the sections for each genus. Data were collected from examination of radiographs, cleared and stained specimens, dried, fresh-frozen, alcohol-preserved and photographs and videos of live and freshly caught specimens. Because trachipterids, particularly larvae and juveniles, are very fragile, nearly all specimens were damaged in some way and not all measurements or counts were made on all the material that was examined. If the caudal fin of a specimen is missing, length is given as the snout-vent length (SV) measurement only. If a specimen is preserved with the jaw in a protruded state, the protracted distance is subtracted to determine the standard length (SL). Scale terminology (i.e., cycloid vs. ctenoid) follows Roberts (1993), although note that our description of "spinous scales" is not intended to suggest homology of Robert's spinoid scales, a form of ctenoid scale, but rather only to describe a cycloid scale that bears one or more lateral spines (as some cycloid scales of some other taxa are known to have; Roberts, 1993). Complete dorsal-fin ray counts could only rarely be counted. Affected measurements and/or counts were removed from analysis. Meristic, morphometric and character descriptions from the literature were also incorporated. No histological determination of maturity was conducted, but rather "adult" condition was identified by the absence of morphological characters that were present in specimens considered to be juveniles at smaller sizes.

Fricke et al. (2020), Wiley \& Johnson (2010) and Van der Laan et al. (2014) were consulted for taxonomic names and authors. Institutional abbreviations follow Sabaj (2020).

It should be noted here that during final revision of the manuscript for this paper, which is based on the text from the first author's dissertation (Martin 2015), it was discovered that several passages from Martin (2015) were copied verbatim or nearly so by Angulo \& López-Sánchez (2017) in the Remarks sections for Trachipterus (two passages on their page 584), Zu cristatus (page 586), and Desmodema polystictum (page 579). We have retained the wording from JMM's dissertation for these sections (Martin 2015, pages 36, 38, 55, 75, respectively), but use this note to clarify that those passages were first written and published by Martin (2015).

\section{Order Lampridiformes Goodrich 1909}

\section{Family Trachipteridae Swainson 1839}

\section{Ribbonfishes, Dealfishes}

Diagnosis (adults). Body elongate (to $2 \mathrm{~m} \mathrm{SL}$ ), ribbon-like, and laterally compressed (strongest compression in Trachipterus, least in $\mathrm{Zu}$ ). Body depth decreasing gradually, tapering to a narrow caudal peduncle. Upper jaw highly 
protrusible, maxilla broad. Both jaws with recurved pointed teeth. Vomer with 1-2 median teeth. Nostrils single (2 nostrils in juvenile Desmodema). Anal fin absent. Dorsal fin originates above or slightly posterior to the eye. Dorsal fin long, extending entire body length to tail. Dorsal-fin rays 120-197, first 5-6 rays reduced in length during ontogeny, and only represented by fin bases in adults (elongate and flexible in juveniles); lateral spinules present along length of the fin rays (most obvious in juveniles). Caudal fin with either 1 (Desmodema) or 2 (Trachipterus and $Z u$ ) lobes; total caudal-fin rays usually 6 to 17; ventral rays of caudal fin either reduced (elongate in juvenile Trachipterus and $\mathrm{Zu}$ ) or absent (in Desmodema); dorsal rays of caudal fin fan-like and sometimes turned dorsally (Trachipterus and $Z u$ ); caudal-fin rays with minute, laterally projecting spinules, weak or absent on central rays. Pectoral fin with $1+10-14$ rays; the first fin ray extremely short. Pelvic fin with 5 to 11 rays (elongate and fanlike in juveniles), either reduced to bases or lost entirely (as in Desmodema); pelvic-fin rays with minute, laterally projecting spinules, weakly developed or absent on posterior-most pelvic rays. Skin covered with bony, bump-like tubercles and pierced with numerous pores. Thin cycloid scales present in all genera. Lateral-line scales with 1 (occasionally 2) spines. Ribs absent, swim bladder rudimentary or absent. Posterior caudal vertebral centra elongate, 2 to 4 times longer than the tenth vertebrae.

Color. Body silver to dark black or brown; frontal profile from dentary symphysis to dorsal-fin origin black. Bright red or crimson dorsal fins in life, black once preserved.

Remarks. Although there are more than thirty nominal species of Trachipteridae (Table 1), there are likely fewer than 10 valid species, with significant taxonomic uncertainty remaining in Trachipterus. Despite the abundance of alpha-taxonomic issues, three genera are readily recognized: Trachipterus, Desmodema, and Zu. Previous generic keys have incorporated characters here found to be incorrect or are the result of an amalgamation of numerous life history stages (for examples, see Walters \& Fitch 1960; Palmer 1961; Fitch 1964; Scott 1983; Heemstra \& Kannemeyer 1984; and Hayashi 2002). The following key can be used for identification of both juvenile and adult stages, and incomplete specimens.

\section{Key to the Genera of Family Trachipteridae}

1 Caudal fin without two lobes, caudal-fin rays running parallel to the long axis of the body; ventral body margin is smooth with

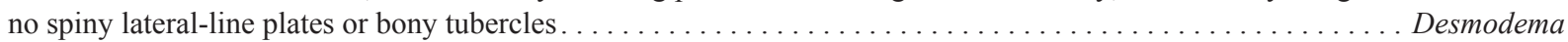
Caudal fin with two lobes, fin rays on the dorsal lobe set at a steep angle oriented dorsally relative to the long axis of the body, ventral caudal rays elongate in juveniles, reduced to bases in adults; ventral edge of caudal region with spiny lateral-line plates

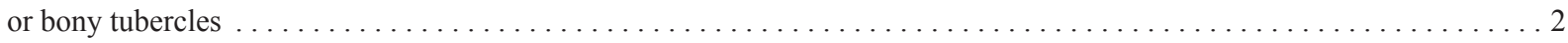
Lateral line runs in a zigzag pattern as an alternating series of spiny plates along the ventral edge of the caudal region; ventral

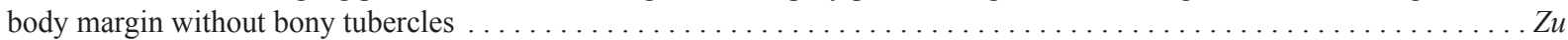
Lateral line runs straight, well above the ventral edge of the caudal region; ventral body margin with bony tubercles.......

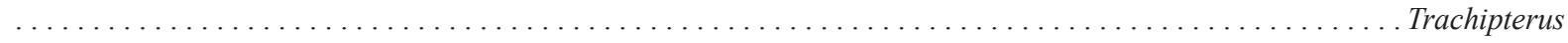

\section{Trachipterus Goüan 1770}

Figures 1A, 2A, 3A, 4-7, 9-17

Type species. Cepola trachyptera Gmelin 1789, by subsequent designation; genus first described without a type species.

Trachipterus Goüan 1770. Hist. Pisc. p. 104 (Cepola trachypera Gmelin)

Gymnogaster Brünnich 1788. K. Dansk. Vid Selsk. p. 408 (arcticus)

Trachyterus Bloch \& Schneider 1801. Blochii Syst. Ichth. p. 480 (taenia)

Bogmarus Bloch \& Schneider 1801. Blochii Syst. Ichth. p. 518 (islandicus) [name only]

Argycticus Rafinesque 1810. Caratt. Nuov. Gen. p. 55 (quadrimaculatus)

Cephalepis Rafinesque 1810. Ind. Ittiol. Siciliana. p. 54 (octomaculatus)

Trachypterus Cuvier 1816. Le Règne Animal.

Epidesmus Ranzani 1818. Opusc. Sci. Bologna. p. 137 (maculatus)

Material Examined. Here we list holotypes of species of Trachipterus that were examined in this study, as well as all other Trachipterus specimens examined. However, the latter are all listed as Trachipterus spp. pending a specieslevel revision of the genus, which is beyond the scope of this paper. 


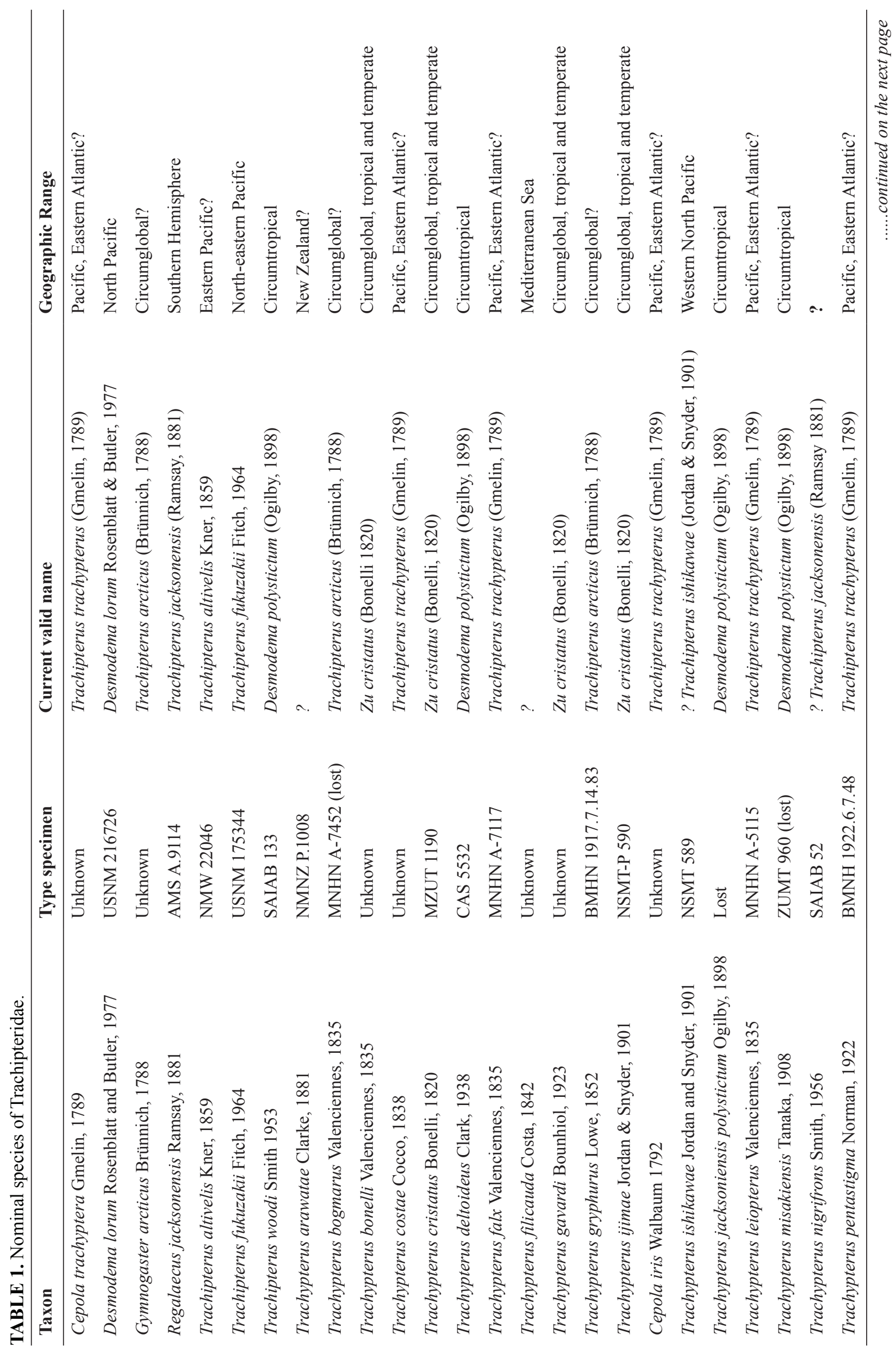




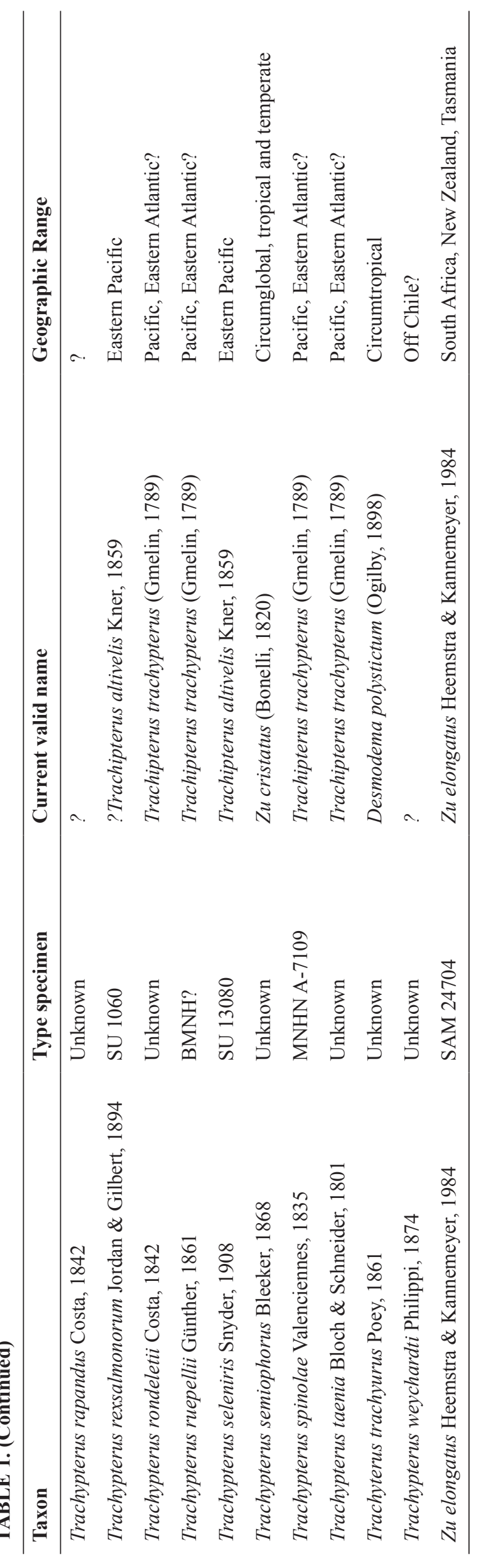


Holotypes examined: Trachipterus arawatae Clarke 1881, NMNZ P.1008 (Holotype, 551 mm SL, Pacific, New Zealand, South Island, Westland); Trachipterus ishikawae Jordan \& Snyder 1901, NSMT-P 589 (Holotype, $1250 \mathrm{~mm}$ SL, Pacific, Japan, off mouth of Tokyo Bay); Trachipterus jacksonensis (Ramsay 1881), AMS A.9114 (Holotype, 736 mm SVL, Pacific, Australia, New South Wales, Manly Beach); Trachipterus gryphurus Lowe 1852, BMNH 1917.7.14.83 (Holotype, radiograph, 635 mm SL, Atlantic, Portugal, Madeira Islands); Trachipterus pentastigma Norman 1922, BMNH 1922.6.7.48 (Holotype, radiograph, $121.5 \mathrm{~mm}$ SL, Pacific, Japan); Trachypterus rexsalmonorum Jordan \& Gilbert 1894, CAS:SU(ICH): 1060 (Holotype, radiograph only, 284 mm SL, Pacific, California, off San Francisco).

Other specimens of Trachipterus spp. examined. Because of the uncertain alpha taxonomy of the genus Trachipterus, which is beyond the scope of this paper, we list all specimens as spp., although many are cataloged as species based on distribution. AMS IB.6691 (1060 mm SL, Pacific, Australia, New South Wales); AMS I.17712 (Dry specimen, 1400 mm TL, Pacific, Australia, New South Wales, Port Jackson); AMS I.21367-035 (165 mm SL, Pacific, Australia, New South Wales, Newcastle); AMS I.24575-001 (Radiograph, 30 mm SL, Pacific, Australia, Queensland, Coral Sea); AMS I.24159-001 (Radiograph, 35 mm SL, Pacific, Australia, New South Wales, Jervis Bay); AMS I.25640-001 (1440 mm SL, Pacific, Australia, New South Wales, off Sydney); AMS I.32117.001 (1860 mm SL, Pacific, Australia, New South Wales, Crowdy Bay); AMS I.36212-001 (1800 mm SL, Pacific, Australia, New South Wales, BMNH 2010.3.23.16-17 (2 specimens, 32.7-59.5 mm SL, Atlantic, off northwest Africa); BMNH 2010.3.23.21-26 (6 specimens, radiographs, 50-120.3 mm SL, Atlantic, King's Trough Flank); CSIRO H1536-1 (1454 mm SL, Pacific, Tasmania, southwest of Tasmania); CSIRO H241 (1100 mm SL, Pacific, Tasman Sea, southeast Tasmania, east of Maria Island); CSIRO H243 (471 mm SVL (1089 mm TL), Pacific, Tasman Sea, Cascade Plateau); CSIRO H245 (1370 mm SL, Pacific, Tasman Sea, southeast Tasmania, east of Maria Island); CSIRO H932-1 (Radiograph, 237.4 mm SL, Pacific, Tasman Sea, southeast Tasmania, Maria Island); CSIRO 2036 (Radiograph, 204.01 mm SL, Pacific, Tasman Sea, Fortescue Bay); CSIRO 2037 (151.24 mm SL, Pacific, New Zealand, Cook Strait); CSIRO 3859-01 (Radiograph, 980 mm SL, Pacific, northwestern Tasmania, Bass Strait); CSIRO B3912 (Radiograph, $141.1 \mathrm{~mm}$ SL, Pacific, Tasman Sea, southeast Tasmania, southeast of Maria Island) CSIRO H4947 (183.32 mm SVL, Pacific, Tasman Sea, South Tasman Rise); CSIRO H6328 (1970 mm SL, Pacific, western Tasmania, west of Granville Harbour); CSIRO unregistered GT 1160 (Frozen, 944 mm SL, Pacific, southern Tasmania, off Maatsuyker Island); CSIRO unregistered (Frozen, $185 \mathrm{~mm} \mathrm{SL}$, Pacific, Tasman Sea, eastern Tasmania, Adventure Bay); HUMZ 69219 (1346 mm SL, Pacific, Japan, Hokkaido); HUMZ 80914 (1209 mm SL, Pacific, central Pacific); HUMZ 132216 (239 mm SL, unknown); HUMZ 141393 (55.9 mm SL, Pacific, Japan); HUMZ unregistered (630 SVL, unknown); KPM-NI0007802 (254 mm SL, Pacific, Japan, Shizuoka Prefecture); KPMNI0010429 (2472 mm SL, Pacific, Japan, Shizuoka Prefecture); KPM-NI0011445 (2240 mm SL, Pacific, Japan, Tokyo); KPM-NI0011644 (2350 mm SL, Pacific, Japan, Kanagawa Prefecture); KPM-NI0012738 (2114 mm SL, Pacific, Japan, Shizuoka Prefecture); KPM-NI0012764 (2472 mm SL, Pacific, Japan, Kanagawa Prefecture); KPMNI0012765 (1889 mm SL, Pacific, Japan, Aichi Prefecture); KPM-NI0012766 (2152 mm SL, Pacific, Japan, Aichi Prefecture); KPM-NI0013001 (1680 mm SL, Pacific, Japan, Shizuoka Prefecture); KPM-NI0013233 (1960 mm SL, Pacific, Japan, Kanagawa Prefecture); KPM-NI0016297 (285 mm SL, Pacific, Japan, Chiba Prefecture); KPMNI0017321 (2000 mm SL, Pacific, Japan, Aichi Prefecture); KPM-NI0023327 (215 mm SL, Pacific, Japan, Akita Prefecture); KPM-NI0023505 (21 mm SL, Pacific, Japan, Shizuoka Prefecture); KPM-NI0025081 (1880 mm SL, Pacific, Japan, Kanagawa Prefecture); KPM-NI0027573 (61 mm SL, Pacific, Japan, Kanagawa Prefecture); MCZ 3895 ( 8 specimens, radiographs (of the largest), 19-230 mm SL, Atlantic, Mediterranean, off Sicily); MCZ 8644 $(\approx 184 \mathrm{~mm}$ SL, Atlantic, northeastern, Portugal, Azores, Fayal); MCZ 8645 (2 specimens, radiographs, 160-213 mm SL, Atlantic, northeastern, Portugal, Azores, Fayal); MCZ 58926 (4 specimens, 17-32.5 mm SL, Atlantic, eastern central Atlantic); MCZ 58958 (11 mm SL, Atlantic, western central Atlantic); MCZ 58959 (16 mm SL, Atlantic, western central Atlantic); MCZ 135299 (Radiograph, 1535 mm SL; no collection data); MCZ 143323 (estimated at $1000 \mathrm{~mm}$ SL, head only, Atlantic, northwestern, off Delaware); MCZ 147873 (8 specimens, radiographs (6), 21-61 mm SL, Atlantic, Mediterranean, off Naples); MCZ 163198 (Radiograph, $\approx 415 \mathrm{~mm} \mathrm{SL}$, Atlantic, northwestern, Bear Seamount); NMI 63.1937 (509 mm SL, Atlantic, Ireland, Donegal); NMI 66.1994 (305 mm SL, Atlantic, Ireland); NMNZ P.001961 (249 mm SL, Pacific, New Zealand, Stewart Island); NMNZ P.002056 (cleared and stained, 432 mm SL, Pacific, New Zealand, South Island, Marlborough); NMNZ P.007087 (89.7 mm SL, Pacific, New Zealand, North Island, Wellington); NMNZ P.016410 (495 mm SL, Pacific, New Zealand, Kermedec Trench/Louisville Ridge); NMNZ P.016453 (1880 mm SL, Pacific, New Zealand, North Island, South Auckland); NMNZ P.031676 (603 mm SL, Pacific, New Zealand, South Island, Marlborough); NMNZ P.037649 (Radiograph only, 960 mm SL; 
Pacific New Zealand, South Island, Nelson); NMNZ P.037650 (Radiograph only, 770 mm SL; Pacific New Zealand, South Island, Marlborough); NMNZ P.037894 (183 mm SL, Pacific, New Zealand, South Island, Otago); NMNZ P.041259 (564 mm SL, Pacific, New Zealand, South Island, Marlborough); NMNZ P.041957 (2023 mm SL, Pacific, New Zealand, North Island, Taranaki); NMNZ P. 041970 (Radiograph, 1724 mm SL, Pacific, New Zealand, North Island, Karikari Peninsula); NMNZ P.042021 (797 mm SL, Pacific, New Zealand, South Island, Parapara); NSMTP 12367 (604 mm SL, Pacific, Japan, Suruga Bay); NSMT-P 40508 (255 mm SL, Atlantic, Suriname); NSMT-P 57538 (101.9 mm SL, Pacific, western North Pacific); NSMT-P 57554 (6 specimens, 45-115 mm SL, Pacific, western North Pacific); NSMT-P 57560 (13 specimens, 105-220 mm SL, Pacific, western North Pacific); NSMT-P 57670 (4 specimens, 20-155.9 mm SL, Pacific, western North Pacific); NSMT-P 76536 (80 mm SL, Pacific, Japan, Ryukyu Islands); QVM 1971.5.3 (75 mm SVL, Pacific, Tasman Sea, eastern Tasmania); QVM 1973.5.36 (212 mm SL, Pacific, northern Tasmania, Bass Strait); VIMS 25015 (1205 mm SL; Atlantic, Charlie Gibbs Fracture Zone); VIMS 42302 (est. 1000 mm SL; Atlantic, Charlie Gibbs Fracture Zone); NMP P6V 5066 (Dry specimen, 1500 mm, Atlantic, Mediterranean, France, Marseille).

Diagnosis (Adults). Body long (to $2640 \mathrm{~mm} \mathrm{SL}$ ), laterally compressed (more compressed than $Z u$ or Desmodema) tapering to a thin caudal peduncle, not greatly constricted posterior to the vent (Fig. 3). Ventral edge of body nearly straight with pointed tubercles. Dermal tubercles and pore system present throughout trunk. Scales cycloid and deciduous, covering the body (commonly overlooked). Lateral line dropping to mid-body on trunk just posterior to the pectoral fins, continues well above the ventral edge in the tail region until the base of the caudal fin; lateralline plates armed with 1 (rarely 2) subconical spines, typically with one peak (rarely 2), spines most prominent in caudal region of larger adults. Relative to the lateral-line scale, spines angled anteriorly (not pointed laterally as in Desmodema or $Z u$ ). Body depth at pectoral fin 3.3-4.5 in SV. Premaxilla with 5-20 strong caniniform teeth, 5-27 teeth on dentary; vomer with 1-4 (most often 1-2) strong teeth; palatine teeth either absent or up to 3 (at least one Trachipterus sp. with 12-15 teeth on each palatine). Gill rakers on the first arch 2-4 + I +7-10, all with multiple spinules. Pseudobranch well developed. Branchiostegal rays 6 . Dorsal fin originating from $1 / 2$ eye diameter to posterior margin of eye. Dorsal-fin rays 133-194, first 4-7 (typically 5 or 6) of which are stout; rays evenly spaced (typically broken in adults); interspace present, remaining fin rays filamentous. Pectoral-fin with one exceptionally short fin ray followed by $8-16$ rays $(1+8-16)$; short fin ray typically decreasing in length with increasing SL; rarely fused with second ray. Pelvic fins appear absent in adults, 4-9 fin-rays decrease in length as SL increases until only a slitlike opening is apparent (as in adult $Z u$, never healed as in Desmodema). Anal fin absent. Caudal fin in two parts; dorsal lobe set at steep, anterior-facing angle to the caudal peduncle, with 8-9 rays (rarely 10), two outermost rays thicker than innermost rays; ventral lobe with up to 6 rays, all greatly reduced with the bases remaining as rudimentary spine-like elements. Minute spinules on the dorsal, pectoral, and caudal-fin rays greatly reduced or absent. Anus located on midventral line (rarely on the left side). Total vertebrae 69-102.

Color (adults). Body silver, occasionally with a dark patch spread across the ventral region anterior to the anus; dentary and premaxilla black in frontal view. Dorsal-fin rays bright red or crimson, dorsal midline black; caudal fin black (red through at least large juveniles).

Remarks. Most descriptions of the genus Trachipterus have primarily relied on data from juvenile specimens. True adult specimens (vs. large juveniles) have rarely been examined and reported in the literature. Savinykh \& Baitalyuk (2011) completed a limited morphological examination of 20 large specimens of Trachipterus from the northern Pacific Ocean. These authors list a maximum size for the genus as $2900 \mathrm{~mm}$ SL (this is mistakenly listed as $290 \mathrm{~mm}$, rather than $\mathrm{cm}$, in Savinykh \& Baitalyuk 2011: table 3) but only report meristic and morphometric data for specimens ranging in size from $910-1790 \mathrm{~mm}$ SL. They assumed all individuals examined had undergone metamorphosis, a process that is considered herein to be very protracted and not directly determined by body size (see below). The authors do not report any information regarding pelvic fins, a character that changes drastically throughout ontogeny, and therefore developmental stages of these specimens cannot be inferred. The present study is the first account to include data from large adult specimens $(>1790 \mathrm{~mm} \mathrm{SL}, \mathrm{N}=16)$ in a revised description of the genus and provides the first synthesized account of the biology and habitat of large adult Trachipterus.

Examination of larger specimens than in previous studies has also allowed for more accurate descriptions of the ontogeny of the pelvic fin (discussed further in Ontogeny: juvenile to adult). In large adult specimens, pelvic-fin rays are completely reduced to the bases, with no shortened pelvic-fin rays, or stubs, as present in larger juveniles. As with the largest specimens of $Z u$, a slit remaining at the pelvic-fin origin is the only remnant of the elongate pelvic-fin rays present in juveniles (Fig. 4). To date, no specimens of Trachipterus examined have the pelvic scar completely healed over, as found in Desmodema. 


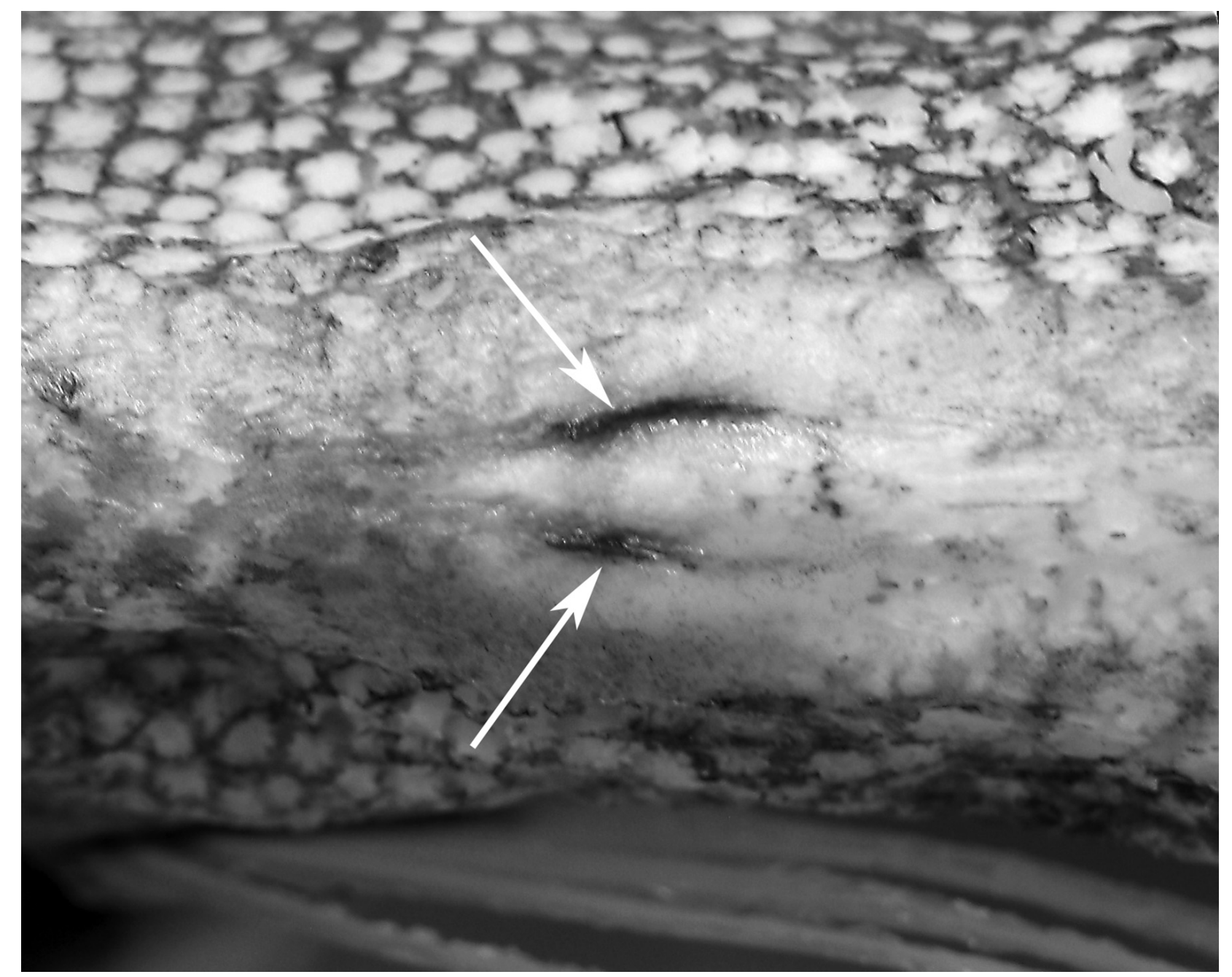

FIGURE 4. Trachipterus sp. (KPM 10429; $2472 \mathrm{~mm} \mathrm{SL}$ ). Ventral view of pelvic "slits" indicating position of the pelvic fin that is present in juveniles (white arrows). Anterior facing left.

Pectoral-fin ray counts previously reported for Trachipterus range from 8-14. Specimens examined in this study greater than $50 \mathrm{~mm}$ SL all show the pectoral fin consisting of one short, spine-like element (Fig. 5) followed by $9-16$ longer fin rays, here notated as 1+9-16. It is unclear if most previous authors included the short element as part of the total pectoral-fin-ray count as, in some specimens, this element can be easily overlooked. One specimen (AMS IB.6691 $645 \mathrm{~mm} \mathrm{SV}$ ) has a pectoral fin-ray count of 1+16 (left) and 1+15 (right), counts not previously reported in the literature for Trachipterus.

Roberts (2012) referred to figures of a so-called "accessory caudal fin" in juvenile and adult specimens of Trachipterus with fin rays extending distally and ventrally and suggested that this structure might be an anal fin. The absence of an anal fin, in part, defines the family Trachipteridae, and is a synapomorphy uniting the Trachipteridae + Regalecidae clade (Olney et al. 1993). No citation was given for this structure and it is likely to be one of two things: 1) the reduced rays on the ventral caudal lobe in Trachipterus (as in McCoy 1886, plate 122, fig. 2; Hamilton 1916); or 2) haemal spines that sometimes pierce the ventral body wall in the posterior portion of the tail region. This latter condition is not uncommon in Desmodema and had been mistakenly referred to as an anal fin (see Desmodema, this study). It is seen occasionally in large Trachipterus (KPM $250811880 \mathrm{~mm} \mathrm{SL}$; Fig. 6), but not to the extent it is present in Desmodema. This is possibly due to greater dorsoventral constriction in the posterior tail region of Desmodema. No trachipterid specimens examined in this study at any ontogenetic stage possess an anal fin.

It is not uncommon for large specimens $(>1600 \mathrm{~mm})$ to have scars resulting from what appear to be bites of cookie-cutter sharks, Isistius spp. In this study, $56 \%$ of large specimens had one or more scars matching the wound marks left by Isistius spp. As many as 22 scars have been found on a single Trachipterus specimen (KPM 12738, 2114mm SL; Fig. 7). Mincarone et al. (2001) reported on three large (1670-1860 mm SL) western South Atlantic 
specimens of Trachipterus sp. from southern Brazil of which all had both recent and healed cookie-cutter shark wounds. Roberts (2012) mistakenly referred to a Lophotus from New South Wales, Australia (AMS I.43718) as the "only well-documented example of a lampridiform fish bitten by a cookie-cutter shark". However, most larger specimens of lampridiform fishes examined in the present study (e.g., Trachipterus, Regalecus, and Lophotus; JMM, pers. obs.) have similar bite scars.

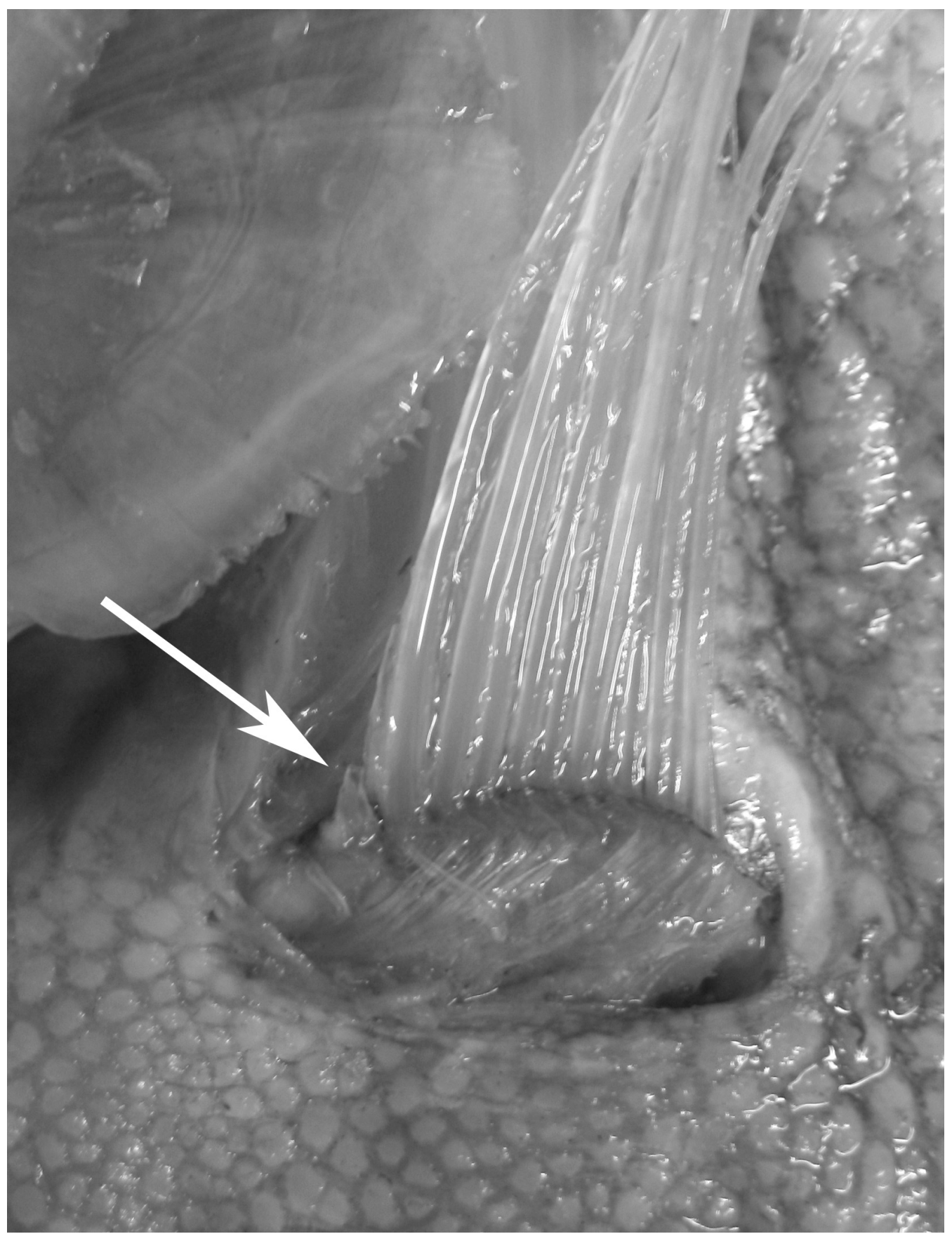

FIGURE 5. Trachipterus jacksonensis (AMS A.9114, Holotype; $736 \mathrm{~mm} \mathrm{SVL).} \mathrm{Left} \mathrm{pectoral} \mathrm{fin.} \mathrm{Note} \mathrm{first} \mathrm{short} \mathrm{pectoral} \mathrm{fin-}$ ray element indicated by white arrow.

Morphology of juveniles. Nearly all nominal species in Trachipterus (Table 1) are based on juvenile specimens, as this life stage is present in shallower, nearshore waters and are better represented in systematic collections (when compared to adults). Like adults, juveniles are laterally compressed, but numerous other morphological differences exist. Due to allometric growth and morphological changes throughout ontogeny, different life-history stages of juvenile and adult specimens of the same species can appear drastically different in regards to: 1) general body shape; 2) fin length and number; and 3) pigmentation patterns. 


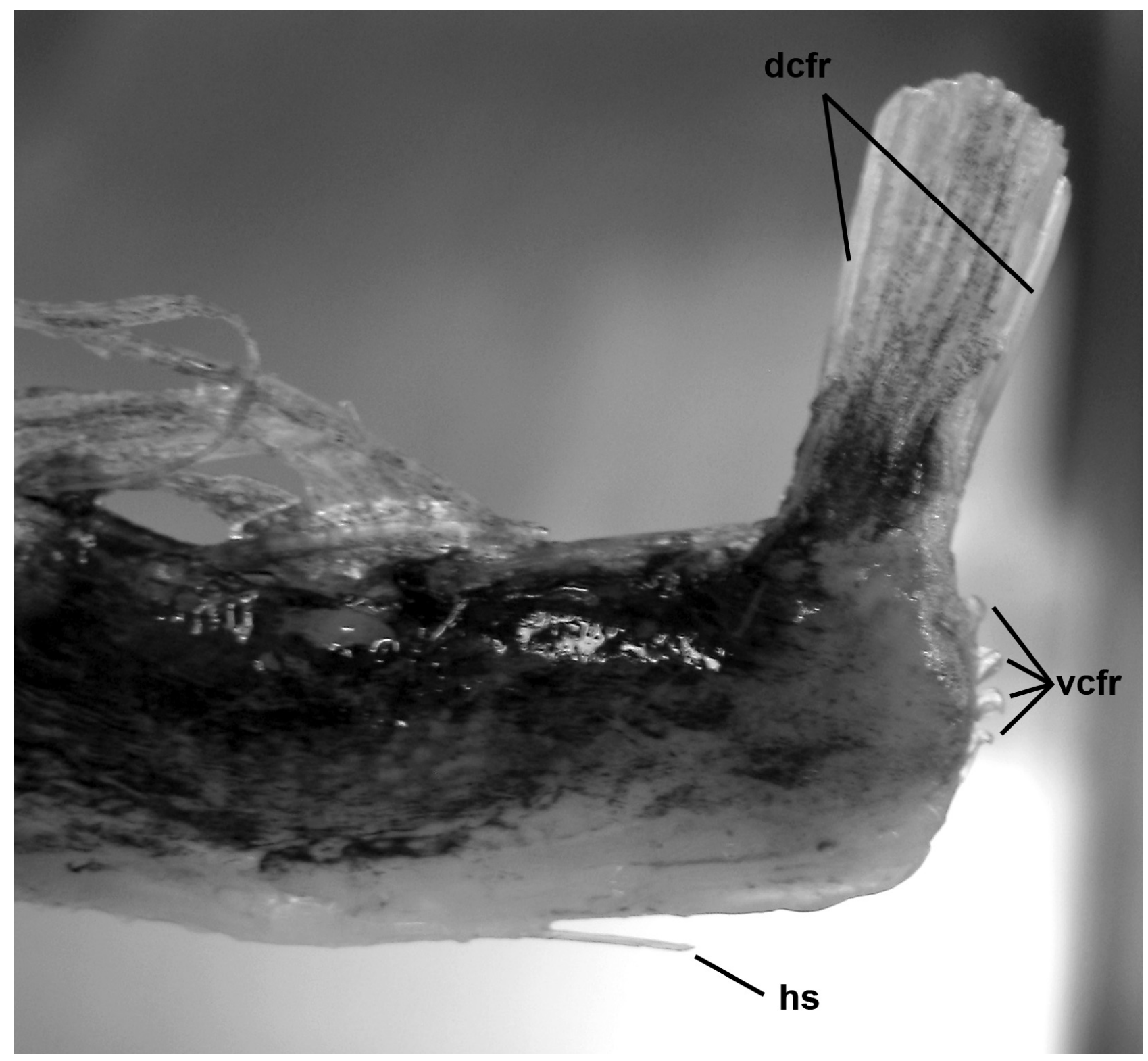

FIGURE 6. Trachipterus sp. (KPM-NI0025081; $1180 \mathrm{~mm} \mathrm{SL).} \mathrm{Caudal} \mathrm{fin} \mathrm{showing} \mathrm{the} \mathrm{orientation} \mathrm{of} \mathrm{the} \mathrm{dorsal} \mathrm{caudal} \mathrm{fin-rays}$ (dcfr) and reduced ventral caudal-fin rays (vcfr). Also note the protruding haemal spine (hs) along the ventral midline.

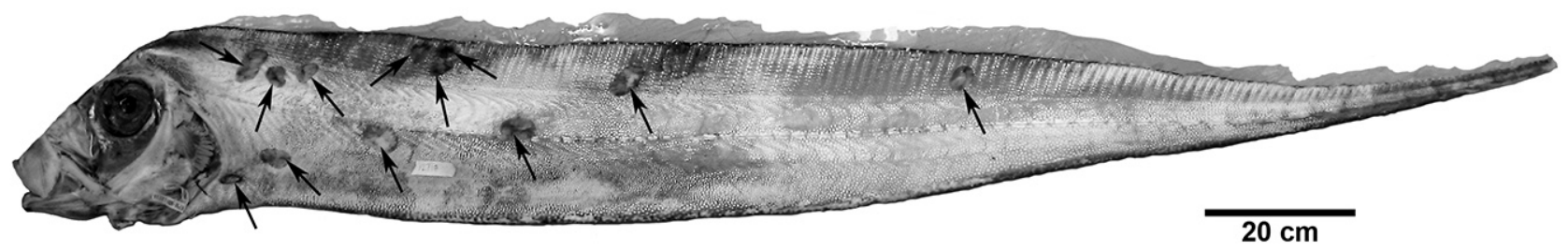

FIGURE 7. Trachipterus sp. (KPM-NI0012738; 2114mm SL). Whole specimen showing scars consistent with bites of a cookie cutter shark, Isistius sp. (indicated by black arrows).

Relative to the standard length, juvenile Trachipterus spp. have a greater head and snout-vent length and are deeper bodied than adults and, conversely, tail length (vent to caudal fin) is relatively shorter in juveniles (Scott 1983, fig. 1; Scott 1984, fig. 1; Fig. 8). Lateral-line orientation also varies between the two stages. In the posterior half of the tail in juvenile Trachipterus, the lateral line runs close to the ventral margin versus its mid-body position in adults. 


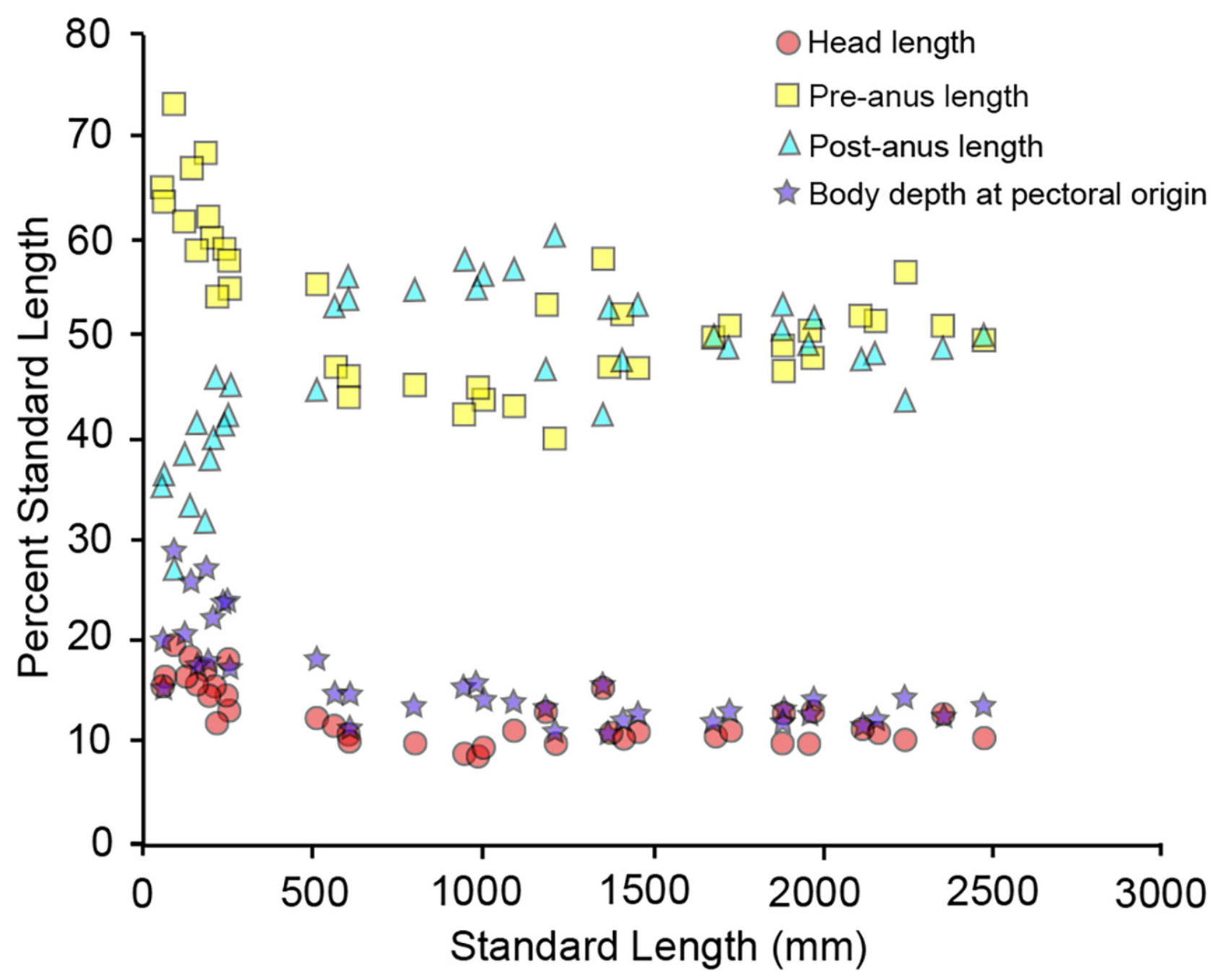

FIGURE 8. Head length, pre-anus length, post-anus (caudal region) length, and body depth at pectoral origin in Trachipterus spp. (55.9 to $2472 \mathrm{~mm} \mathrm{SL})$.

In juveniles, the first 5-6 dorsal-fin rays are typically elongate. There is a membranous interspace between these anteriormost rays and the more posterior portion of the dorsal fin (i.e., the majority of the fin), which is all that is present in adults. In several specimens examined in this study, however, the condition is slightly different and consists of 1 short fin ray, followed by $4-5$ elongate rays that successively decrease in length and are followed by a space (e.g., NSMT 57670, 20 mm SL; KPM 27573, 61 mm SL (Fig. 9); HUMZ 132216, 239 mm SL). Having the first ray being much shorter than the remaining rays is also apparent in the pectoral and pelvic fins. Observing a small juvenile specimen $(12.9 \mathrm{~cm} \mathrm{SL})$ that was dip-netted near the surface and maintained in an aquarium, Moritz et al. (2015) described potential luring behavior, in which the elongate dorsal-fin rays were moved in a wide arc approaching $180^{\circ}$.

Pelvic-fin rays in early juveniles are greatly elongate (Fig. 9) and the fin consists of $0-1+5-9$ fan-like rays that have bulb-like swellings present (typically only seen in live specimens); the first elongate ray is more stout than the others. The first short, spine-like ray may be absent and is easily overlooked when it is present. The length of pelvicfin rays can reach well beyond the tip of the caudal fin in young specimens. Two lobes are present in the caudal fin. The dorsal lobe contains 6-10 elongate rays, fan-like in life and is held vertically in live individuals (Fig. 2A) with the two outermost rays thicker than the inner rays (Fig. 10). The ventral caudal lobe contains 4-7 rays that are not as reduced as they are in adults (Fig. 6), but are rather represented as short, spine-like bases.

Juvenile Trachipterus trachypterus were observed in situ by Macali et al. (2020) in the upper $10 \mathrm{~m}$ of water during nighttime SCUBA dives near an upwelling on the Mediterranean coast of Italy. These individuals were observed to orient vertically, and upon recognition of potential predators (the divers), the fish would orient with their heads 
up and their elongate pelvic and caudal-fin rays extended. Periodic, quick flicking of these fins was hypothesized by Macali et al. (2020) to mimic jellyfishes. From video from a submersible, Mortiz et al. (2015) also observed a juvenile maintaining a vertical orientation and using undulation of its dorsal fin for locomotion.

A juvenile Trachipterus (KPM 27573, 61 mm SL; Fig. 9), that was dip-netted from the Sea of Japan, kept alive for 12 hours and immediately frozen at death, displayed minimal damage. This specimen, which was the most complete available for this study, was defrosted and examined immediately. Because of the condition of the of the fish, numerous morphological characters not previously observed, likely due to capture damage of these extremely fragile fishes, could be described and are presented below.
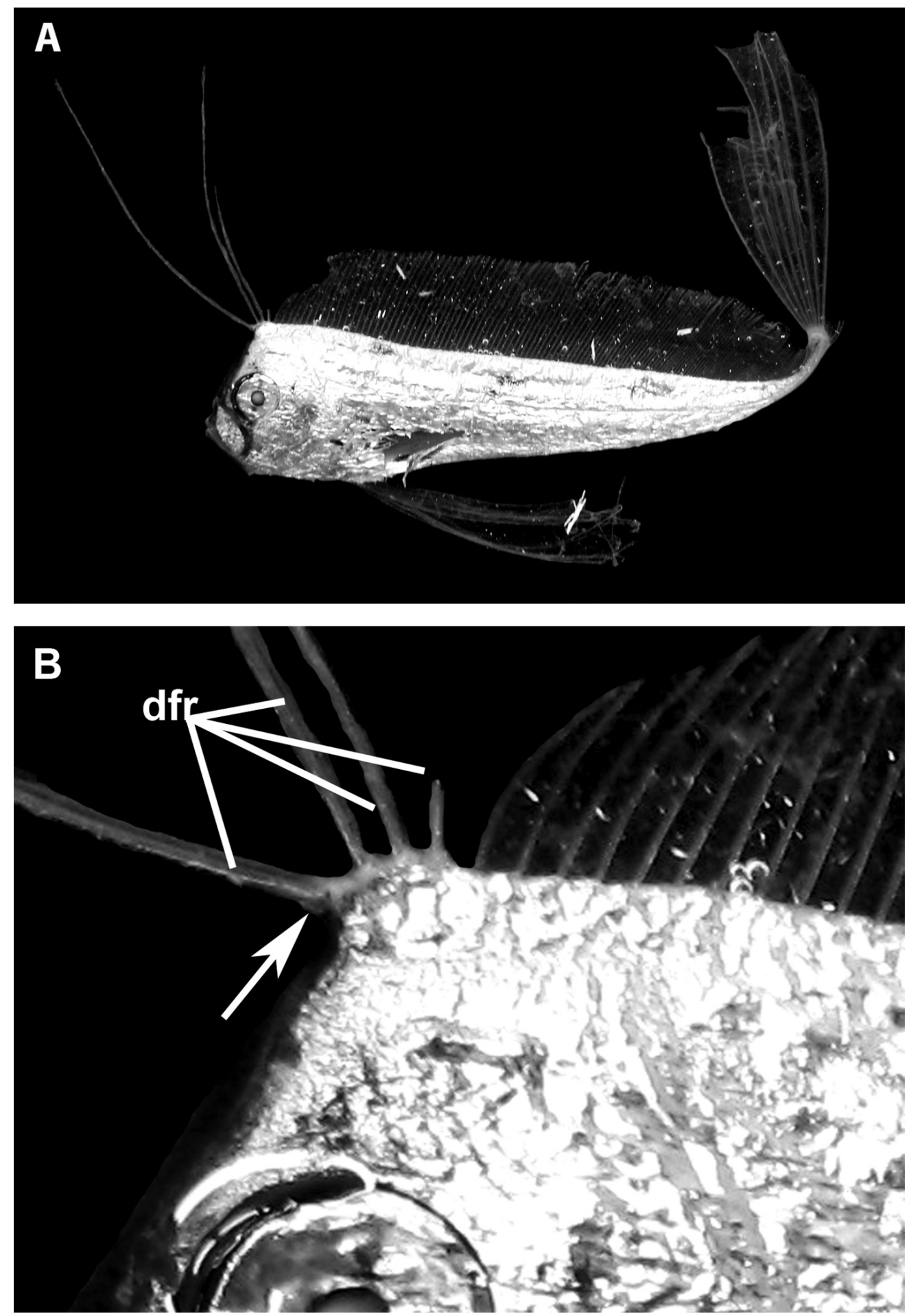

FIGURE 9. Trachipterus sp. (KPM-NI0027573; $61 \mathrm{~mm} \mathrm{SL).} \mathrm{Specimen} \mathrm{dipnetted} \mathrm{from} \mathrm{Maizuru} \mathrm{Bay,} \mathrm{Sea} \mathrm{of} \mathrm{Japan.} \mathrm{A.} \mathrm{Speci-}$ men defrosted for examination at KPM. B. Anterior dorsal-fin rays (dfr) showing one short ray (white arrow) followed by four elongate rays (the fourth is broken), a short interspace, and the remaining rays of the elongate dorsal fin. 


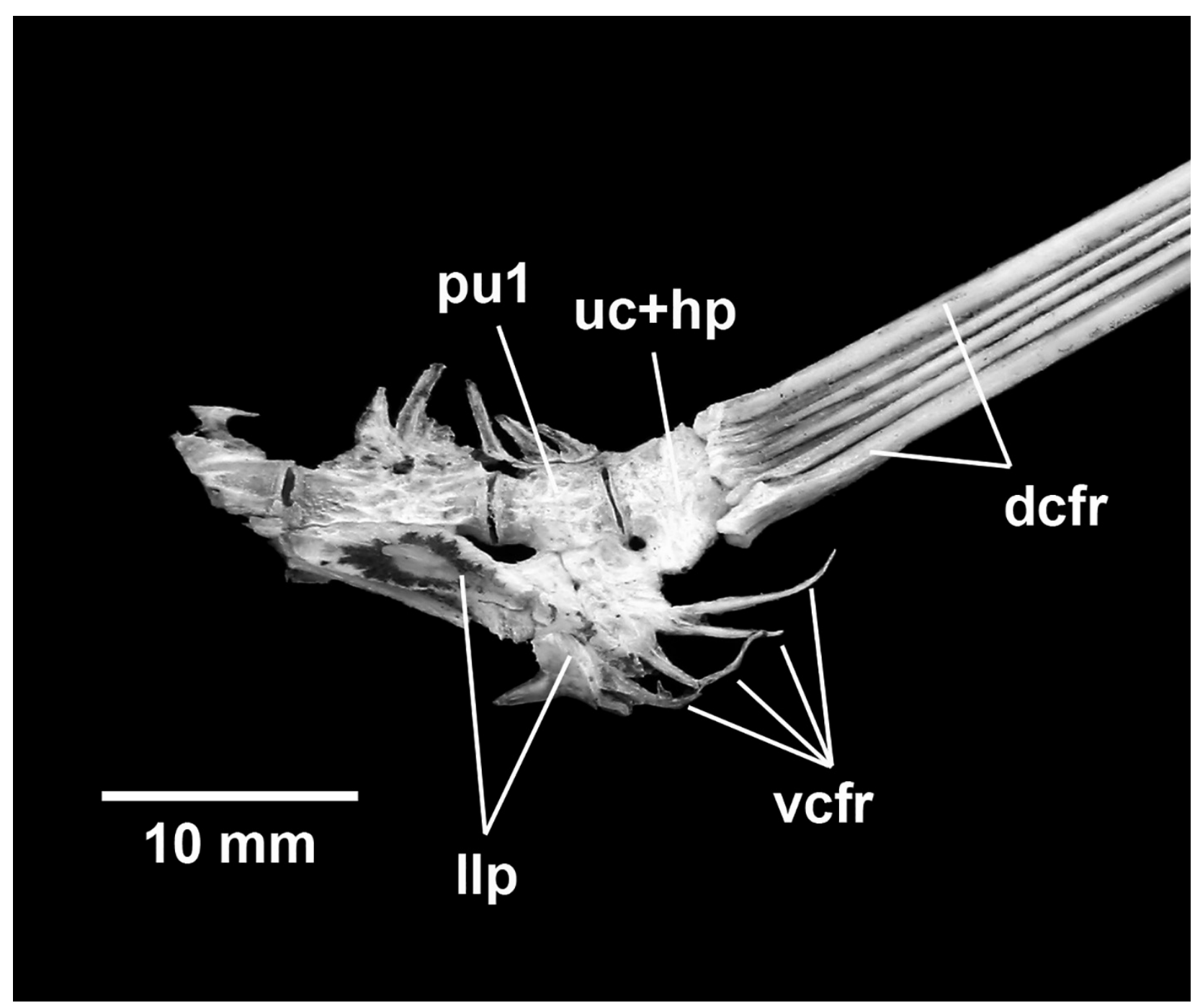

FIGURE 10. Trachipterus arcticus (VIMS 25015, $1205 \mathrm{~mm} \mathrm{SL).} \mathrm{Caudal-fin} \mathrm{skeleton} \mathrm{showing} \mathrm{supporting} \mathrm{elements} \mathrm{(preural}$ centurum 1, pu1; fused ural centrum and hypural plate, $\mathrm{uc}+\mathrm{hp}$ ) with elongate dorsal caudal fin rays (dcfr) and reduced ventral caudal fin rays (vcfr). Also shown are the posteriormost lateral line plates (1lp).

The presence of lateral spinules on the dorsal-, caudal-, and pelvic-fin rays are characters shared by all trachipterid fishes. However, in KPM 27573 the spinules on the first elongate dorsal-fin ray are not laterally directed, but rather project anteriorly. McCoy (1886: plate 22.1) describes and illustrates a similar condition of the pelvic fins, in which the first pelvic-fin ray has "a row of spinular granules on front". This condition was not observed in any other trachipterid specimens examined in this study and its preservation is attributed to specimen quality in both cases, as McCoy's (1886) specimen was hand-delivered shortly after capture and examined when it was freshly dead. The anterior orientation in these spinules corresponds with the vertical orientation that is assumed by trachipterid fishes and possibly adds a level of protective value, as the preceding element is extremely short, or it could serve a hydrodynamic function.

Branching of fin rays has been reported in the posterior-most rays of the pectoral and pelvic fins (McCoy 1886; Jordan \& Gilbert 1894). However, all fins of KPM 27573 possessed branched rays: the posteriormost fin rays of the pectoral and pelvic fins, the inner-most caudal-fin rays, and the anteriormost elongate dorsal-fin rays. As these regions of the pectoral, pelvic, and caudal are the most fragile and filamentous of the fin-rays, it is likely that the most distal, branching ends of these rays typically are damaged or lost during capture or preservation. Branching of the pelvic fins was also observed in specimens up to $604 \mathrm{~mm}$ SL (NSMT 12367).

Color. In addition to reduction in fin-ray number and length and changes in body proportions, the greatest difference between juvenile and adult Trachipterus is in coloration pattern. As with adults, fins are red or crimson, the frontal profile from the dorsal fin origin to the tip of the lower jaw is black and the body is silver. However, juveniles 
most commonly possess several large, black spots on their lateral surfaces: there are typically 3-4 spots located dorsal to the lateral line and 1-2 located ventral to the lateral line (Fig. 11). Numerous species have been described based on variation in the number and location of the spotting pattern (Emery 1879; Hamilton 1916) which appears to vary in regards to geography, ontogeny and, most likely, taxonomy.

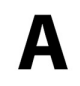

A

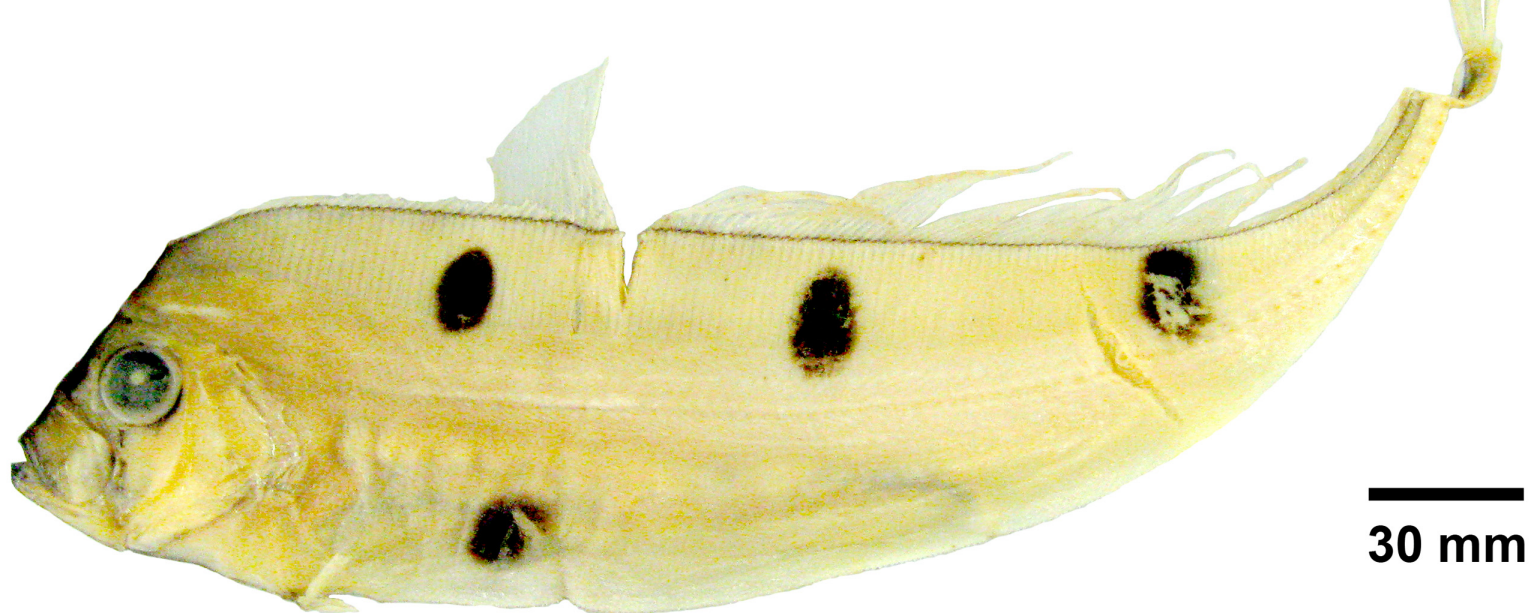

B

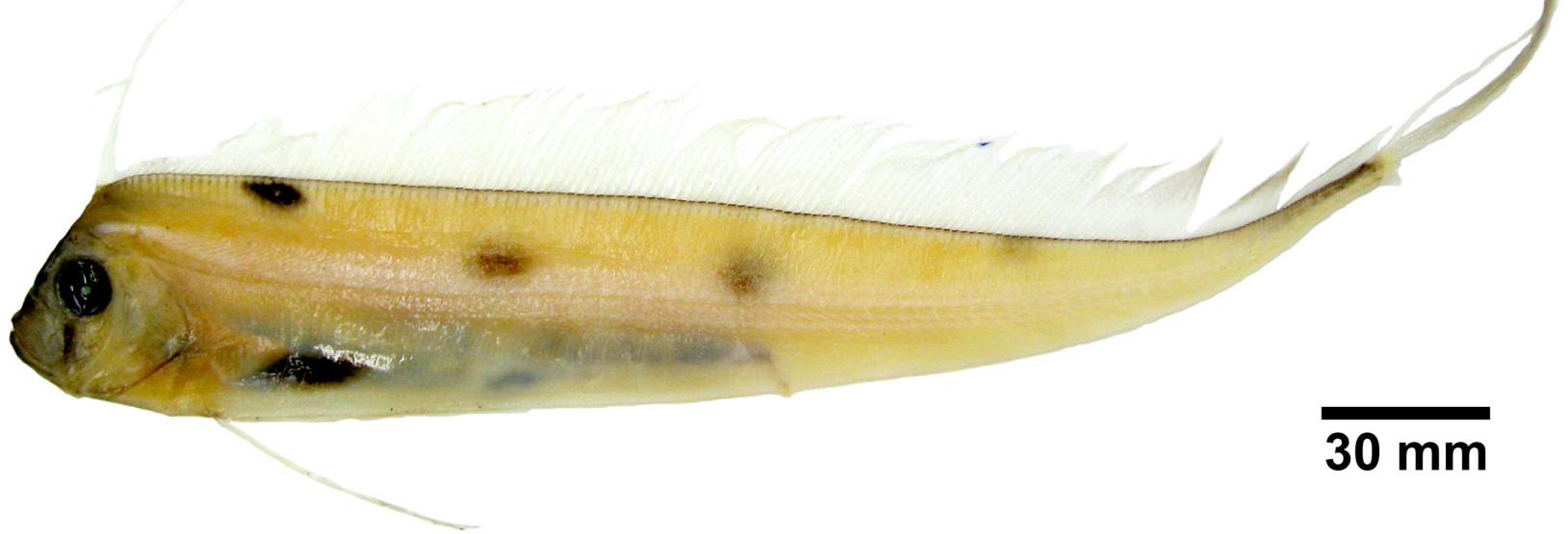

FIGURE 11. Juvenile specimens of Trachipterus spp. from A, Tasmania (CSIRO H-4947; $183.32 \mathrm{~mm} \mathrm{SVL)} \mathrm{and} \mathrm{B,} \mathrm{West} \mathrm{Pacific}$ (KPM-NI0007802; $254 \mathrm{~mm} \mathrm{SL).}$ 
Variation of the typical pattern includes 0-6 dorsal spots and 0-2 ventral spots. Establishing taxonomic identity based on juvenile spotting patterns is confounded by ontogeny associated with the color pattern. Spots are reduced in pigmentation, and eventually lost as standard length increases (see Ontogeny section below). Although a few exceptions have been noted, one of the most consistent geographical variations of the spotting pattern involves the location of the anterior-most dorsal spot. In specimens from the Atlantic Ocean and Mediterranean, the anteriormost dorsal spot is positioned below the dorsal midline. In specimens from the northern and southwestern Pacific, the first dorsal spot is located on the dorsal midline, in contact with the base of the dorsal fin. Specimens examined in this study collected from Tasmania and New Zealand exhibit the pattern described for Atlantic specimens (Fig. 11A). However, specimens collected off eastern Australia in the Pacific Ocean follow the Pacific pattern (Fig. 11B). Lateral asymmetry in spotting patterns, in which the spots are offset posteriorly on either the left or right side, also exists (BMNH 2010.3.23.21-26; NMNZ P.041259).

Juvenile to adult ontogenetic change. As with the other trachipterid genera, the transition from juvenile to adult does not appear to be correlated to size alone, and is hypothesized to occur over a longer time period, relative to Desmodema. Several morphological changes occur throughout development from juvenile to adult in Trachipterus, typically with several changes occurring simultaneously: 1) proportional elongation of body shape, which becomes more slender; 2) loss of the elongate dorsal-fin rays; 3) loss of the pelvic-fin rays; 4) reduction of the elongate dorsal caudal-fin rays; 5) reduction of ventral caudal-fin rays to rudiments; 6) reduction of anterior/lateral spinules on finrays; 7) increase in the prominence of dermal tubercles on the body and ventral midline; 8) loss of body spots.

Even without the opportunity to examine true adults, McCoy (1886:84) hypothesized that "the young are deeper and shorter in proportion than the old. " As standard length increases, head length, snout-vent length, and body depth at the pectoral-fin origin decrease, while tail length (= post-anus length; standard length- minus snout-vent length) increases (Fig. 8). Throughout ontogeny, individuals become proportionately more slender. Relative tail length also increases as a result of the lengthening of posterior vertebrae during ontogeny as successive posterior vertebrae are progressively longer. Meek (1890) first reported on an increase in the length of posterior vertebrae, relative to more anterior vertebrae. Walters \& Fitch (1960) noted that those vertebrae in the mid-tail region are 2.5 to 4 times longer than those in the mid-trunk region.

As individuals progress through the juvenile stage and increase in length, the anterior-most (first 4-7) elongate dorsal-fin rays serially decrease in length, eventually reduced to a faintly detectable dorsal ridge that is the only evidence of the elongate fin-rays that once existed. This is also the case with the elongate rays of the dorsal caudal lobe. The rays of the ventral caudal lobe are reduced, first to spine-like rudiments (Fig.6) and eventually to a smooth lobe.

With the decrease in length of elongate fin rays, the lateral spinules on the dorsal-fin rays and the dorsal caudalfin rays, which are extremely numerous and prominent in early juveniles, also decrease to the point of nonexistence. Hamilton (1916:373) stated that "no radical change takes place on the surface of fin rays with increasing age" while he was attempting to align several ontogenetic stages of Trachipterus from New Zealand with the correct species name. Hamilton noted the potential use of this character as diagnostic and stated that "unless the adult forms...lose the granulations on the fin rays...there can be no identity... with a form like T. jacksonensis which has no spinules". At that time, T. jacksonensis was the only nominal species from the southwestern Pacific based on an adult specimen, and therefore, was described as having no lateral spinules on the fin rays. However, this is not a diagnostic character but rather an ontogenetic one.

Although it is one of the first morphological transitions to begin, loss of the pelvic-fin rays such that only a pelvic slit exists is one of the last transitions to be completed. By $1250 \mathrm{~mm}$ SL, nearly all specimens examined had barely detectable pelvic-rays, reduced to the level of the ventral surface of the body. However, in at least one specimen of $1880 \mathrm{~mm}$ SL (KPM 25081), rudiments of the first elongate pelvic fin-ray were visible. At lengths greater than $1880 \mathrm{~mm} \mathrm{SL}$, only the pelvic slit was visible and no trace of pelvic-fin rays was detected.

Loss of the characteristic spotting pattern of juvenile Trachipterus (typically 3-4 dorsal spots and 1 ventral spot) appears to be the most gradual and most protracted of ontogenetic transitions. The general trend is a decrease in total number of spots with an increase in SL (Fig. 12). Although there is some variation of the number and location of spots present in juvenile specimens, loss typically occurs posteriorly to anteriorly and then ventrally to dorsally. When only two spots are present on juveniles, they are the anteriormost dorsal spot and anteriormost ventral spot. No data exist regarding the size/stage and the appearance of spots, as they are not present in larval specimens. No spots were detected in specimens smaller than $51 \mathrm{~mm}$ SL. 
While most ontogenetically variable characters are marked with reduction, there is an increase in the prominence of tubercles across the body surface and along the ventral midline during ontogeny. Walters (1963) noted that these tubercles are cartilaginous in young Trachipterus but are bony in large adult specimens. Lateral tubercles were first detected at $215 \mathrm{~mm}$ SL (KPM 23327). As SL increases, the body tubercles become most distinct on the ventral midline, postanal region and along each side of the dorsal-fin pterygiophores (Fig 13A.). Walters (1963) hypothesized that the integumentary structure in trachipterids function as a drag-reduction mechanism by ensuring boundary-layer stability. The tubercles become greatly enlarged along the midventral line and project beyond the body surface (Fig. 13B.).

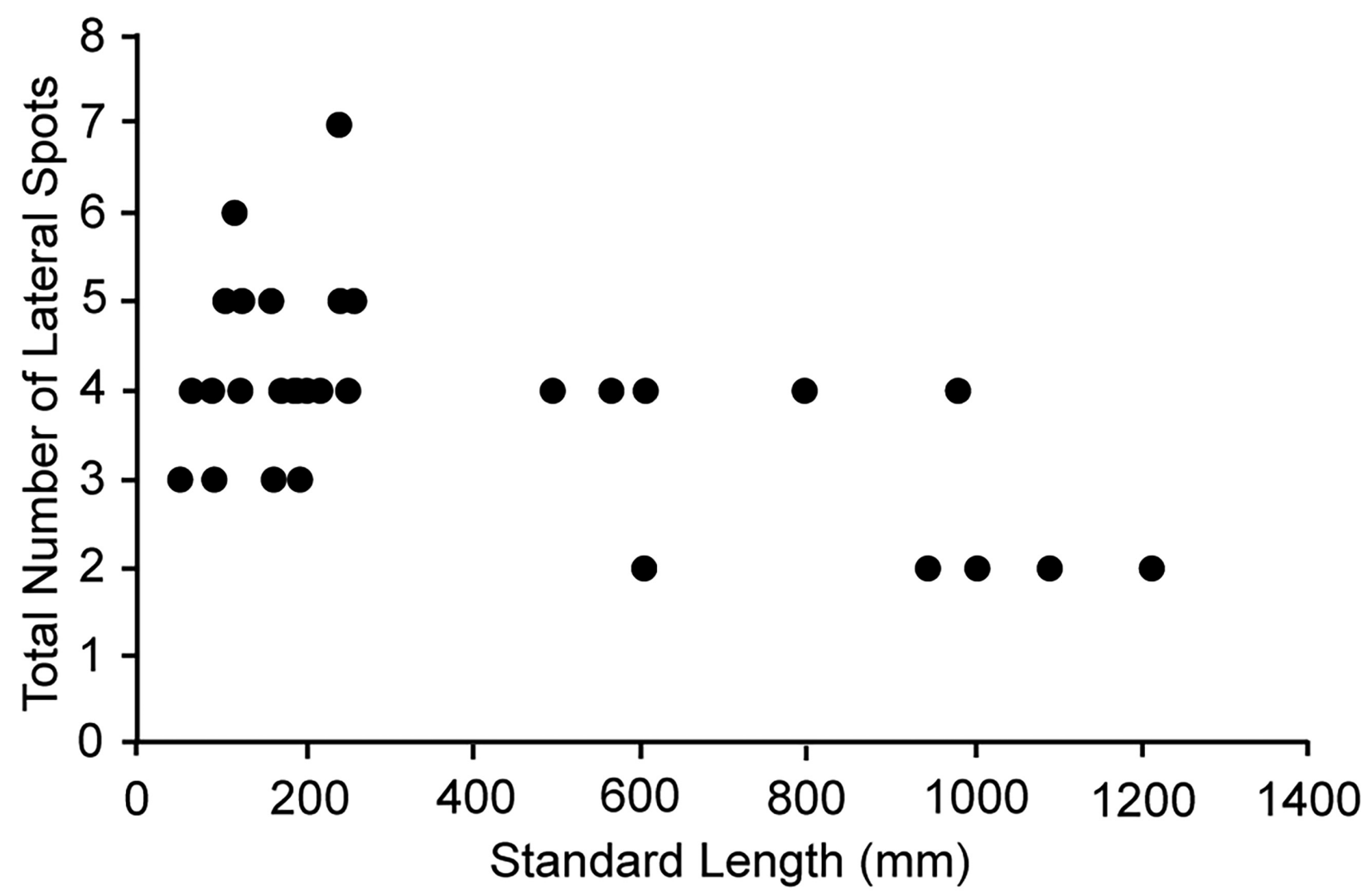

FIGURE 12. Trachipterus spp. Relationship of the total number of lateral spots (dorsal and ventral spots combined) and standard length (mm).

The adult stage is reached when the following characters are obtained: 1) adult proportions (as described above) are attained; 2) elongate dorsal-fin rays are non-existent; 3) pelvic fins are reduced to open slits with no detectable fin rays; 4) elongate dorsal caudal-fin rays are reduced in length; 5) ventral caudal-fin rays are reduced to rudimentary bases; 6) spinules are not present on the dorsal-fin rays and the dorsal caudal-fin-rays; 7) dermal tubercles are bony and project beyond the body on the ventral midline; and 8) no lateral spots are detected either dorsally or ventrally. Data on sexual maturity and reproductive behavior, which are greatly lacking from the literature, would contribute to better understanding of developmental transitions in Trachipterus.

Taxonomic history. The genus Trachipterus was established, without an included species, by Antoine Goüan in his 1770 work Histoire des Poissons. Goüan's description for Trachipterus was likely based on a juvenile specimen(s). First, Goüan described a pelvic fin. In adult Trachipterus the pelvic-fin rays are reduced to bases in which no rudiments of the fin-rays are left externally. In contrast, pelvic fins of juveniles are long ("longer than the pectoral" as described by Goüan). The caudal-fin rays are described as elongate. This is likely a reference to the rays of the dorsal caudal lobe, which in juveniles are elongate and fan-like. Goüan's original description noted the presence of "prickles" on the dorsal- and pelvic-fin rays and the caudal-fin rays as "rough". These prickles likely refer to the spinules present on the fin rays. These spinules are reduced throughout ontogeny and are rarely detectable in adult fishes. Further, juvenile ribbonfishes are more abundant and are found in more nearshore habitats compared to adults, which are primarily offshore, deep-water fishes. Availability for collection due to this habitat difference likely contributed to the rarity of adult specimens in $18^{\text {th }}$ century zoological collections. 

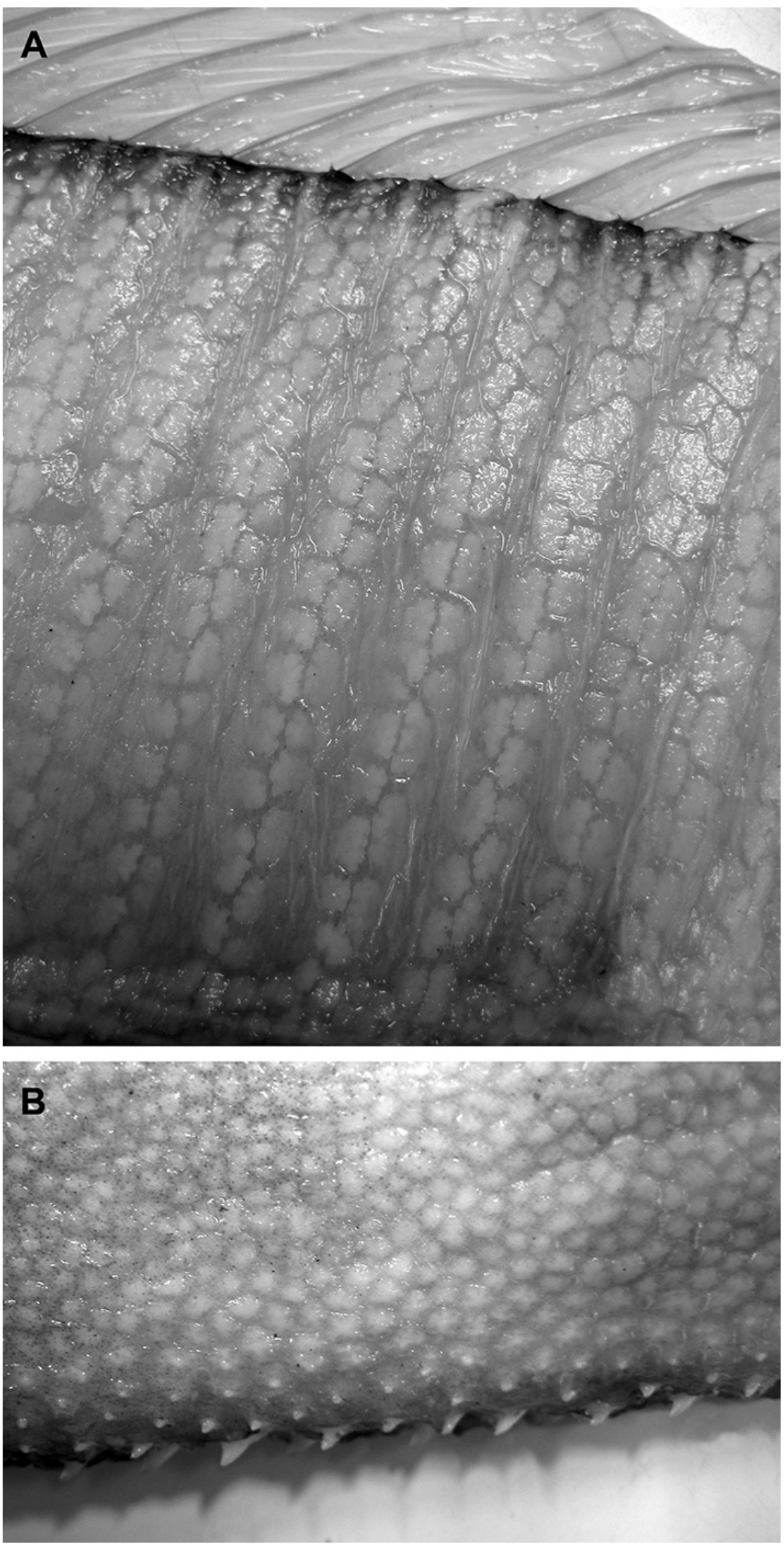

FIGURE 13. Trachipterus sp. (HUMZ 80914; 1209 mm SL). A, Flattened tubercles along the dorsal fin pterygiophores. B, Tubercles along the mid-ventral body margin; project beyond the body wall and are directed anteriorly. 
In Goüan's original description, Trachipterus was defined as a genus in which the body is "Squamae nullae" (without scales). Many authors (McCoy 1886; Walters \& Fitch 1960; Palmer 1961; Fitch 1964; Scott 1983; Heemstra \& Kannemeyer 1984) also note the absence of scales at all life stages as a diagnostic character for Trachipterus. This has in turn been used to distinguish Trachipterus from $Z u$, and according to some authors, Trachipterus from Desmodema (Rosenblatt \& Butler 1977). However, Nishimura (1964) reported a Trachipterus specimen he identified as T. ishikawae as having a "body feebly covered with non-overlapping scales". Nishimura (1964) noted that, after 10 months of preservation in formalin, there was no trace of squamation. Close examination of an adult specimen identified as T. jacksonensis that was caught on hook and line (therefore minimally damaged) from New Zealand (NMNZ P.41970; $1724 \mathrm{~mm} \mathrm{SL}$ ) revealed the presence of simple, fragile, non-overlapping cycloid scales on the lateral surface of the body (covered by the pectoral fins) and at the base of the dorsal-fin rays (Fig. 14). Upon further examination, scales were also found in a specimen identified as T. trachypterus (NMNZ P.16453; 1880 $\mathrm{mm} \mathrm{SL}$ ). Having been collected in a trawl, this specimen was severely damaged and scales were only detected on the lateral surface of the body covered by the pectoral fins. Scales have since been found in numerous specimens of Trachipterus spp. in sizes from $215 \mathrm{~mm}$ SL (KPM 23327) to $2472 \mathrm{~mm}$ SL (KPM 10429, a formalin-preserved specimen). Scales were originally detected during examination periods of at least 1 hour at which point scales would begin to lift at the edges, which is when they were observed. The scales are inconspicuous and potentially lost due to damage and preservation methods.

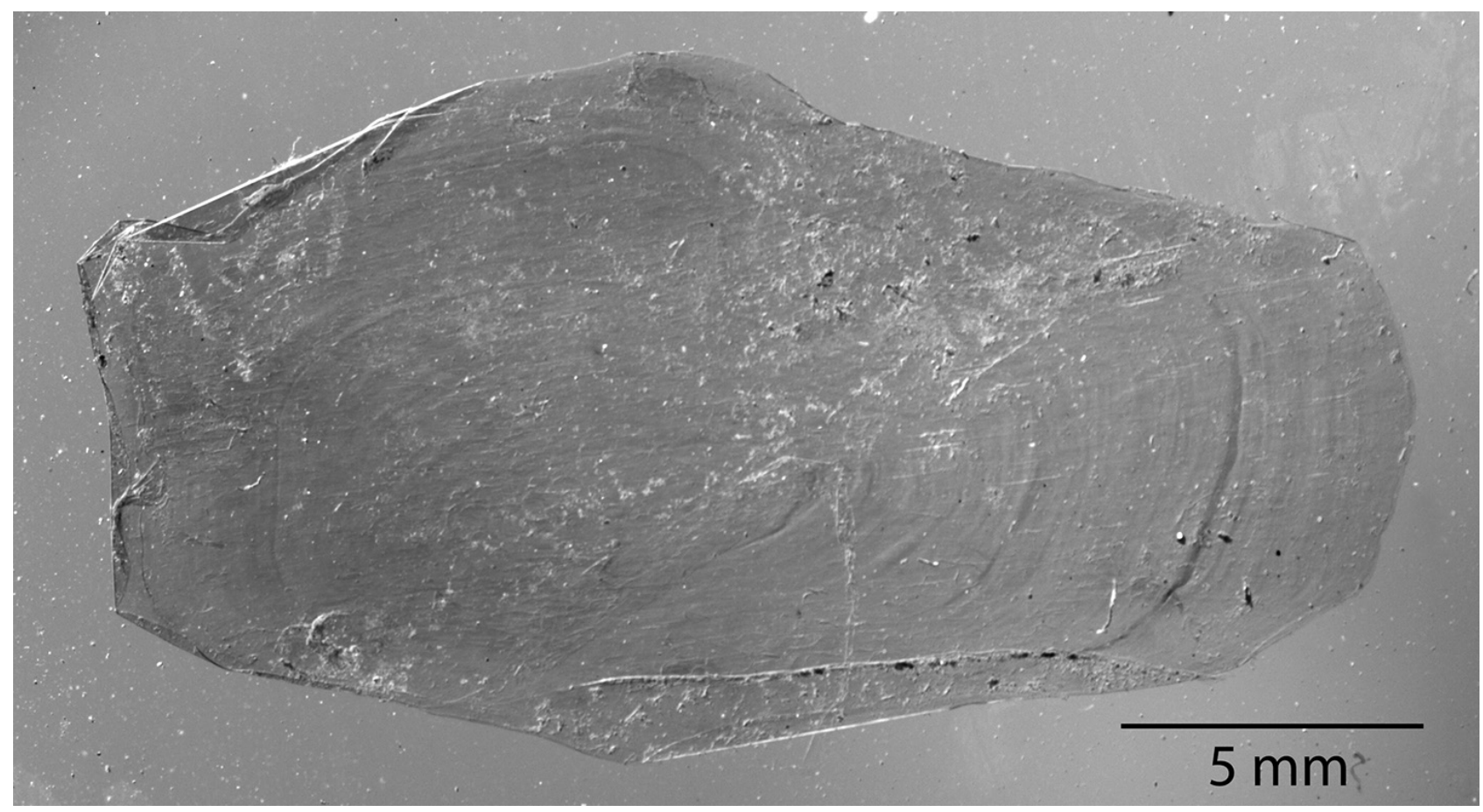

FIGURE 14. Trachipterus sp. (NMNZ P.41970; $1724 \mathrm{~mm} \mathrm{SL).} \mathrm{Scale} \mathrm{collected} \mathrm{from} \mathrm{the} \mathrm{base} \mathrm{of} \mathrm{the} \mathrm{dorsal-fin} \mathrm{rays.} \mathrm{Anterior}$ facing left.

\section{Species-level diversity of Trachipterus}

"I feel convinced that several of the described species are really only differently observed individuals of one or two species."

- Frederick McCoy, 1886, regarding Trachipterus

Most nominal species in Trachipteridae are in the genus Trachipterus (Table 1). The lack of nomenclatural stability and the proliferation of names can be attributed to several factors. Ontogenetic variation is great in Trachipterus spp. and a closely staged developmental sequence has not been established for any species. Several nominal species were described from successive growth stages of the same form (see Emery 1879). Specimens of Trachipterus, particularly large adult specimens, are rare in systematic collections. This results in limited reference material and 
has likely contributed to the practice of so-called "taxonomy by geography" (i.e., identification of a species based on presumed geographic range of it and related species). Compounded with this rarity is the extremely delicate nature of the elongate fin rays and the highly compressed, fragile body (relevant at all life stages); undamaged specimens are even more rare leading to incomplete, inaccurate descriptions. Large geographic gaps in knowledge regarding the biology of Trachipterus spp. exist. These issues have resulted in no agreement as to the number of valid species of Trachipterus. Few studies included examination of type specimens, relying instead on published data that were subject to all the issues previously mentioned. Additionally, many studies included relatively few specimens from a limited geographic range, failing to capture individual, ontogenetic, and geographic variation both within and among species of Trachipterus. Alpha taxonomic uncertainty will continue to exist in Trachipterus until some of these challenges have been overcome.

Trachipterus was first described without an associated species. Jordan \& Gilbert (1882) subsequently designated Cepola trachyptera Gmelin 1789 as the type species for the genus; reasons to support the designation were not provided by the authors. As noted by Heemstra \& Kannemeyer (1984), Gmelin's original description of $C$. trachyptera was inadequate to determine which Adriatic species he was attempting to describe. Because Gmelin placed the species in the genus Cepola, it is likely to assume that the fish was compressed, elongate, and had a dorsal fin running the length of the body. The original description also listed the species as having a steep forehead, rough fins with saw-like prickles, and a straight lateral line. Several lampridiform fishes known from the Adriatic fit that description including species of Regalecus, Lophotus, Zu cristatus, and Trachipterus trachypterus (sensu Palmer 1961). Although we agree with Heemstra \& Kannemeyer (1984) that Gmelin was describing T. trachypterus (sensu Palmer 1961), the process of elimination and assumptions made by Heemstra \& Kannemeyer (1984) that allowed the authors to reach that conclusion require qualification.

Heemstra \& Kannemeyer (1984) ruled out Regalecus by incorrectly stating that lateral spinules on the fin-rays are absent. Olney (1984) described the presence of lateral spinules on fin-rays in Trachipterus, Zu, Lophotus, and Regalecus. This may not have been known to Heemstra \& Kannemeyer as it appears that both works were simultaneously in press. However, it remains unlikely that Gmelin described Regalecus, as the lateral spinules present in Trachipterus are much more abundant when compared to Regalecus at all sizes, and better correspond to the "rough fin" $($ trach $=$ rough; pter $=$ fin $)$ description $(J M M$, pers. obs., $)$. Heemstra \& Kannemeyer did not provide a rational for exclusion of Lophotus, but it is likely that Gmelin would have made some mention in his original description of an ink-gland, which is obvious at nearly all size classes. Finally, the lateral line in $Z u$ zigzags in all juvenile and adult stages, so that genus is eliminated as a possibility. After synonymizing numerous nominal species, which are actually successive ontogenetic stages of T. trachypterus, Palmer (1961) concluded that this is the only species of Trachipterus present in the Mediterranean.

As T. trachypterus is one of the first nominal species of Trachipterus and the original description was broad enough to encompass all species currently recognized in the genus, it has been used to describe most specimens of all sizes from all over the world. It is currently recognized as having a worldwide distribution, although this is subject to great uncertainty. Even though T. trachypterus is a valid species name, there is a large overlap in meristic and morphometric data for the most currently recognized valid species of Trachipterus (Olney 1984: table 98; Savinykh \& Baitalyuk 2011: table 1). However, what portion of that overlap defines T. trachypterus remains unresolved.

Although the genus occurs worldwide, most studies have been based on specimens from the Atlantic Ocean (including the Mediterranean) and the eastern Pacific Ocean. The largest geographic gap in literature is from the Indo-West Pacific Ocean, most specifically the Indian Ocean proper and the southwestern portion of the Pacific. A significant number of specimens from the western Pacific Ocean have accumulated in collections (see below). Adequate material available for examination from the Indian Ocean, however, is still lacking.

The most comprehensive examinations of Trachipterus from the Indo-West Pacific are those reviews by Ogilby (1898) for Australia's Pacific coast, by Hamilton (1916) for New Zealand waters and, most extensively, by Scott (1983) for Tasmanian waters. Savinykh \& Baitalyuk (2011) addressed the taxonomic status of "Trachypterus" [sic] from the northern Pacific Ocean. Hayashi (2002) presented a key to the species of Trachipterus in Japan, including both juvenile and adult characters.

Taxonomic history of Trachipterus from the western Pacific Ocean. In his description of an "odd Trachypterus" [sic] specimen from Newcastle, New South Wales, Australia, Ogilby (1898) reviewed the literature pertinent to four species, based on specimens from the south-western Pacific Ocean. He recognized this new specimen as different from all others and designated a subspecies T. jacksonensis polystictus. It has since been elevated to a 
species, and is the type species for the genus Desmodema Walters \& Fitch 1960; it is currently recognized as Desmodema polystictum (Ogilby 1898) (see Remarks in the section on Desmodema). In his comparison of specimens, Ogilby (1898) recognized two specimens of T. altivelis Kner 1859 described by Hutton $(1873 ; 1876)$ as juveniles of T. jacksonensis (Ramsay 1881). However, for a juvenile specimen he recognized T. arawatae Clarke 1881 as a valid species and did not speak to the potential that it may be an immature form of another currently recognized species of Trachipterus. Because he did not consider that species could have disjunct distributions, Ogilby failed to draw comparisons with any northern Pacific forms. He did, however, note a similarity of form between Australian specimens and an individual collected at Valparaiso, Chile identified as T. altivelis.

Building upon Ogilby's (1898) review, Hamilton (1916) examined an additional six specimens collected from the Australasian and New Zealand regions. Hamilton also drew comparisons of Australasian forms to those described from the northwest Pacific (Japan), northeast Pacific (California) and southeast Pacific (Chile). Hamilton reexamined or interpreted from drawings, all specimens in collections at that time and concluded that two species, T. jacksonensis (Ramsay 1881) and T. trachypterus (Gmelin 1789), are present in the region.

Nearly seventy years elapsed before Scott's (1983) review, which included all three genera of Trachipteridae as well as species of Regalecidae. This is undoubtedly the most comprehensive synthesis regarding general literature and nomenclature of trachipterids from the Indo-West Pacific, primarily focused on Australian and New Zealand waters. However, Scott's examination of material was restricted to specimens only collected from Tasmanian waters, and primarily those deposited at the Queen Victoria Museum (QVM, Launceston, Tasmania). Further, he focused primarily on juvenile specimens and did not include data collected from any large adults.

Nomenclatural problems have led extensively to confusing misidentifications in the region and beyond (Table 1). Scott's (1983) review of Trachipteridae in Tasmania synonymized T. jacksonensis (Ramsay 1881) and T. arawatae Clarke 1881 (Fig. 15), with priority given to T. arawatae as the valid name, due to the publication date preceding that of Ramsay's by one month. In their frequently cited review of Trachipteridae from South Africa, Heemstra \& Kannemeyer (1984) did not cite the review of Tasmanian Trachipteridae by Scott (1983). They maintained the validity of T. jacksonensis (Ramsay 1881) and synonymized T. arawatae Clarke 1881 with T. trachypterus (Gmelin 1789). To further complicate matters, examination of the holotype of T. arawatae Clarke 1881 (NMNZ P.1008, a juvenile specimen $51 \mathrm{~mm}$ SL, Fig. 15) in the present study revealed discrepancies in some of the original meristic data (primarily pectoral, pelvic, and caudal-fin rays counts). These are likely the result of specimen condition and the lack of advanced microscopic equipment at the time of its description. As noted specifically by McCoy (1886), the caudal fins of trachipterids are excessively delicate, the fin rays are extremely fragile, and "the slightest touch in separating rays to count them breaks them in pieces." It is likely that in an effort to preserve the completeness of the specimen, originally collected by hand and examined intact, that Clarke did not accurately count fin rays. The holotype was preserved and stored in a small vial and it appears likely that the caudal-fin rays either broke, or were cut (due to the straight, smooth separation) to fit the specimen inside the vial. However, it is only because of this "cut" that all caudal rays can be clearly seen and counted. If not for the specimen damage, counts would be consistent with those proposed by Clarke (1881).

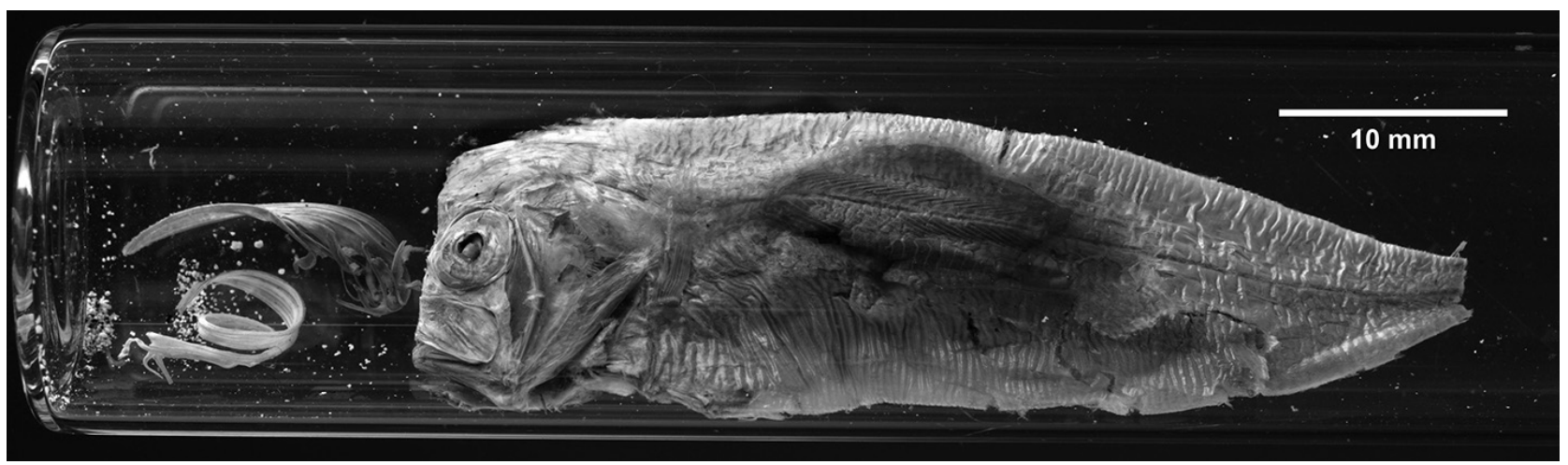

FIGURE 15. Trachipterus arawatae Clarke 1881. Holotype; NMNZ.P.1008; $51 \mathrm{~mm}$ SL. Photo acquired from The Museum of New Zealand Te Papa Tongarewa website (https://collections.tepapa.govt.nz/object/180115) and used under CC BY 4.0; modified from file titled: peregrin dealfish, Trachipterus trachypterus (Gmelin, 1789). 
Few authors have examined the actual holotype, but rather, have taken data from the literature. Based on Clarke's (1881) account, the pectoral fin consists of 9 rays, which would align the specimen more closely with $T$. trachypterus, as suggested by Heemstra \& Kannemeyer (1984). Upon examination of the holotype, at least 11 (possibly 12) pectoral-fin rays were counted. The present status of $T$. arawatae Clarke 1881 , therefore, remains uncertain but is likely a juvenile specimen of either T. trachypterus or T. jacksonensis/T. ishikawae (see below).

Many meristic characters overlap among nominal species of western Pacific Trachipterus. Pectoral-fin ray counts and number of vertebrae, especially abdominal counts (as many specimens are incomplete with a portion of the tail region missing) appear to have the most utility for distinguishing species. One current problem involves how pectoral-fin ray counts are described in the literature. The pectoral fin consists of one short, spine-like ray, followed by longer fin rays. Few species accounts specifically mention this element, and it is therefore unknown if it is included in counts. In some specimens it is easily overlooked and in others, it may fuse to the first elongate ray. There is a lack of consistency in notation, and, therefore uncertainty in the actual values. However, present data tentatively suggest at least two groups: one group with a pectoral-fin ray count of 1+12-17 and another group with 1+8-11. A general trend detected in the geographic distribution in these two groups suggests that specimens with fewer pectoral-fin rays are more likely to originate in New Zealand and Tasmanian waters.

Upon examination of the holotype for T. jacksonensis (Fig. 16), accurate pelvic-fin ray counts were recorded. Ogilby (1898) listed the specimen as having 14 pectoral-fin rays. Both the left and right pectoral fins have a $1+13$ count suggesting that Ogilby recognized and recorded the first short ray in the total number. Examination of the holotype of T. ishikawae (Jordan \& Snyder 1901; Fig. 17) revealed the same count (1+13), which was not given in the original species description. Subsequent reports of T. ishikawae give different counts for different regions of the northwestern Pacific: 1+11-12 (Nishimura 1964, Sea of Japan), 8-11 (Masuda et al., 1984; Pacific coast of Japan) and 7-10 (Savinykh \& Baitalyuk 2011, Northwest Pacific Ocean), none of which correspond to data from the type specimen.

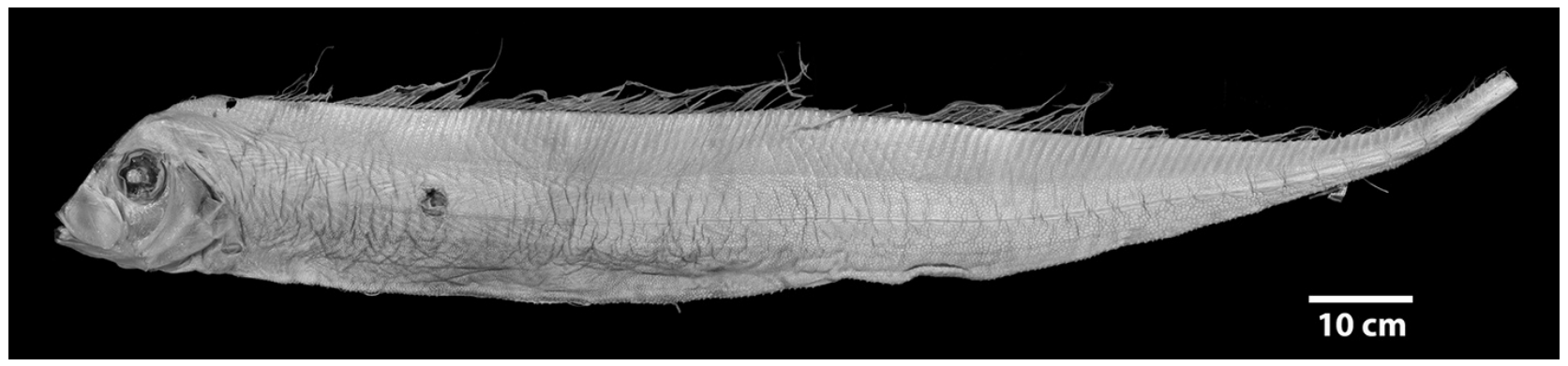

FIGURE 16. Trachipterus jacksonensis (Ramsay 1881). Syntype; AMS A.9114; 931 mm SVL. Photo C Australian Museum, provided courtesy of Kerryn Parkinson and Amanda Hay.

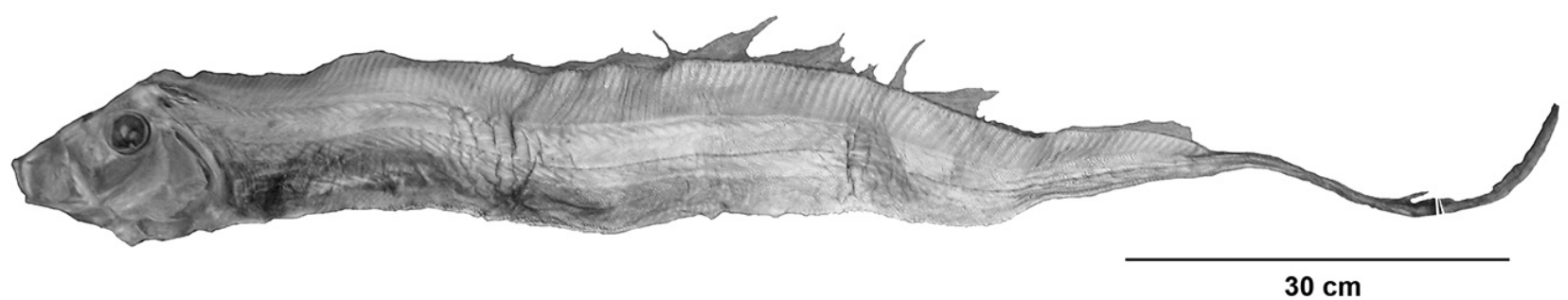

FIGURE 17. Trachipterus ishikawae Jordan \& Snyder 1901. Holotype; NSMT 589; 1250 mm SL.

Savinykh \& Baitalyuk (2011) attempted to clarify the taxonomic status of the genus from the northern Pacific Ocean. Based on examination of only 20 individuals with little specific locality data provided, they concluded that only three species are valid in the northern Pacific Ocean: T. trachypterus, T. jacksonensis and T. fukuzakii Fitch 1964 (restricted to the eastern Pacific). However, no diagnoses for the species were provided. The authors also demoted T. ishikawae and T. altivelis to junior synonyms of T. trachypterus based on their inability to delimit the species with meristic characters (Savinykh \& Baitalyuk 2011: table 1; see note in Methods). There is no indication in the Savinykh \& Baitalyuk (2011) study that holotypes were examined for accuracy and comparative purposes, which potentially confounds their results. In the type description for T. ishikawae, Jordan \& Snyder (1901) did not provide meristic information for the pectoral fin (the caudal lobe is broken and the pelvic fins are reduced). The 
holotype of T. ishikawae (Jordan \& Snyder 1901) has the pectoral fin intact and a fin ray count of I + 13 (JMM, pers. obs.). Nishimura (1964) reported the count as I +12 in specimens of T. ishikawae. Neither count overlaps with values reported for T. trachypterus, but these counts do, however, overlap with the counts on the holotype of T. jacksonensis (1+13).

\section{Putatively valid taxa in the western Pacific Ocean}

1. Trachipterus trachypterus (Gmelin 1789). Holotype: No types known. Mediterranean.

2. Trachipterus altivelis Kner 1859. Syntype: NMW 22046. Valparaiso, Chile. Unavailable for examination in current study.

3. Trachipterus arawatae Clarke 1881. Holotype NMNZ P.1008, $51 \mathrm{~cm}$ SL. Hominy Cove, Jackson's Bay New Zealand. Examined.

4. Trachipterus jacksonensis (Ramsay 1881). Syntype: AMS A.9114, $1408 \mathrm{~mm}$, caudal missing (736 mm SV). Manly Beach, Port Jackson, New South Wales, Australia. Examined.

5. Trachipterus ishikawae Jordan \& Snyder 1901. Holotype: NSMT 589, $1250 \mathrm{~mm}$ SL. Off the mouth of Tokyo Bay, between Misaki and Boshu. Examined.

Because these species are reported in the literature as having a western Pacific distribution and they have not been unambiguously synonymized with any other taxa, the current status of these nominal species needs to be addressed. As the type species for the genus, T. trachypterus is a valid name although its range remains uncertain. Palmer (1961) and Heemstra \& Kannemeyer (1984) recorded the distribution as eastern Atlantic (including the Mediterranean) and the central and western Pacific. The original species description (Gmelin 1789) was minimal and included no information regarding meristic data. The diagnoses provided by Palmer (1961) and Heemstra \& Kannemeyer (1984) include a wide range in values (e.g., total vertebrae 84-96; dorsal-fin rays 145-184), allowing potential overlap of several characters with other nominal species. Designation of a neotype and establishing how characters vary geographically will be important for determining the presence of T. trachypterus in the western Pacific.

Of the taxa listed above, the holotypes of both T. altivelis and T. arawatae are juvenile specimens. It is possible that both represent a different ontogenetic stage of previously described taxa. For example, T. altivelis as diagnosed by Fitch (1964), overlaps with T. trachypterus (according to both Palmer, 1961 and Heemstra \& Kannemeyer 1984) in all meristic data presented. Although Fitch (1964) synonymized T. weychardti Philippi 1847, T. seleniris Snyder 1908, and T. rexsalmonorum Jordan \& Gilbert 1894 with T. altivelis, the author did not address any relationship with T. trachypterus since the species was not described from the eastern Pacific. Trachipterus altivelis is possibly a junior synonym of T. trachypterus (Gmelin 1789). The present status of T. arawatae (Clarke 1881) is also uncertain. Hamilton (1916) and Heemstra \& Kannemeyer (1984) both recognized T. arawate (Clarke 1881) as a junior synonym of T. trachypterus. Alternatively, Scott (1983) entered T. jacksonensis (Ramsay 1881) into synonymy with T. arawatae (Clarke 1881), which was given nominal priority since the publication date of Clarke preceded that of Ramsay by one month.

In the original description of T. ishikawae (Jordan \& Snyder 1901), the numbers for pectoral-fin rays were not given. The authors noted that the caudal lobe was broken and therefore provided no counts for caudal-fin rays. Subsequent authors have typically used data from: 1) a later paper by Jordan \& Snyder (1904), which was based on non-type specimens and provided no certainty regarding whether or not they were conspecific with the type (e.g., Smith 1956); 2) from Nishimura (1964) working in the Sea of Japan, a non-type locality (Savinykh \& Baitalyuk 2011); 3) or Masuda et al. (1984) working throughout the Japanese Archipelago and synthesizing numerous locales and non-type specimens (Savinykh \& Baitalyuk 2011). This has resulted in a wide range of values in characters associated with the name T. ishikawae without reference to the type specimen (Savinykh \& Baitalyuk 2011: table 1). In examination of the holotype, the caudal lobe was found to be intact (JMM, pers. obs.; the caudal fin is also visible in Jordan \& Snyder, 1901: plate XVII, fig. 10, a photograph of the type specimen) with the caudal-fin ray count of $9+4$, and a pectoral-fin ray count of $1+13$, both of which are greater than values reported in the literature for $T$. ishikawae. Both counts are also greater than the range commonly reported for T. trachypterus, which Savinykh \& Baitalyuk (2011) recognize as the senior synonym of $T$. ishikawae. The holotype of $T$. ishikawae shares with the holotype of T. jacksonensis similar pectoral-fin ray counts (1+13), and tubercles arranged in vertical rows along the dorsal-fin pterygiophores. However, the holotypes are still in need of detailed redescription, which could then 
allow the limits of geographic variation to be better established. Trachipterus ishikawae has not been reported from the southern hemisphere and T. jacksonensis has not been reported from the northern hemisphere. The relationship between the two (i.e., whether they are sister-species, phenotypic variants of the same species, etc.) needs to be more fully examined.

More data are needed to confidently establish the species diversity of Trachipterus from the western Pacific Ocean, assign species to the correct nomenclature, and to provide accurate species descriptions. A study including detailed examination of all holotype specimens is needed to establish baseline diagnostic characters. As large, delicate specimens can pose a challenge to radiograph, any additional data on vertebral counts will be beneficial. Trachipterus requires further revision worldwide to correctly allocate the suite of characters present in the group. Additionally, reviewing all life stages and examining specimens from all regions of the world's oceans will capture greater ontogenetic and geographical variation.

\section{$Z u$ Walters \& Fitch 1960}

Figures 2B, 3B, 18-22

Type species. Trachypterus cristatus Bonelli 1820, Gulf of Spezia, Mediterranean Sea

Diagnosis (Adults): Body elongate (to $1400 \mathrm{~mm} \mathrm{SL}$ in Z. elongatus, to $1200 \mathrm{~mm} \mathrm{SL} \mathrm{in} \mathrm{Z.} \mathrm{cristatus),} \mathrm{laterally} \mathrm{com-}$ pressed (more robust than Trachipterus or Desmodema) tapering to a thin caudal peduncle. Ventral edge of body nearly straight or with one fleshy keel from the posterior edge of the pelvic fin base to the anus (if keel is present, it is most prominent directly anterior to the anus) in specimens greater than $800 \mathrm{~mm} \mathrm{SL}$, with keel decreasing in prominence as SL increases. Dermal tubercles and pore system present throughout trunk. Ventral edge of the body not covered in dermal tubercles as in Trachipterus. Ventral body margin curves dorsally at point where lateral line meets mid-ventral line, posterior to anus. Scales cycloid and deciduous, covering the entire body; most apparent on caudal peduncle and along lateral-line; visible scale pockets present if scales are missing. Lateral line dropping to mid-body on trunk near pelvic fin rudiments and continues to drop ventrally until just posterior to the anus where it joins the lower edge of the body and continues in a zigzag pattern, as each alternate scale is offset dorsally, until the base of the caudal fin; lateral-line plates elongate at the point the zigzag pattern commences. Lateral-line plates armed with 1 (sometimes 2) subconical spines, much larger than those of Trachipterus or Desmodema, these however may be small in large adults. Relative to the lateral-line scales, spines point laterally (not angled anteriorly as in Trachipterus). Body depth at P1 10.6-12.9\% SL. Premaxilla with 9-21 strong caniniform teeth, 6-12 on dentary; vomer with 2-4 strong teeth; palatine teeth absent or up to 3 teeth. Gill rakers on the first arch 2-3 + I +7-9, all with 1-3 spinules. Pseudobranch well developed. Branchiostegal rays 6. Dorsal fin originating at posterior margin of eye. Dorsal-fin rays 120-151, first 6 dorsal-fin rays stout, evenly spaced (typically absent in adults); interspace present, remaining fin rays filamentous. Pectoral-fin rays 10-13, the first being shorter and stouter than more posterior rays. Pelvic fins appear absent in adults, and are typically represented by a short bony base (which decreases in length as SL increases) in a slit-like or circular opening. Anal fin absent. Caudal fin in two parts; dorsal lobe set at an angle to the caudal peduncle, fan-like with 8-12 rays, most commonly 9 , two outermost rays thicker than innermost rays; ventral lobe with up to 5 rays, all greatly reduced with the bases remaining as spine-like elements (not as rudimentary as in Trachipterus). Spinules on the dorsal, pectoral, and caudal-fin rays greatly reduced or absent. Anus located on midventral line. Total vertebrae 62-69 (Z. cristatus) or 84-88 (Z. elongatus).

Color: Silver to dark black or brown all over body. Bright red or crimson dorsal, pectoral, and anterior portion of caudal fin; membranes between caudal fin rays black distally. Faint traces of dark vertical bars, more prominent posterodorsal to the anus and along the caudal region (6 or 7 complete bars).

Morphology of juveniles. Juvenile $Z u$ spp. have more elongate bodies and are much more laterally compressed than adults, with a body tapering to a thin caudal peduncle. The ventral edge of body between the pelvic-fin base and the anus is scalloped with 1-3 fleshy keels, the number and prominence of keels decreasing with increasing SL. Keels are smooth-edged in Z. cristatus (Fig. 18) and jagged-edged in Z. elongatus (Fig. 19). There are dermal tubercles and a pore system found throughout the trunk, although not as obvious as in adults. Scale pockets are present and deciduous scales are variably present. Scales are most commonly observed associated with lateral-line and in the caudal region. The caudal region curves dorsally posterior to the anus. This curvature exists on all juvenile 
specimens examined as well as in observations and photographs taken of live juveniles; the same body form has been observed in live juvenile specimens of Trachipterus (Moritz et al. 2015). This body curvature possibly works in conjunction with the fan-like dorsal lobe of the caudal fin, which may provide support needed to maintain the head-up, tail-down swimming orientation prior to the ability to maintain that position through dorsal-fin undulation, as is assumed for adults.

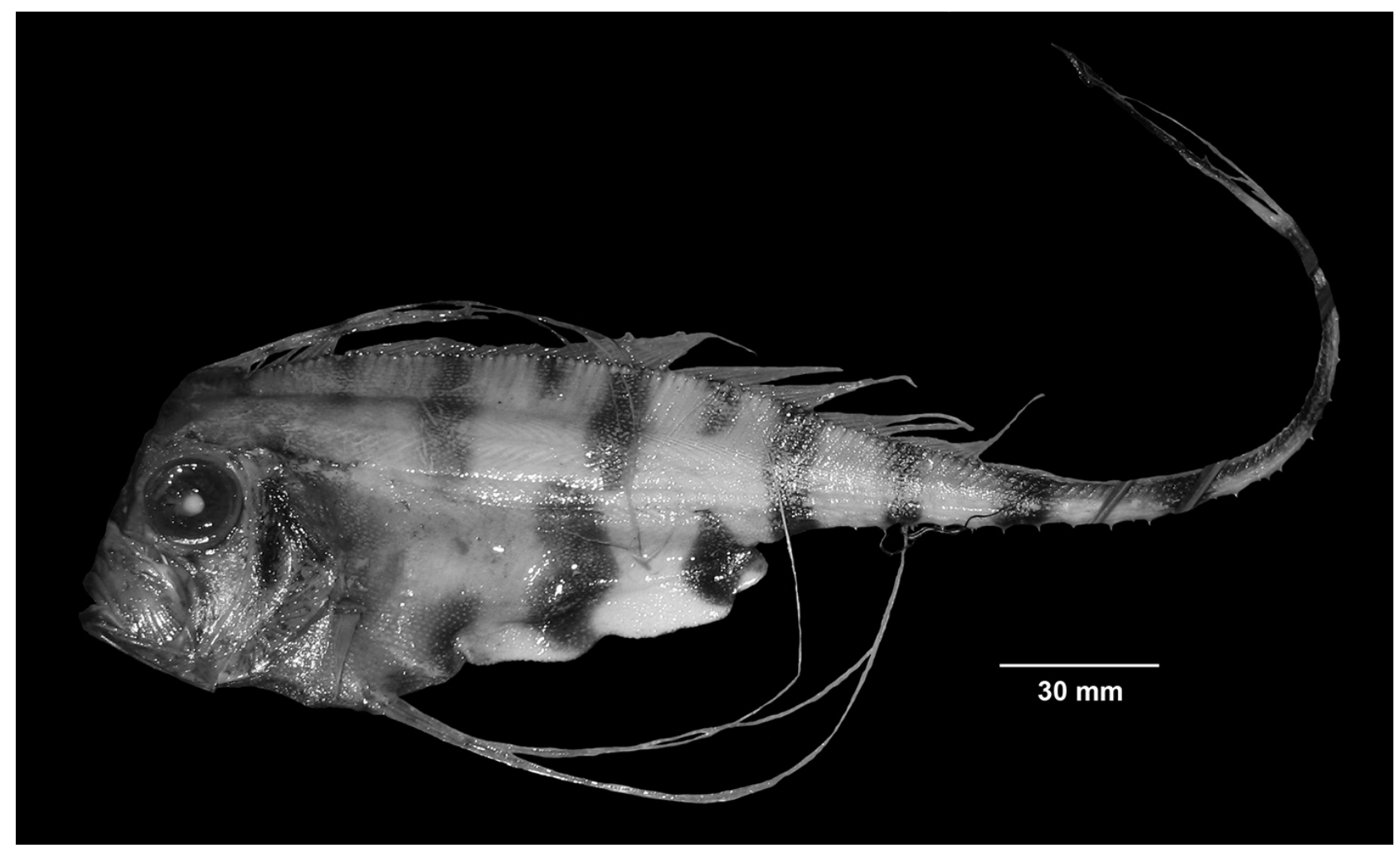

FIGURE 18. Zu cristatus (Bonelli 1820). AMS I.39622-001; 330 mm SL.

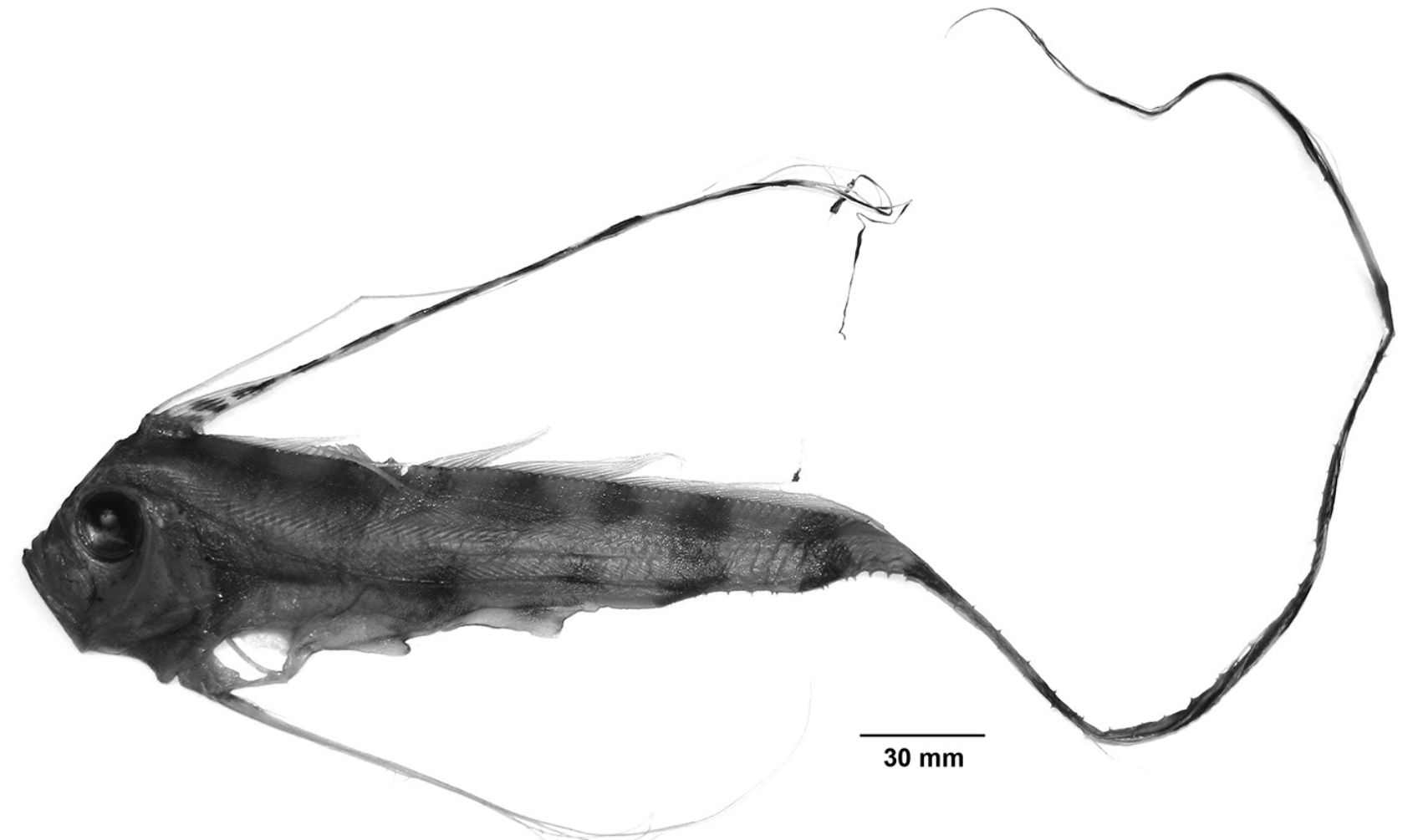

FIGURE 19. Zu elongatus Heemstra \& Kannemeyer 1984. NMNZ P.5681; 426 mm SL 
Dorsoventral constriction occurs immediately posterior to the anus in Z. cristatus, with the decrease in body depth occurring more subtly in Z. elongatus. The lateral-line orientation is the same as adults in Z. elongatus; in $Z$. cristatus, the lateral line runs nearly straight until the point of ventral constriction where it proceeds along the ventral mid-line in a zigzag pattern. The lateral-line plates bear strong, subconical, laterally directed spines, stronger overall and more prominent on the anterior plates than those in adults. The first six dorsal-fin rays are extremely elongate, and make up what has been referred to as the nuchal crest or pennant by previous authors (Walters \& Fitch 1960; Fitch 1964). Hayashi (2002) noted that there is no separation between the first six anterior dorsal rays and the posterior soft rays in juveniles as in adults. However, in all material examined herein, there is a slight separation between the nuchal pennant and the remaining dorsal-fin rays. Pelvic-fin rays are also extremely elongate and range from 6-9 (8-9 only in Z. elongatus); the first ray is extremely short and stout. Several authors list pelvic rays as 5-6, however, it is possible that the first short ray was overlooked due to its small size. Bolin (1933), however, describes the pelvic "spine" from two large (533 and $835 \mathrm{~mm} \mathrm{SL}$ ) specimens of Z. cristatus. The dorsal-fin rays of the nuchal pennant and those of the pelvic fin bear pigmented, membranous flaps that are serially arranged throughout the length of the rays (Fig. 20). The elongate rays of the pelvic fins and the anterior portion of the dorsal fin are reduced during the transition to adulthood and eventually lost entirely. The rays in the ventral lobe of the caudal fin have been reported as consisting of 1 or 2 long filaments (Walters \& Fitch 1960; Heemstra \& Kannemeyer 1984). Due to their fragility, they are often lost upon collection and therefore rarely observed in preserved specimens. However, filamentous caudal-fin rays are observed in images captured of living specimens (Fig. 21; see also Heemstra \& Kannemeyer 1984: fig. 8, which was based on a live specimen). Rays of both caudal lobes, even when reduced, are covered with minute laterally projecting spinules.

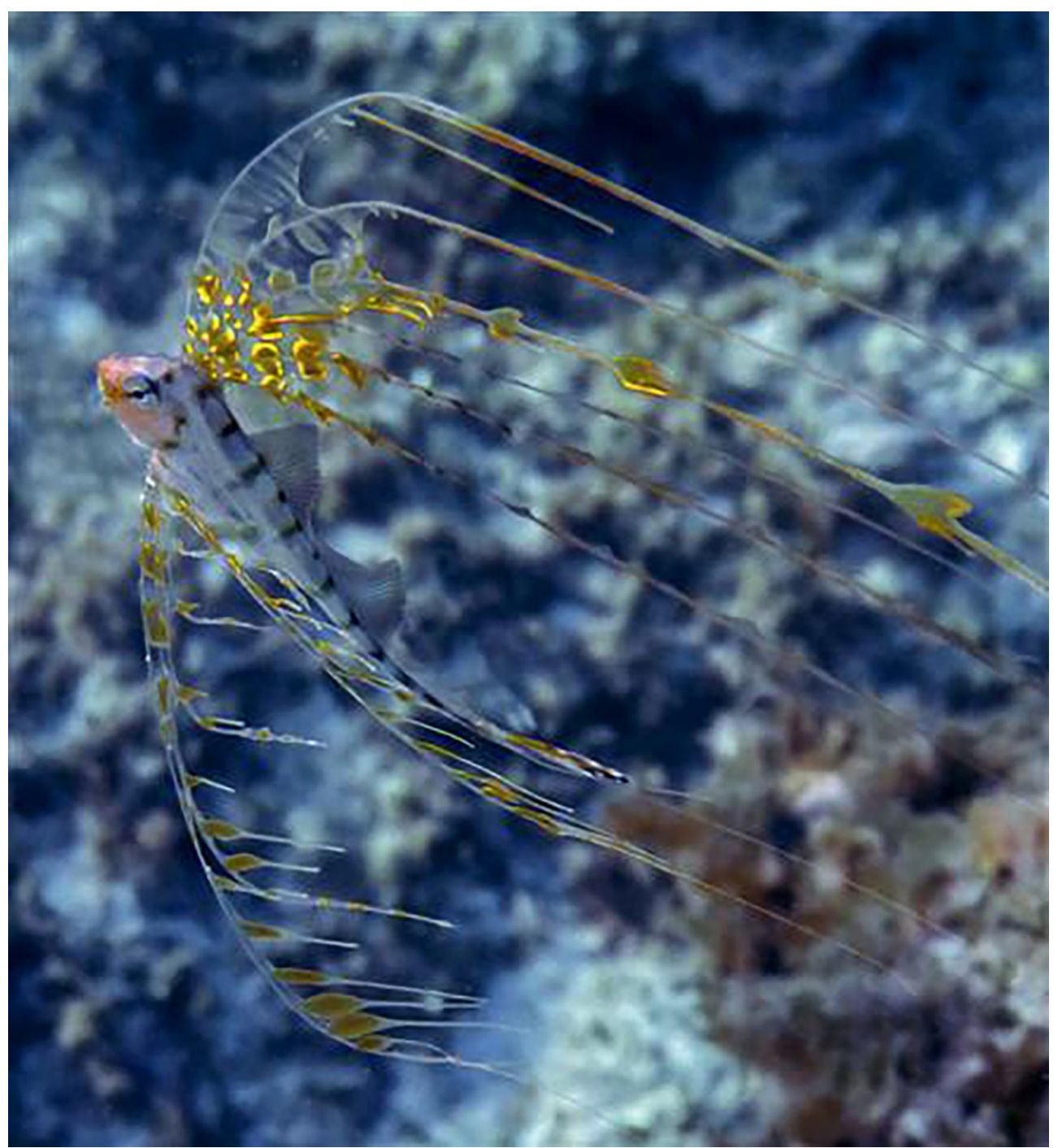

FIGURE 20. Zu sp. Live specimen (not collected) photographed in Mallorca, Spain. C Michael Makowiecki, used with permission. 
Color. Specimens of Z. cristatus greater than about $150 \mathrm{~mm}$ SL with dorsal, pectoral, pelvic and anterior portion of the caudal fin red or crimson, posterior portion of the caudal fin black (freshly caught specimens of Z. elongatus unknown). Dark bars on the trunk and caudal region (less apparent with increase in size), typically 5-7 bars (5-6 in Z. cristatus, $6-8$ in Z. elongatus) on the dorsal part of the trunk and 3-4 bars on the ventral portion of the trunk. Posterior to the anus complete bars run from the dorsal to ventral midline with 6 in Z. cristatus and 5-7 in Z. elongatus. Inter-membranes of the dorsal rays in the nuchal pennant with several large spots, most obvious in live specimens less than about $150 \mathrm{~mm}$ SL. Some variation in coloration and spotting patterns exists (see Martin 2015: fig. 21).

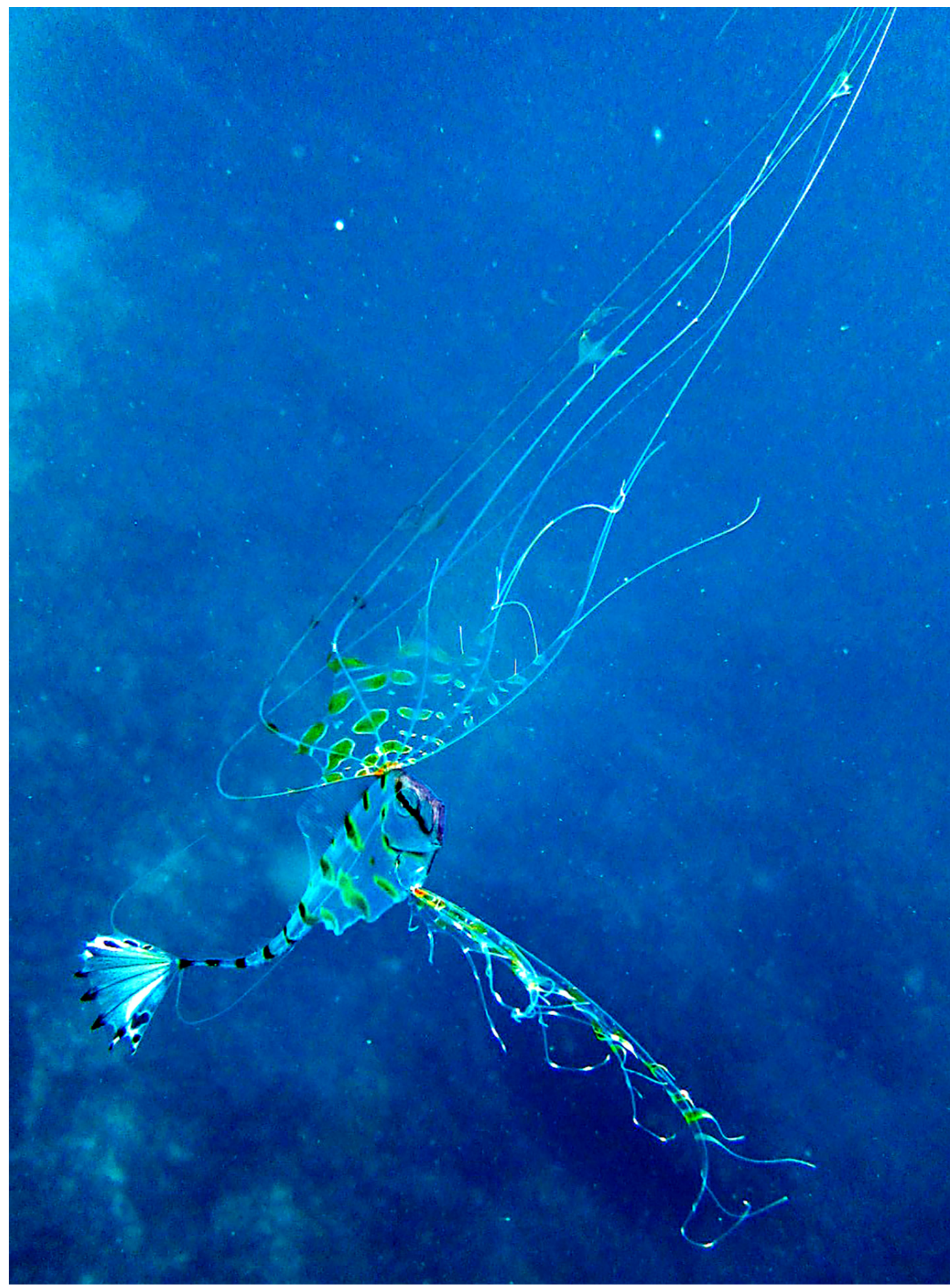

FIGURE 21. Zu sp. Live specimen (not collected) photographed in Nusa Penida, Indonesia. C Helen Mitchell, used with permission. 
Juvenile to adult ontogenetic change. As observed by Palmer (1961), juvenile characters remain until a "definitive developmental stage is attained" and this does not appear to be strictly correlated with size. Therefore, juveniles encompass a wide range of lengths (from roughly $35 \mathrm{~mm}$ to $800 \mathrm{~mm} \mathrm{SL}$ ). It appears that the following changes occur throughout development from juvenile to adult in the following order, though some overlap in relative timing exists: 1) reduction in ventral scalloping; 2) decrease in lateral compression; 3) reduction in rays of the ventral caudal lobe; 4) reduction in the length of the first six anterior dorsal-fin rays; 5) reduction in the length of the pelvic- fin rays; 6) reduction in post-anal ventral constriction; and 7) reduction in vertical bars in the following order: ventral, dorsal, caudal region. The timing of characters 1-3 appear to have the greatest overlap, however, the completion of character 3 occurs first.

Specimens greater than $800 \mathrm{~mm}$ SL are extremely rare in collections. Heemstra \& Kannemeyer (1984) stated that "metamorphosis takes place in the $600-800 \mathrm{~mm}$ size range." and this is supported by specimens examined in this study (pers. obs, JMM). Ji et al. (2009) described and illustrated a $528 \mathrm{~mm}$ SL specimen of Z. cristatus (PKU 98) from Korea possessing characters $2-7$ above. However, a reduction in ventral scalloping is apparent.

Notes on eggs and larvae. Eggs and larvae have not been described for Z. elongatus. Therefore, the following is based on Z. cristatus only. Sanzo (1918) first described eggs and larvae from the Mediterranean. Additional descriptions have been made by Sparta (1933, Mediterranean), Olney \& Naplin (1980, western North Atlantic), Olney (1984, general review), Okiyama (1988, 2014, Japan), Charter \& Moser (1996, eastern North Pacific, California), Beltrán-León \& Herrera (2000, Colombia), Dulčić (2002, Adriatic), Olney \& Richards (2006, western Central North Atlantic), and Dr. Al Connell (unpublished, Western Indian Ocean, South Africa). Young et al. (1994) reported on Z. cristatus larvae from Taiwan, although the specimens were severely damaged and the authors note that the meristic data do not match those for the species and that their identifications are based on pigmentation patterns only.

Planktonic eggs range from $1.85-2.33 \mathrm{~mm}$ in diameter and have a homogenous yolk ranging from 1.4-2.0 mm in diameter. There appears to be some geographic variation in yolk diameter with ranges off the California coast from 1.40-1.80 mm (Charter \& Moser 1996, $\mathrm{n}=5$ ), 1.63-1.95 mm from the Adriatic (Dulčić 2002, $\mathrm{n}=4$ ), and 1.90-2.03 mm (Olney \& Naplin 1980, $\mathrm{n}=3$; Olney \& Richards 2006) in western North Atlantic specimens. Four eggs collected off the coast of Durban, South Africa ranged from 2.06-2.33 mm in egg diameter; yolk diameters were not measured (A. Connell, pers. comm). Eggs have a thick chorion (see Olney 1984: fig. 194B), tinted amber, to dark pink or red, as is characteristic of the Lampridiformes. The yolk is scattered with melanophores (Sanzo 1918; Charter \& Moser 1996; Dulčić 2002).

The embryos feature precocious development of the dorsal and pelvic rays, both with pigmented swellings on the first, most elongate ray of each fin. Hatching size has been reported as smaller than $3.7 \mathrm{~mm}$ NL (eastern Pacific, Charter \& Moser 1966) to $6.5 \mathrm{~mm}$ NL (Mediterranean, Sanzo 1918). Olney \& Naplin (1980) reported a dechorionated, late stage embryo from the western North Atlantic $(5.13 \mathrm{~mm} \mathrm{NL})$ and suggested that this is the minimal hatching size. Pigmentation of newly hatched larvae from the Mediterranean was reported as four dorsal spots alternating with four ventral spots (Sanzo 1918: plate 1, fig. 6). The same pattern was exhibited by a $5.8 \mathrm{~mm}$ NL larvae two days post-hatch collected off Durban, South Africa (A. Connell, pers. comm.). Dulčić (2002) reported an additional spot in the caudal region of a late-stage embryo from the Adriatic. In addition to a much smaller size at hatching, the pigmentation pattern described by Charter \& Moser (1996) for newly hatched preflexion larvae is also quite different with only three dorsal and one postanal melanophores. Also, the elongation of the first dorsal- and pelvic-fin rays, and the number of pigmented swellings of a $5.8 \mathrm{~mm}$ NL preflexion larvae illustrated by Charter \& Moser (1996, fig. 4) is much greater than in any other larvae of that size or stage. It is not yet known if these differences reflect variations in populations, or misidentifications. However, myomere counts for Charter \& Moser's (1996) specimens (total $=62-70 ; 24-32$ preanal in preflexion larvae) are within the range of $Z$. cristatus.

Flexion is reported to occur at $8.3-9.6 \mathrm{~mm}$ (Charter \& Moser 1996). The caudal-fin rays form prior to the pectoral-fin rays. Pigmentation increases across the entire body and the number of dorsal and ventral spots increase with development. At roughly $14 \mathrm{~mm}$, the remaining anterior dorsal- and pelvic-fin rays elongate, and dorsal pigment spreads forming large blotches and the ventral pigment spreads across the abdomen, with only one distinct post-anal spot remaining (see Charter \& Moser 1996: fig. 4; Olney \& Richards 2006). Olney \& Richards (2006) reported that at $14 \mathrm{~mm} \mathrm{SL}$, in addition to the pigmentation changes mentioned above, "...the ventral profile in the abdominal region anterior to the anus becomes irregular \& scalloped." However, Sparta (1933) recorded the first appearance of a "hint of the formation of the three reliefs" (lobes of the scalloping) in a $28 \mathrm{~mm}$ specimen. It is also at this size for which Sparta (1933), supported by specimens examined in this study, reported the following: 1) the 
first six dorsal fin rays exceed the total body length and contain numerous lozenge-shaped expansions; 2) the first pelvic-fin ray exceeds the total body length and the pelvic rays show numerous lozenge-shaped expansions; 3 ) the second element of the ventral caudal lobe is a long filament; and 4) a total of 5 bars in the caudal region. Specimens near $21 \mathrm{~mm}$ SL (MCZ 157795) show irregularities in the ventral profile anterior to the anus, but scalloping does not appear until closer to $40 \mathrm{~mm}$ SL. By $42.8 \mathrm{~mm} \mathrm{SL}$, the body depth in the abdominal region increases (Charter \& Moser 1996), and by $49 \mathrm{~mm}$ SL post-anal ventral constriction leading to a thin elongate caudal peduncle occurs and the zigzag pattern of spinous lateral-line scales posterior to the anus become apparent (MCZ 59320). Based on the deep anterior region, thin caudal region, and ventral scalloping, Sparta (1933) mistakenly determined that a $75 \mathrm{~mm}$ specimen had attained the "definitive shape of the adult." However, we interpret these characters as representing the early phases of a prolonged juvenile stage.

A specimen dip-netted from Japan and in excellent condition (KPM 23199, $12 \mathrm{~mm}$ TL) allowed for observation of new characters. As in all trachipterids, $Z u$ possesses what has been reported as lateral spinules on the dorsal, pelvic, and caudal rays (see Backus et al. 1965: fig. 2). However, the spinules on the first dorsal-fin ray project anteriorly. This character is also observed in early life stages of Trachipterus and recorded here for the first time as well.

Larvae to juvenile ontogenetic change. Charter \& Moser (1996) suggested that the juvenile stage is reached when the postanal dorsal and ventral pigmentation form vertical bars and that this stage persists to at least $321 \mathrm{~mm}$. Olney \& Richards (2006) suggested a juvenile period from $14 \mathrm{~mm}$ SL to $300 \mathrm{~mm}$ SL based on the presence of ventral scalloping, and relative pre- and post-anal body depth. Caudal barring is not reported until $28 \mathrm{~mm}$ in Sanzo (1918). Sparta's (1933) Mediterranean specimens had five vertical bars, increasing to seven vertical bars by $75 \mathrm{~mm}$ SL; six bars were illustrated by Olney \& Richards (2006: fig. E) for their $65 \mathrm{~mm}$ SL specimen. However, in a 49.5 $\mathrm{mm}$ SL specimen (MCZ 59320), vertical barring in the caudal region is not apparent, pigmented dorsal and ventral spots are present, pre-anal scalloping, and the post-anal ventral constriction are apparent. Additionally, caudal barring can persist in specimens well beyond $300 \mathrm{~mm} \mathrm{SL}$ (for example, see Ji et al. 2009: fig. 3C, $528 \mathrm{~mm} \mathrm{SL}$ ). Palmer (1961) did not examine specimens less than $31 \mathrm{~mm}$ SL, although he did observe that "in some instances smaller sized individuals show fewer juvenile characters than other specimens of larger size," suggesting that size is not the only factor related to morphological changes.

Palmer (1961) hypothesized an undefined "metamorphosis" that takes place between 50 and $70 \mathrm{~mm}$ and refers to this as the postlarval stage. Heemstra \& Kannemeyer (1984) referred to prejuvenile, juvenile, and adult stages of $Z u$, with no clearly defined endpoints but appear to break them up by size (prejuvenile as 64-610 mm SL; juveniles $630-800 \mathrm{~mm} \mathrm{SL}$; adult $>800 \mathrm{~mm} \mathrm{SL}$ ). These authors also suggested that the elongate dorsal-fin rays and the pelvic fins were both lost during the transition from the prejuvenile to juvenile stages. Larvae were not examined by Palmer (1961) or Heemstra \& Kannemeyer (1984) and larval to juvenile transitions were not discussed. Sparta (1933) assumed that the ventrally scalloped, vertically barred caudal region stage of $Z u$ was the adult form.

The transformation stage between larvae and juvenile $Z$. cristatus is marked by changes in body shape, fin position and elongation, pigmentation patterns, and scale formation. Metamorphosis of $Z u$ to the juvenile stage is attained when the following endpoints are reached: 1) elongation of the six anterior most dorsal-fin rays and the pelvic-fin rays, 2) pelvic fins migrate anteriorly to the posterior edge of the cleithrum, 3) the preanal ventral midline consists of three fleshy lobes or scallops and abdominal body depth increases, 4) postanal ventral constriction form a thin elongate tail, 5) squamation begins, 6) zigzag of spined lateral-line scales in caudal region develops, and 7) dorsal and ventral pigmentation develops as blotches or vertical bars and at least five vertical bars on the caudal region.

Ontogeny and habitat. During the transformation between larvae and juvenile fishes, and frequently in conjunction with a change in habitat, body shape and pigmentation patterns change and the loss of specialized larval characteristics, such as elongate fin rays, typically occurs. This is not entirely the case in $Z u$. Body shape and pigmentation patterns do change during this transition. There is also enhancement of larval characters as the dorsal and pelvic-fin rays elongate.

Small juveniles have been collected from nearshore shallow waters. The larvae and early juvenile stages appear to remain in the photic zone. Dorsal and pelvic-fin rays appear to shorten and lose their pigmented ornamentation, although, these elongate fin rays persist until the adult stage. These changes do not appear to be accompanied by an immediate change in habitat. It also seems that movement into deeper water from juveniles to adults is gradual, as both juvenile stages and adults are found in deeper waters.

In addition to general body shape and pigmentation, several trends in proportional changes occur during ontog- 
eny: 1) snout-vent length percent of standard length decreases with decreasing length and 2) eye diameter percent of snout-vent length decreases with increasing length. Smaller (in terms of SL) fish have a longer postanal tail, larger eyes, and greater amounts of banding than larger fish. Large juveniles and adults exist without the banding patterns across the trunk and caudal region.

The juvenile stage of $Z u$ is prolonged and encompasses a wide range of lengths with development into and out of the juvenile stage being highly variable. Morphologically, the juvenile stage is reached at the point when ventral scalloping is obvious and metamorphosis to an adult occurs when that scalloping is lost.

Adult $Z u$ are extremely rare in systematic collections. In contrast to juveniles, adults inhabit offshore epipelagic-to mesopelagic habitats. Though some recent records exist (Quigley \& Henderson 2014; Garcia-Barcelona et al 2016), adults are rarely encountered as by-catch in offshore trawls or longline fisheries and are "cast ashore in the wakes of storms" more infrequently than juveniles (Walters \& Fitch 1960). Because of the scarcity of the adult stage, it has only been minimally addressed in the literature and most identification keys and diagnoses available for $Z u$ are based on juvenile characters. Juvenile and adult stages of $Z u$ are strikingly different. During the transition from juvenile to adult, the most identifiable juvenile characters (e.g., ventral scalloping, elongate dorsal and pelvic rays and black bars across the body) are either greatly reduced or lost entirely. One obvious character that persists throughout development from early juvenile to adult is the zigzag pattern in the caudal region of the lateral line. This pattern emerges as a result of spiny lateral-line scales that alternate between a lateral and ventral orientation posterior to the anus. As many other morphological characters change throughout ontogeny, the persistent zigzag pattern in the post-anal portion of the lateral line readily distinguishes juvenile and adult $Z u$ from other lampridiform genera.

Taxonomic history. While revising the suborder Trachipteroidei, Walters \& Fitch (1960) established the genus $Z u$ based on Bonelli's (1820) Trachypterus cristatus, of which the holotype is a juvenile specimen (MZUT 1190; $590 \mathrm{~mm}$ SL, $700 \mathrm{~mm} \mathrm{TL}$ ). In their description of the genus, Walters \& Fitch (1960) did not provide a list of materials examined. Although the authors stated that specimens from egg to adult were represented in their description, no indication was given of how many specimens of each life stage were examined or where the collection localities of their material were. For egg development and larval morphology, Walters \& Fitch relied heavily on the work of Sanzo (1918) and Sparta (1933) from Mediterranean collections. Juvenile samples were readily available to Walters $\&$ Fitch from both coasts of North America. However, they did not reference the work of Tortonese (1958) who reported a $980 \mathrm{~mm}$ SL specimen from the Ligurian Sea and described that specimen as Trachypterus cristatus Bonelli 1820 with having a wavy ventral profile in the caudal region (referring to the zigzag lateral line pattern). Tortonese also noted that the preanal ventral profile did not have prominent waves (scalloping) and that the typically dark vertical zones were inconspicuous and the bars did not extend downward. Therefore, two of the most recognizable characteristics of the more common juvenile stage were absent from this larger specimen. Walters \& Fitch (1960) described the genus $Z u$ as having a ventral profile that “... is scalloped between the pelvic fin and the beginning of the tail" and stated that the "...juvenile and adult color pattern consists of about 6 wavy dark vertical bars on the dorsal part of the trunk..." making no mention of the developmental differences described by Tortonese (1958).

Palmer (1961) reviewed the Trachipteridae of the Mediterranean and the Northeast Atlantic Ocean and also concluded that $T$. cristatus was generically distinct and chose to use the name $Z u$ proposed by Walters \& Fitch (1960). Twenty-six specimens of $Z u$, ranging from 31 to $655 \mathrm{~mm} \mathrm{SL}$, were examined by Palmer (1961). However, the author did not examine larvae or adults. Even though Palmer referenced Tortonese's (1958) adult specimen of $980 \mathrm{SL}$, no morphological description of adult specimens of this size were included in his generic description. For example, he noted that specimens greater than $30 \mathrm{~mm}$ SL have a scalloped ventral profile. Regarding ontogenetic changes in $Z u$, Palmer noted that juvenile characters persist and the transition to the adult stage is not strictly correlated with size. Palmer observed that, in some cases, smaller-sized specimens may show fewer juvenile characters than larger-sized individuals. Numerous specimens support this statement, although Palmer's example is not one of them. He referenced a $32 \mathrm{~mm}$ "larval form", reported by Günther (1887) and taken by the Challenger expedition near the Philippines, as having lost almost all traces of juvenile characters. This specimen (BMNH 1887.12.7.21) has elongate rays of the dorsal and pectoral fins, which are both dominant juvenile characters, although the anteriormost dorsal-fin rays are broken likely due to capture (pers. obs.). Palmer misinterpreted other characters, such as the absence of ventral scalloping, as being lost. Sparta (1933) reported on a $28 \mathrm{~mm}$ specimen in which the scalloping was just beginning to develop. Charter \& Moser (1996) confirmed the appearance of a deeply scalloped ventral profile by $42.8 \mathrm{~mm}$. The Challenger specimen has not yet developed ventral scalloping. 
Trachipteridae of the eastern Pacific Ocean were reviewed by Fitch (1964) with five specimens of $Z u$, including three larvae (8-10 mm SL), one juvenile (213 mm SL) and one adult (535 mm SL). However, Fitch based his generic description on the juvenile and adult specimen only. The collection locality of the adult was listed as Idzu, Japan, and therefore is not representative of the eastern Pacific. Based on Fitch's description (no figure was provided), his adult specimen was a large juvenile. Fitch (1964, also Walters \& Fitch 1960) stated that juveniles and adults have a scalloped ventral profile, vertical dark bars, and describes the nuchal crest, none of which are present in metamorphosed adults. In adults, the scalloping along the ventral profile is either absent or reduced to a single fleshy keel located directly anterior to the anus (Fig. 22A). The elongate dorsal rays are reduced and the pectoral-fin rays are greatly reduced to nubbins or completely absent with the presence of a 'pelvic scar' (Fig. 22B). The characteristic black transverse bars of the juvenile stages are not apparent on the trunk of adult $Z u$ in either preserved specimens or in photos of freshly caught adults (JMM, pers. obs.), although remnants of barring on the tail may still be present.
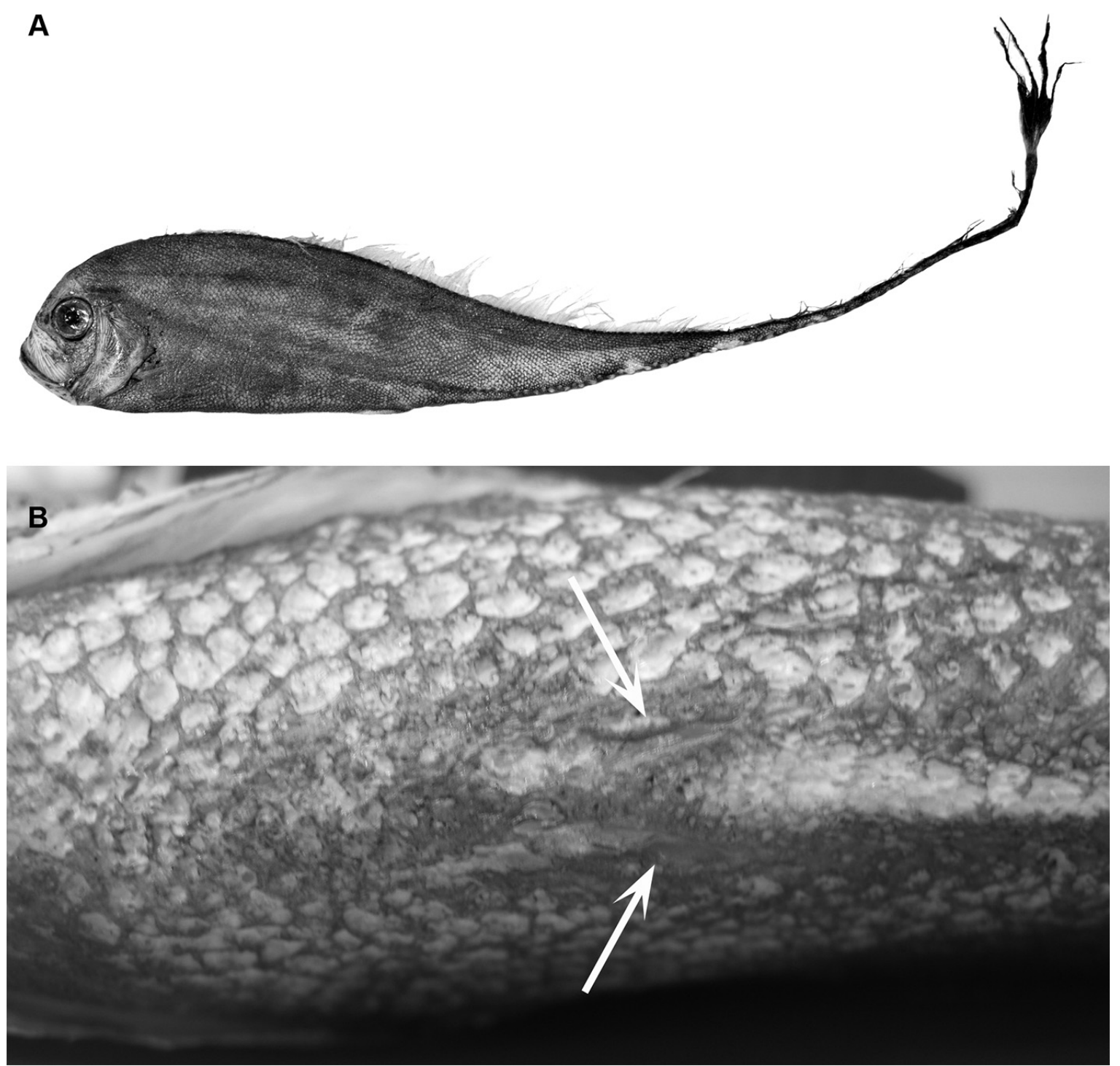

FIGURE 22. Zu cristatus (Bonelli 1820). CSIRO H-6325-01; $1142 \mathrm{~mm} \mathrm{SL.} \mathrm{A,} \mathrm{Whole} \mathrm{specimen,} \mathrm{prior} \mathrm{to} \mathrm{fixation.} \mathrm{B,} \mathrm{Ventral}$ view of pelvic "slits" (white arrows).

Fitch (1961) suggested that Trachypterus semiophorus Bleeker 1868 from the Indo-Pacific and T. ijimae Jordan \& Snyder 1901 from Japan are conspecific and belong to the genus $Z u$, but he did not synonymize them with Z. cristatus. Bolin (1933) had earlier described a juvenile (533 mm SL) and an adult specimen (835 mm SL) of $T$. ijimae (= Z. cristatus) collected off the California coast. Fitch \& Schultz (1978) reported on a true adult specimen (980 $\mathrm{mm}$ SL) and acknowledged the radical difference between the juvenile and adult stages.

Species-level diversity. After it was established by Walters \& Fitch (1960), Zu was reviewed by Palmer (1961) 
in the Atlantic and Mediterranean, Fitch (1964) in Eastern Pacific and Heemstra \& Kannemeyer (1984) from South African waters. Prior to Heemstra \& Kannemeyer's (1984) review of Trachipteridae from South African waters, the genus $Z u$ was considered monotypic. Heemstra \& Kannemeyer described $Z$. elongatus and discussed characteristics regarding juvenile and adult life stages in the generic diagnoses for both Z. cristatus and Z. elongatus from South Africa. Currently, there are two recognized species in the genus, Z. cristatus (Bonelli 1820) and Z. elongatus Heemstra \& Kannemeyer 1984. Adults are known for both, although eggs, larvae and early juveniles are known only for Z. cristatus.

Here we summarize the morphological differences between the two species. Data are synthesized from literature and observations of new specimens, including some representing new geographic locations. The diagnosis of Z. elongatus is based on specimens greater than $304 \mathrm{~mm}$ SL.

\section{Zu cristatus (Bonelli 1820)}

Figures 2B, 3B, 18, 22

Type species. Trachypterus cristatus Bonelli 1820

Holotype. MZUT 1190. $590 \mathrm{~mm}$ SL. Purchased from a fisherman at the Port of Genoa, taken from the Gulf of Spezia.

Material Examined. Trachypterus ijimae (= Zu cristatus) NSMT P 590 (holotype, 137 mm SL, Pacific, Japan, Tokyo Bay); AMS I.17877-022 (304 mm SL, Pacific, Australia, New South Wales, Sydney); AMS I.27499-001 (211 mm SL, Pacific, Australia, Queensland, Hamilton Island); AMS I.36042-001 (6 mm TL, Pacific, Australia, Queensland, Osprey Atoll); AMS I.36044-001 (5 mm TL, Pacific, Australia, Queensland, Osprey Atoll); AMS I.38598-003 (310 mm SL, Pacific, Australia, New South Wales, Sydney); AMS I.39622-001 (330 mm SL, Pacific, Australia, New South Wales, Angourie Point); AMS I .42086-005 (35 mm SL, Pacific, Australia, Queensland, Coral Sea); AMS I.42452-018 (30 mm SL, Pacific, Australia, Queensland, Coral Sea); BMNH 1887.12.7.21 (32 mm SL, Pacific, Philippines); HUMZ 3045 (197 mm SL, Pacific, Taiwan); HUMZ unregistered (872 mm SL, unknown); KPM-NI0023199 (12 mm SL, Pacific, Japan, Ogasawara Islands); MCZ 59320 (49 mm SL, Atlantic, Caribbean); MCZ 157795 (21 mm SL, NW Atlantic); VIMS 40937 (271 mm SL, Gulf of Mexico); NPM K 1/d2998 Atlantic, Mediterranean, Adriatic, Dalmatia).

Diagnosis: Dorsal-fin rays 120-151 total (135-145 most common), six most anterior in juveniles more robust and elongate than others; pectoral-fin rays 10-12, first element short and stout; pelvic-fin rays 6-7, first short and stout, elongate in juveniles, reduced to only bony base in adults; caudal-fin rays 10-12, dorsal lobe with 8-9 rays, ventral lobe with $2-3$ rays, ventral lobe greatly reduced in adults. Gill rakers $2-3+8-9$. Lateral-line plates 96-106. Vertebrae: 63-69 total, 22-24 precaudal, 32-33 preanal. SVL 40.6-50.1\% SL (43.1-54.9\% in specimens from 137-248 mm); body depth $19.7-21 \% \mathrm{SL}$ (decreasing with increasing SL); eye diameter 5.1-7.2 \% SV, eye diameter 1.5-2.0 in length of lower jaw. Premaxilla with 9-21 teeth, 10 on dentary; vomer with 1-4 teeth in adult; palatine teeth present (up to 3 on each) or absent.

Remarks. In juveniles, the three fleshy lobes present on the ventral midline (i.e., the scalloped ventral margin) between the pelvic-fin base and the anus are smooth (Fig. 18). The post-anal ventral constriction is abrupt in juveniles and the orientation of the lateral line runs straight from its origin to the point of ventral constriction just posterior to the anus, at which point it joins the ventral midline.

The presence of deciduous cycloid scales was reported by Bolin (1933), Tortonese (1958), Walters \& Fitch (1960), Palmer (1961), and Fitch (1964). Rosenblatt \& Butler (1977) indicated that there were no scales present on their eight specimens of $Z u$. Heemstra \& Kannemeyer (1984) suggested squamation over the entire body and reported the presence of only scale pockets on adults, except near the tail. On all adult specimens examined here there are thin delicate scales present in the caudal region that can appear as shiny patches and scale pockets are present across trunk. One adult specimen (HUMZ unregistered, $872 \mathrm{~mm} \mathrm{SL}$ ) was covered in delicate, imbricated cycloid scales throughout the body, but scales were absent in the head region. Each scale on the trunk overlapped multiple skin tubercles. In juveniles, scales typically persist along the lateral line and onto the caudal fin.

Distribution: Worldwide in tropical and temperate waters.

Habitat: It appears there is an ontogenetic shift in habitat. There is a trend of increasing collection depth and distance from shore with increasing length. Adult specimens are rarely collected in bottom trawls or long-lines rang- 
ing in depth from roughly $150-1200 \mathrm{~m}$ (to $400 \mathrm{~m}$ in the Mediterranean and to $1200 \mathrm{~m}$ in the Tasman Sea). Juvenile specimens are found in more nearshore, midwater habitats. Although rare, early juveniles have been photographed on coral reefs in all oceans (Figs. 20,21). Eggs and larvae are planktonic and not uncommon in long-term ichthyoplankton surveys (e.g., Great Barrier Reef, Gulf of Mexico, Eastern Pacific).

Geographic variability. While revising the Trachipteridae of the Mediterranean and Northeast Atlantic, Palmer (1961) reported that the first five dorsal-fin rays of Z. cristatus are elongate. However, this is in contrast to all other reported values from all oceans, including the Mediterranean and Northeast Atlantic. In all specimens examined here, the first six dorsal rays are elongate in larvae and juveniles, and persist as the nuchal pennant which is separated from the remaining dorsal-fin rays in adults. There does not appear to be any geographic variation in this character. However, specimens from the Eastern Pacific Ocean tend to have slightly fewer total dorsal-fin rays $(6+$ 132-138) than those from the Western Pacific Ocean $(6+137-145)$.

\section{Zu elongatus Heemstra \& Kannemeyer 1984}

Figure 19

Holotype. SAM 24707. 1166 mm SL. Trawled SW of Cape Province, $411 \mathrm{~m}$ bottom depth.

Material Examined. CSIRO H 6325-01 (1142 mm SL, Pacific, Tasman Sea, Lord Howe Rise); CSIRO H 5915-01 (Photographs only, 1325 mm SL, Indian, Madagascar Ridge); NMNZ P.5681 (426 mm SL, Pacific, New Zealand, South Island, Nelson); NMNZ P.000834 (129.75 SVL ( $\approx 420 \mathrm{~mm}$ SL), Pacific, New Zealand, South Island, Marlborough); QVM 1972.5.511 (405 mm SL, Pacific, northwest Tasmania, Stanley).

Diagnosis. Dorsal-fin rays 138-147 total, in juveniles first six more robust and elongate than remaining; pectoral-fin rays 11-13, first element short and stout; pelvic-fin rays 7-9, elongate in juveniles, bony base only in adults; caudal-fin rays 17 , dorsal lobe with $12-13$ rays, ventral lobe with $4-5$ rays. Gill rakers $2-3+7-9$. Lateral-line plates 125-143. Vertebrae: 84-88 total, 29-32 precaudal, 37-40 preanal. SVL 31-42 \% SL; body depth 14.5-20.4 \% SL; eye diameter 9.0-12.9\% SV, eye diameter 1.5-2.0 in length of lower jaw. Premaxilla with 9-21 teeth, 6-9 on dentary; vomer with two teeth in the adult, juveniles with three vomerine teeth; palatine teeth variably present.

Remarks. In juveniles, the three fleshy tabs are present on the ventral midline between the pelvic-fin base and the anus and are much more angular in appearance (Fig. 19) when compared to the smoother, lobe-shaped scalloping of $Z$. cristatus. The post-anal ventral constriction is not as abrupt as in juveniles of $Z$. cristatus, but rather tapers more gradually. In both juveniles and adults of $Z$. elongatus, the lateral line originates against the uppermost portion of the operculum and gradually slopes toward the ventral mid-line until the vent is reached. In comparison, the lateral line of $Z$. cristatus runs straight from its origin to the point of ventral constriction just posterior to the anus, upon which it joins the ventral midline.

Meristic and morphometric information presented here includes data from specimens collected from previously unreported geographic locations (waters off of Australia, New Zealand and western Indian Ocean-Madagascar Ridge) and larger size classes ( $>1142 \mathrm{~mm} \mathrm{SL}$ ). Incorporation of these data provide a broader geographic and ontogenetic description than previously reported for Z. elongatus from the Atlantic waters of South Africa.

Distribution. Known from the Atlantic Ocean off South Africa, Pacific Ocean and Tasman Sea (New Zealand and Tasmania), and the western Indian Ocean (off Madagascar Ridge). Shirke et al (2017) reported the first record of Z. elongatus from the southeast Bay of Bengal, represented by a $1280 \mathrm{~mm}$ SL specimen collected from a depth of $408 \mathrm{~m}$ on longline in Andaman and Nicobar Islands waters. However, the specimen photographed (Shirke et al 2017: fig. 2) lacks the zigzag series of lateral-line plates, which is a diagnostic character of the genus $Z u$. Additionally, the specimen has tubercles along the mid-ventral line that project beyond the body wall and flattened tubercles along the dorsal fin pterygiophores, both are characters that are absent in $Z u$ and present in Trachipterus. The meristic counts provided also fall within the range for the genus Trachipterus. As the specimen is Trachipterus sp., the presence of $Z$. elongatus in the southeast Bay of Bengal is not confirmed.

Previously known from Atlantic waters of South Africa, off northwestern Cape Province (collected by trawlers, bottom depths range from 411-580 m) and from New Zealand waters (Heemstra \& Kannemeyer 1984). New Zealand specimens have been collected mostly by bottom or midwater trawls and at bottom depths ranging from 480-1133 m, with sizes ranging from about 200 to $1330 \mathrm{~mm}$ SL. Some smaller specimens (in the 250-400 mm SL range) have been recorded as washed up on beaches. Specimens smaller than $240 \mathrm{~mm}$ SL have yet to be reported. 
Examination of material in the Australian National Collection at CSIRO and at the QVM confirms the presence of Z. elongatus in Australian waters. The CSIRO specimen, an adult (CSIRO H6325-01, $1142 \mathrm{~mm} \mathrm{SL}$ ), was collected by demersal trawl at $1000 \mathrm{~m}$ near Lord Howe Rise in the Tasman Sea. The QVM specimen, a juvenile (damaged, about 405 mm SL, QVM 1972/5/511), was washed ashore at East Inlet, Stanley on the northwest coast of Tasmania. Both specimens fall within the meristic ranges given for Z. elongatus, and the juvenile specimen possesses angular scallops and 7 postanal vertical bars. This species was not found in any mainland Australian collections examined. A specimen collected from the western Indian Ocean, off the Madagascar Ridge (CSIRO H5915-01, 1325 mm SL,) extends the range of the species to the southern Indian Ocean.

Geographic variability. Heemstra \& Kannemeyer (1984) reported data on five South African specimens and two New Zealand specimens; data from the New Zealand specimens were not included in the diagnosis or description of $Z$. elongatus. Upon comparison of these reported values and additional specimens examined it appears that some differences are present in Z. elongatus specimens from South Africa $(\mathrm{n}=5)$, New Zealand and Tasmania $(n=5)$, and a single specimen collected from the southwestern Indian Ocean. Vertebral counts for the New Zealand specimens were different from South African specimens: 1) total vertebrae, 88 vs. 84-87; 2) pre-anal, 37, 39 vs. 38-40; 3) precaudal, 30, 32 vs. 29-31. The eye diameters for New Zealand and Tasmanian specimens are also larger, relative to snout-vent length (11.5-12.9\%) than for the South African specimens (9-10\%) and for the Indian Ocean specimen (10.7\%). Although some differences among specimens collected at different locations are present, so few specimens are available that it is unclear if these differences represent true geographic variation, ontogenetic variation, or artifacts of the small sample size. More specimens of similar sizes are needed for comparison.

\section{Desmodema Walters \& Fitch 1960}

Figures 23, 24, 26-29

Type species. Trachipterus jacksoniensis polystictus Ogilby 1898, Newcastle, New South Wales, Australia.

Material Examined. Species-specific material listed below. Desmodema spp.: HUMZ 113370 (273 mm SL, Pacific, Japan, Hokkaido); HUMZ 186227 (942 mm TL, Pacific, Japan, off Miyagi); NSMT-P91125 (63.9 mm SVL, Pacific, Japan, Kyushu, Kagoshima Prefecture)

Diagnosis (Adults). Body long (to $1100 \mathrm{~mm} \mathrm{SL}$ ), laterally compressed, tapering to a thin, exceedingly elongate caudal peduncle posterior to the anus; whiplike caudal region (narrower than in Trachipterus; exceedingly more elongate than $Z u$ ) curved dorsally. Snout-vent length about $1 / 3$ to $1 / 4$ SL, relative SVL decreasing with increasing SL. Dermal tubercles and pore system present throughout trunk, tubercles on ventral edge of body do not project beyond the general body surface as in Trachipterus. Slight to strong dorsal curve of the body margin in the trunk/ caudal region posterior to anus. Scales cycloid, with ridges or with 1 to 4 spinous ridges (D. lorum). Lateral line runs the length of the elongate caudal region and ends at the caudal base. Lateral-line plates with 1 or 2 spines that are much smaller than in Trachipterus or $Z u$. Relative to the lateral-line scale, the spines point laterally (not angled anteriorly as in Trachipterus). Body depth at pectoral fin 7.2 to $17.9 \%$ SL, decreasing with increasing length; body depth at anus 5.4-13.3\% SL, decreasing with increasing length. Seven pterygiophores anterior to first neural spine, 1 or 2 between first and second neural spine. Teeth on premaxilla 1-4, with one or two in the form of large, recurved fangs; 2 (4 in NSMT 57647) large recurved fangs on the dentary; vomerine teeth variably present. Gill rakers on the first arch $2-4+7-10$, most commonly $3+9$, spinules variably present on upper arch rakers. Pseudobranch well developed, inner operculum strongly pigmented at the gill margin. Dorsal-fin rays $116-215$, anteriormost 5-6 rays reduced to a dorsal ridge (i.e., a bony process representing the pterygiophores of the anteriormost elongate dorsal-fin rays of juveniles) that originates over the preopercle; first few fin rays relatively short, the subsequent rays increasing in length, reaching a maximum length over and slightly posterior to the anus; fin rays on the whiplike caudal region gradually decreasing in length. Pectoral-fin rays 1+ 10-14 (one exceptionally short fin ray followed by 10-14 rays). Pelvic fins absent, bony bases not present as in adult Trachipterus and $\mathrm{Zu}$; skin growing over slit-like opening where elongate pelvic-fin rays of juveniles existed (more obscured than in $Z u$ and Trachipterus). Caudal-fin rays 6-8, typically 7; no ventral caudal lobe is present and all rays are supported by the terminal centrum; caudal fin parallel to the caudal peduncle (not dorsally perpendicular as in Trachipterus and $\mathrm{Zu}$ ). Minute lateral spinules on the dorsal-, pectoral-, and caudal-fin rays greatly reduced or absent. Anal fin absent. Anus most commonly situated on the left side, occasionally on the midventral line. Total vertebrae 71-77 (D. polystictum) or 106-111 (D. lorum). 
Color. Body primarily silver, dark brown or black dorsally. Dorsal-fin rays bright red or crimson except those in the whiplike caudal region, as well as the caudal-fin rays, which are black. Pectoral fin clear or black. Anterior profile, front of snout, tip of mandible to the anteriormost dorsal-fin ray black. Based on D. polystictum (see Remarks).

Remarks. Specimens of Desmodema are reported as chocolate brown by Harrisson \& Palmer (1968). However, Rosenblatt \& Butler (1977) attributed this to preservation, with $D$. lorum much darker than D. polystictum when preserved. Fresh specimens or images of fresh specimens of $D$. lorum are not available and the color of adults in life is unknown. It is hypothesized that $D$. lorum is overall darker in color because of a deeper, darker habitat than D. polystictum.

The presence of a short first pectoral-fin ray has not been previously reported. Haemal spines of the posterior most vertebrae (last 10 or so) may pierce through the body wall, most likely as a result of the dorsoventral constriction associated with the caudal region or due to the fragility of this region and subsequent damage during collection. These protruding haemal spines are frequently mistaken for anal-fin rays. Unlike other trachipterids, there is no ventral caudal lobe in Desmodema. All caudal-fin rays originate from the terminal centrum and its fused hypural; the ventral hypural is rayless (see Rosenblatt \& Butler 1977: fig. 1).

Notes on juveniles. Compared to adults, juvenile Desmodema are profusely spotted, deeper bodied, have a relatively shorter postanal length, and, depending on the stage (early vs late), elongate anteriormost 5-6 dorsal-fin rays and pelvic-fin rays may or may not be present. In young juveniles (Fig. 23) the body outline is almost triangular, with the maximum body depth at the pelvic fin. As body depth decreases, the dorsal-fin ray length increases until just anterior of the caudal peduncle. The 5-6 anteriormost elongate dorsal-fin rays, referred to as the dorsal pennant by Rosenblatt \& Butler (1977), are present (see Amaoka et al. 1992: fig. 23). Pelvic fins are also present and the fin rays are extremely elongate, exceeding the body length. These elongate dorsal- and pelvic-fin rays are flat and fan-like in appearance and lack any ornamentation (as in $Z u$ ).

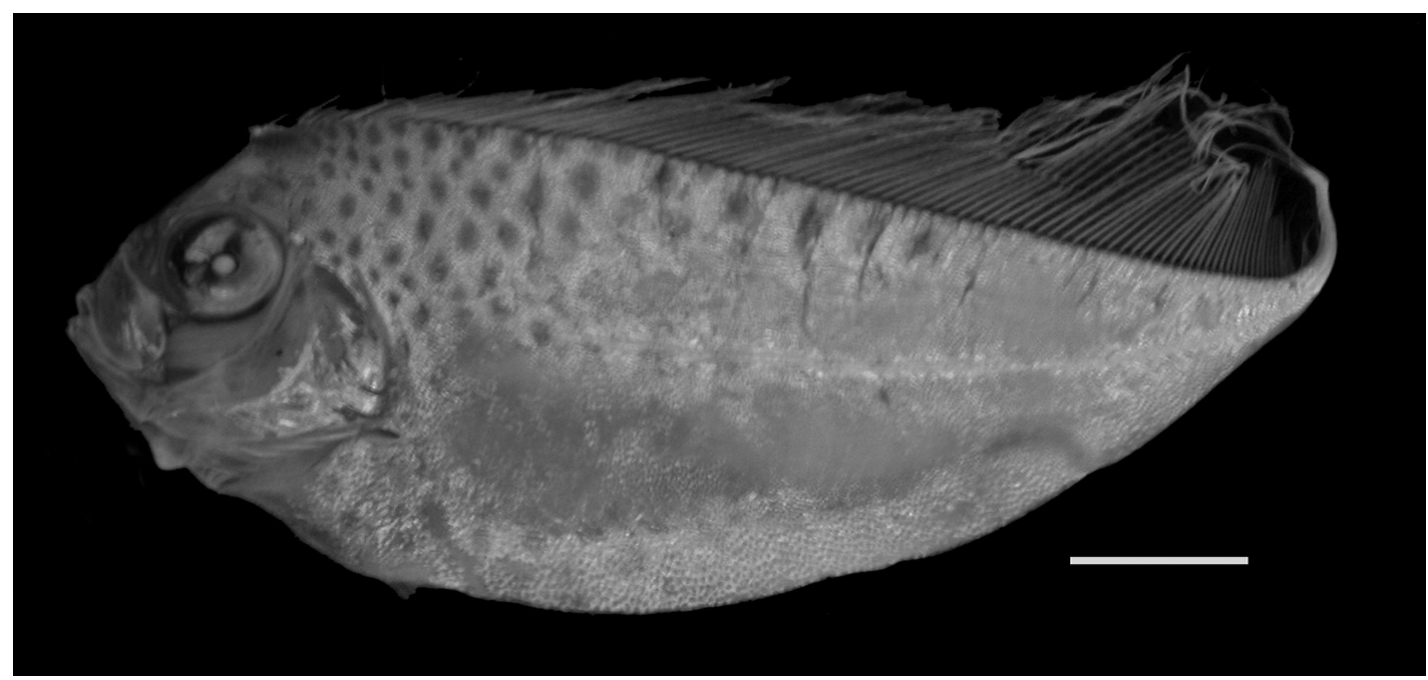

FIGURE 23. Desmodema polystictum (Ogilby 1898). VIMS 42794; $66.1 \mathrm{~mm}$ SL.

As individuals grow the body outline becomes more rounded. The dorsal pennant begins to reduce in length, ultimately represented by a bony ridge of pterygiophores in adults (Fig. 24). The elongate pelvic fins are absent, but a small slit-like opening at the position of the pelvic fin may be present. This heals over completely in adult specimens. The loss of pelvic-fin rays appears to happen to the bases of the pelvic fins (unlike Trachipterus where reduced pelvic-fin rays protrude from the body wall), and is hypothesized to happen relatively quickly as proposed by Rosenblatt \& Butler (1977). Observations of the material examined for this study support this hypothesis as no specimens showed an intermediate stage in which there are reduced pelvic-fin ray lengths (in which fin ray breakage is not obvious). Also, pelvic-fin ray stumps (as found in Trachipterus and $Z u$ ) were not identified. The whip-like tail extension is thin and relatively short in small juveniles, greatly increasing in length relative to the SVL. The dorsalfin rays present in the tail region are short in comparison to those present in the trunk region of the dorsal fin. A gas bladder is present in juveniles to about $300 \mathrm{~mm}$ (Rosenblatt \& Butler 1977). 


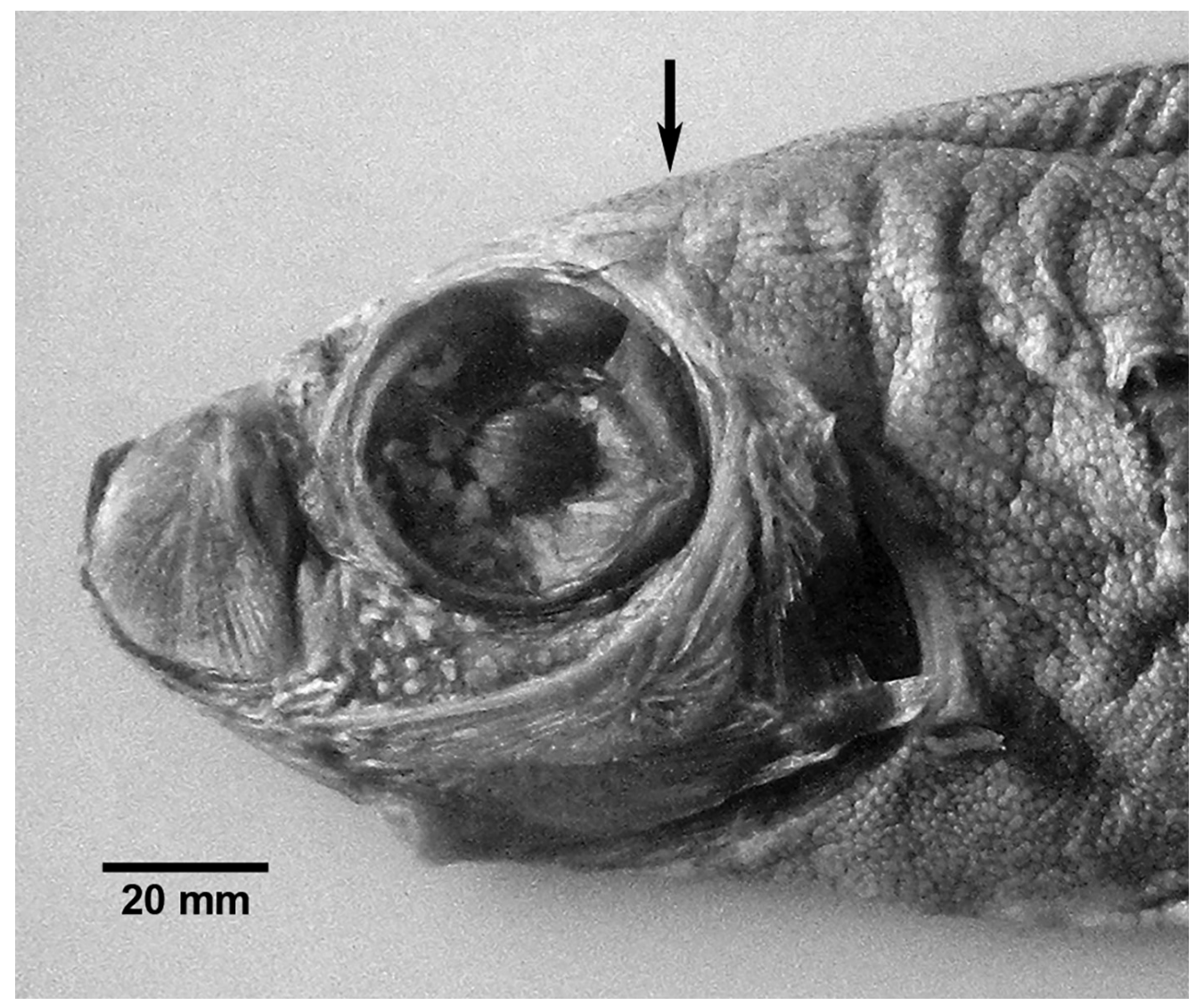

FIGURE 24. Desmodema sp. USNM 165552; $367 \mathrm{~mm} \mathrm{SVL.} \mathrm{Head} \mathrm{in} \mathrm{lateral} \mathrm{view.} \mathrm{Arrow} \mathrm{indicating} \mathrm{position} \mathrm{of} \mathrm{bony} \mathrm{ridge.}$

Color. Juveniles are characteristically silvery and profusely spotted. The spots are typically larger dorsally, more abundant in the dorsal and anterior regions than ventrally and posteriorly and are reported as bluish to blackish in freshly collected specimens. Spots are black in preserved specimens. Dorsal, pelvic, and caudal-fin rays are red (coloration typically lost during preservation). If elongation of the whip-like caudal region has begun, then the dorsal-fin rays in this region are black and the caudal-fin rays may be either red or black.

Ontogeny (juvenile to adult). There is a protracted period of transition from the juvenile stage to the adult and this transition does not appear to be correlated solely with size. Rosenblatt \& Butler (1977) termed one stage of transition in this period, in which rapid morphological changes are hypothesized to occur, as a metamorphosis. The following changes occur throughout development from juvenile to adults, typically in the order listed, although some overlap in relative timing exists: 1) body shape from triangular to teardrop; 2) body depth from deepest at the head, shifting posteriorly to roughly $1 / 3 \mathrm{SVL} ; 3$ ) loss of the dorsal pennant; 4) loss of the pelvic fins; 5) elongation of the whip-like caudal region; 6) loss of spotting; and 7) caudal and dorsal-fin rays on the whip-like caudal region change from red to black.

In early juveniles, the anteriormost dorsal-fin rays (typically 5, sometimes 6) are extremely elongate, and the complete reduction of these rays results in the dorsal ridge present in adults. Pelvic-fin rays are also elongate in young juveniles and reduced to their bases in adults. New material and both still photos and video of live juvenile specimens in their natural habitat (which were unavailable to Rosenblatt \& Butler 1977) suggest that these reductions may occur more gradually then previously suggested. Juvenile specimens in videos (in which damage due to collection has not occurred) filmed off Japan have functioning dorsal- and pelvic-fin rays, which are intermediate in length. Reduction of these fin rays has begun but elongation of the caudal region has not. Therefore, it appears that the elongation of the caudal region does not begin until the loss of the elongate dorsal and pelvic-fin rays commences and continues after the loss of elongate fin rays is complete. In specimens between 50 to $142 \mathrm{~mm} \mathrm{SL}$, SVL ranges from $58-82 \% \mathrm{SL}$. This decreases to $29-54 \% \mathrm{SL}$ in specimens $271-430 \mathrm{~mm}$ SL and in specimens ranging from 935 to $1098 \mathrm{~mm} \mathrm{SL}, \mathrm{SV}$ is $24.2-33.6 \%$ SL (Fig. 25.). The elongate whip-like caudal region acts to extend the length of lateral line, which reaches its posterior tip. 


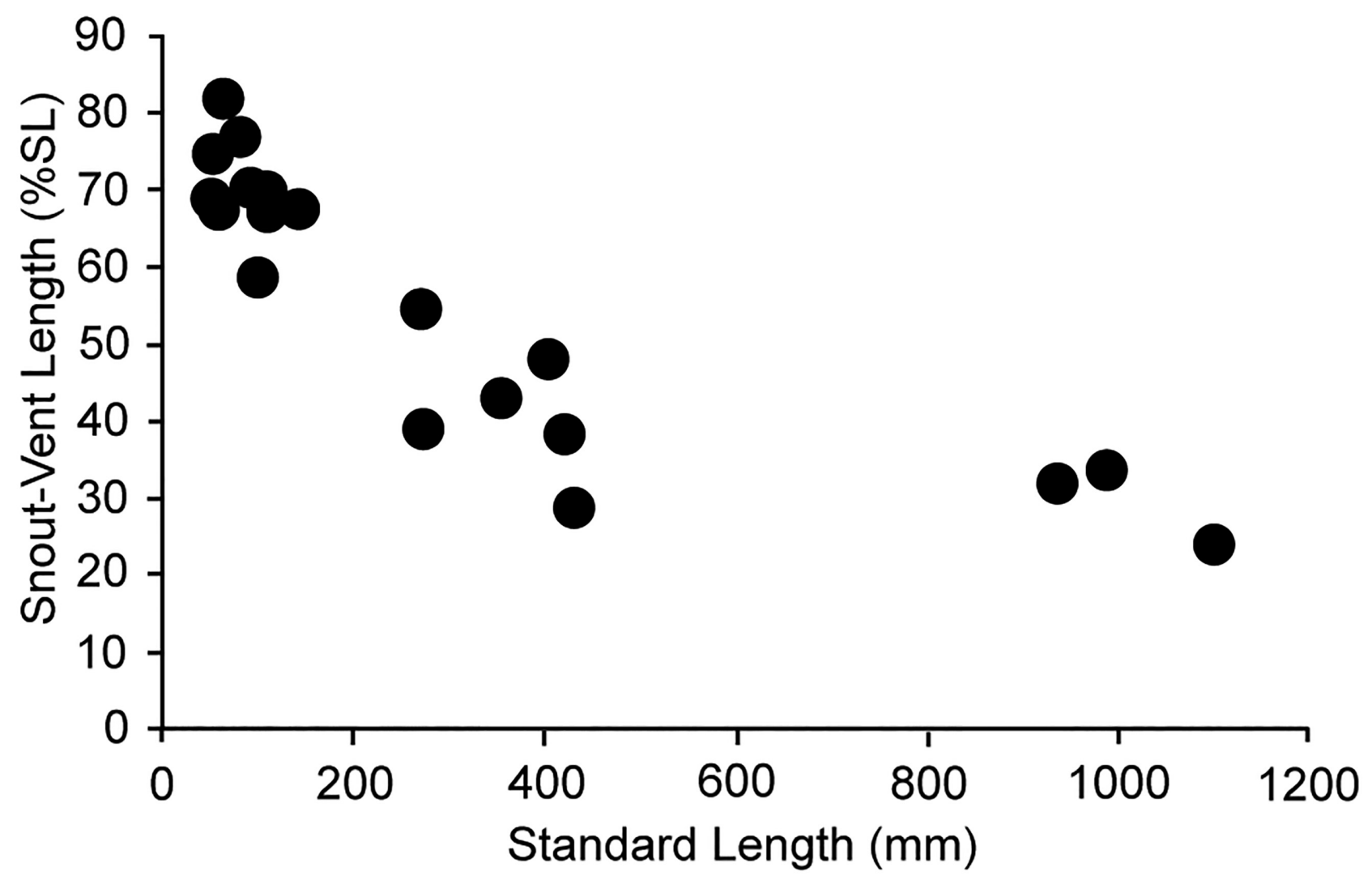

FIGURE 25. Desmodema spp. Snout-Vent Length expressed as percent standard length.

It is hypothesized that the transition from juvenile to adult is more rapid for Desmodema than in either Trachipterus or $Z u$, but it is not likely to happen as fast as predicted by Rosenblatt \& Butler (1977). A more gradual transition appears to occur with these characters. Abrupt changes that would suggest a complete and immediate loss do not appear to describe ontogeny of Desmodema. However, additional complete specimens in these transitional stages need to be examined.

Significant color changes occur during the juvenile to adult transition. Caudal and dorsal-fin rays along the caudal region are red in young juveniles. With progression into the adult stage these fin rays change to a deep black. This typically occurs after the loss of the elongate dorsal and pelvic-fin rays and elongation of the caudal region, however, the blackening of the caudal-fin rays may occur prior to any reduction in elongated rays or tail extension. The loss of the polka-dotted spotting is the most gradual of the morphological transitions and the last to be completed. Spots, which are not all uniformly sized, are lost in posterior-to-anterior (NSMT 57555), and ventral-to-dorsal (NSMT 91459) directions. Rosenblatt \& Butler (1977) reported a $95 \mathrm{~mm} \mathrm{SV}$ specimen (species unknown) as their largest with polka-dotted spotting pattern. In the current study, a complete (full-body) polka-dotted spotting pattern was observed in a $147.8 \mathrm{~mm}$ SVL (271 mm SL) specimen of D. polystictum (NSMT 63975); a $125.4 \mathrm{~mm}$ SVL (430 $\mathrm{mm}$ SL) specimen of $D$. lorum (NSMT 57555) retained an abundance of polka-dotted spotting anteriorly.

Notes on eggs and larvae. In their review of lampridiform genera, Walters \& Fitch (1960) stated that eggs and early larvae of Desmodema were unknown (see also Olney 1984). Charter \& Moser (1996) described eggs and larvae of $D$. lorum from the northeastern Pacific Ocean. Regarding D. polystictum, Walters \& Fitch (1960), Olney (1984), Olney \& Richards (2006), and Fahay (2007) all reiterated that eggs and early larvae were unknown. However, Pertseva-Ostroumova \& Rass (1973) described thirteen eggs and two early larvae identified as D. polystictum from the southeastern equatorial Pacific Ocean. These specimens were not available for examination for the current study, but based on the illustrations (see Pertseva-Ostroumova \& Rass 1973: fig. 26) and morphological descriptions, this identification is supported. The eggs and larvae of Desmodema differ from $Z u$ and Trachipterus based on the number of melanophores scattered throughout the yolk (much greater in Desmodema) and by having roughly 70 myomeres. This corresponds with myomere counts reported for D. polystictum (D. lorum with 102-112; Charter \& Moser 1996; of other trachipterids, only Z. cristatus and some species of Trachipterus have approximately 70 
myomeres). Additionally, the distribution for D. lorum is restricted to the northern Pacific Ocean. Okiyama (2014) described and illustrated a $27.5 \mathrm{~mm}$ SL specimen of $D$. polystictum. Recently, two eggs that were collected off the northwestern coast of Sri Lanka were identified as D. polystictum morphologically and through DNA barcoding (Rathnasuriya et al. 2019). These eggs were collected temporally and geographically close to large numbers of adult specimens (99 individuals over two sampling stations) that were taken in nighttime trawls of the upper $30 \mathrm{~m}$ of the water column, suggesting that this portion of the Central Indian Ocean is a spawning area for D. polystictum. Regardless, early life history information for any species of Desmodema is very limited.

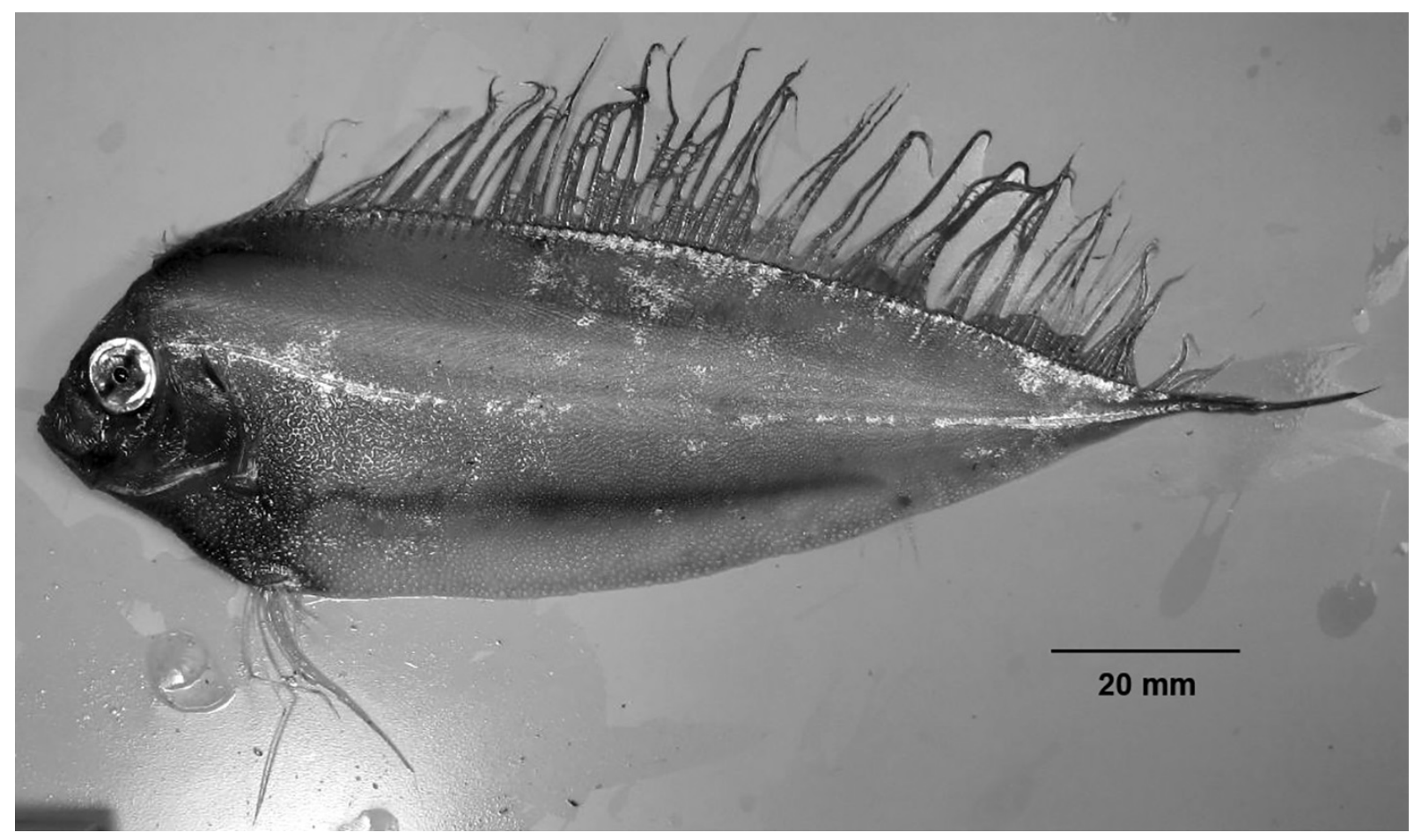

FIGURE 26. Desmodema polystictum (Ogilby 1898). Fresh specimen trawled at $1000 \mathrm{~m}$ depth, representing the first record from Oman. Photo C Laith Jawad, used with permission.

Planktonic eggs are large and range from $2.3-2.7 \mathrm{~mm}$ in diameter (D. lorum $2.4-2.5 \mathrm{~mm}$; D. polystictum 2.3-2.7 mm). They have a homogenous yolk ranging in diameter from 2.0-2.4 mm (D. lorum 2.1-2.3 mm; D. polystictum 2.0-2.4 mm) and no oil globule (Charter \& Moser 1996: fig. 1; Pertseva-Ostroumova \& Rass 1973: fig. 26; Rathnasuriya et al. 2019: fig. 2). Eggs of lampridiform fishes are reported as being brightly colored either pink, red, or amber (Olney 1984). An amber to pink chorion is reported for D. lorum (Charter \& Moser 1996), however, the English translation of Pertseva-Ostroumova \& Rass (1973) makes no mention of any pink or red coloration to the egg. Similarly, the images published by Rathnasuriya et al. (2019: fig. 2) do not show any reddish coloration, nor does their description make any mention of this coloration. Pigmentation patterns described for the eggs and embryos for both species are similar with melanophores scattered on the yolk and two rows of melanophores dorsally on the epaxial myomeres. Eggs are epi- to upper mesopelagic and have been collected from 0-100 m.

Hatching length is reported as $<6 \mathrm{~mm}$. Pertseva-Ostroumova \& Rass (1973) were able to incubate a later stage egg for seven days and at hatching the larva was $5.1 \mathrm{~mm}$ (after preservation). The first dorsal fin-ray of this larva was elongate and had two pigmented swellings and three shorter rays posterior to it. The pigment pattern described for a $6.2 \mathrm{~mm}$ larva of $D$. polystictum damaged during collection (the ends of the dorsal and pelvic rays were broken) consisted of accumulations of melanophores on the forebrain, ascending process of the premaxilla, the lower jaw, gut and the base of the pelvic fins. On the caudal fin there were three large concentrated spots along the dorsal edge and two spots on the ventral portion. (Pertseva-Ostroumova \& Rass 1973). Preflexion pigmentation described for D. lorum is similar except for the lack of concentrated spots in the dorsal and ventral regions of the tail (Charter \& Moser 1996).

Flexion for Desmodema is reported to occur at greater than $11.3 \mathrm{~mm}$ (Charter \& Moser 1996) followed by development of the caudal and, lastly, the pectoral-fin rays. Postflexion pigmentation patterns for $D$. lorum show an increase of pigmentation on the head, over the brain and around the eye, laterally on the body and on the dorsal 
pterygiophores. The juvenile polka-dotted spotting pattern is not apparent in D. lorum of roughly $25 \mathrm{~mm}$ (Amaoka et al. 1992) but a complete pattern is attained by $52.3 \mathrm{~mm}$ SL (USNM 164325).

Myomere counts for $D$. lorum are 106-112. Total myomere counts for the two larvae described as D. polystictum (Pertseva-Ostroumova \& Rass 1973) were 70 and $72+$ ? (the last few were not counted). Along with egg morphometric data and the pigmentation patterns, these counts suggest that these larvae are representative of $D$. polystictum.

Ontogeny and habitat. As with other trachipterids, morphological changes throughout development correspond with changes in habitat association as larvae and juveniles transition from a planktonic existence in the euphotic zone into deeper, more offshore waters. Specimens with elongate dorsal- and pelvic-fin rays are observed in the epipelagic zones. Spotted juveniles are taken at or near the surface where their pigmentation pattern may function as "protective coloration in the light-dappled environment" (Rosenblatt \& Butler 1977: 845) and break up the body shape of the fish. Tanaka (1908) reported the presence of spotted juveniles (Trachypterus misakiensis $=D$. polystictum) with elongate pectoral-fin rays near shore after stormy weather, suggesting an epipelagic habitat and somewhat limited swimming ability. Spotted juveniles have also been captured via nightlight in surface waters (Trachypterus misakiensis $=$ D. polystictum; Herre \& Harold 1950). Specimens figured by Tanaka (1908) and Herre $\&$ Harold (1950) depict spotted juveniles with elongate pelvic-fin rays and greatly reduced anteriormost dorsal-fin rays, supporting the notion that elongate fin ray loss is not simultaneous as proposed by Rosenblatt \& Butler (1977). However, capture data suggest that spotted juveniles may have a greater depth range. Numerous spotted juveniles have been collected in stomachs of lancetfish (Alepisaurus spp.) that were caught on longlines set between 150-305 m (Fitch 1964; Fourmanoir 1969; Rosenblatt \& Butler 1977; however, the lancetfish prey may not have been eaten at the same depth where the lancetfish were caught), $113 \mathrm{~mm}$ SL specimen from the vicinity of the Line Islands in the central Pacific was captured in an open-net tow to about $100 \mathrm{~m}$ (King \& Ikehara 1956), and the first record of $D$. polystictum from Oman (Fig. 26), a juvenile in which spots are not visible, was collected at $1000 \mathrm{~m}$ by a deep-water trawler (Laith Jawad, pers. comm.).

Rosenblatt \& Butler (1977) suggested that a loss of the spotting pattern, elongation of the caudal region and loss or reduction of a gas bladder coincide with a change in habitat as individuals move offshore and adapt to an assumed vertical orientation, as in other members of Trachipteridae. However, vertical orientation is exhibited even at very young ages (larvae prior to the development of spotting patterns with extremely elongate dorsal and pelvic-fin rays, and spotted juveniles) in nearshore surface habitats as evidenced by videos and photographs of live larvae and juveniles filmed from eastern Japan (e.g., http://dailyomi.blog.fc2.com/blog-entry-169.html?sp). Adult D. polystictum (with a dorsal ridge, complete loss of the pelvic-fin rays, elongate caudal region and pigmentation changes consisting of loss of spotting and black vs. red dorsal and caudal rays in the elongate caudal region) are collected in offshore water to roughly $500 \mathrm{~m}$ (Rosenblatt \& Butler 1977). At least one instance of an adult D. polystictum swimming vertically in shallow (5-6 m) water has been reported from Guadeloupe, French West Indies (Fig. 27, Daniel Rabbe, pers. comm). This individual has all typical adult characters consisting of complete loss of first 5-6 dorsalfin rays, complete loss of pelvic-fin rays, elongation of the caudal region, loss of spotting and blackening of the fin rays on the elongate caudal region. Specimens matching this description are typically found in deeper, offshore water, and therefore this record is a unique occurrence.

Taxonomic history. In 1897, a rare fish washed up on the beach at Newcastle, New South Wales. The specimen was passed along to the Australian Museum's ichthyology curator, J. Douglas Ogilby for identification. At the time of Ogilby's description of the individual, only eight related specimens were known from Australasian waters and Ogilby recognized this ninth as a young trachipterid (140 mm SL). Ogilby (1898: 656) noted the differences between this specimen and the other described Australasian specimens, such as fin-ray numbers and morphology, head profile, body contour, and proportions. Regarding its specific identity, he states "...these fishes pass through many and puzzling changes in their passage from youth to maturity, and recognizing, therefore, the necessity for exercising the greatest caution in dealing with specimens of different ages but from neighboring localities, it is equally incumbent on us to guard against falling into the opposite error by carelessly uniting together... what may prove to be very distinct species." While clearly aware of potential ontogenetic and geographic variations and unable to fully align this individual with other Australasian representatives, Ogilby made the decision to rank this specimen as a subspecies of Trachypterus jacksonensis (Ramsay 1881) based primarily "on account of the numerous spots which ornament the head and body". The coloration of this specimen varied significantly from all ontogenetic stages of all other species known at the time. 


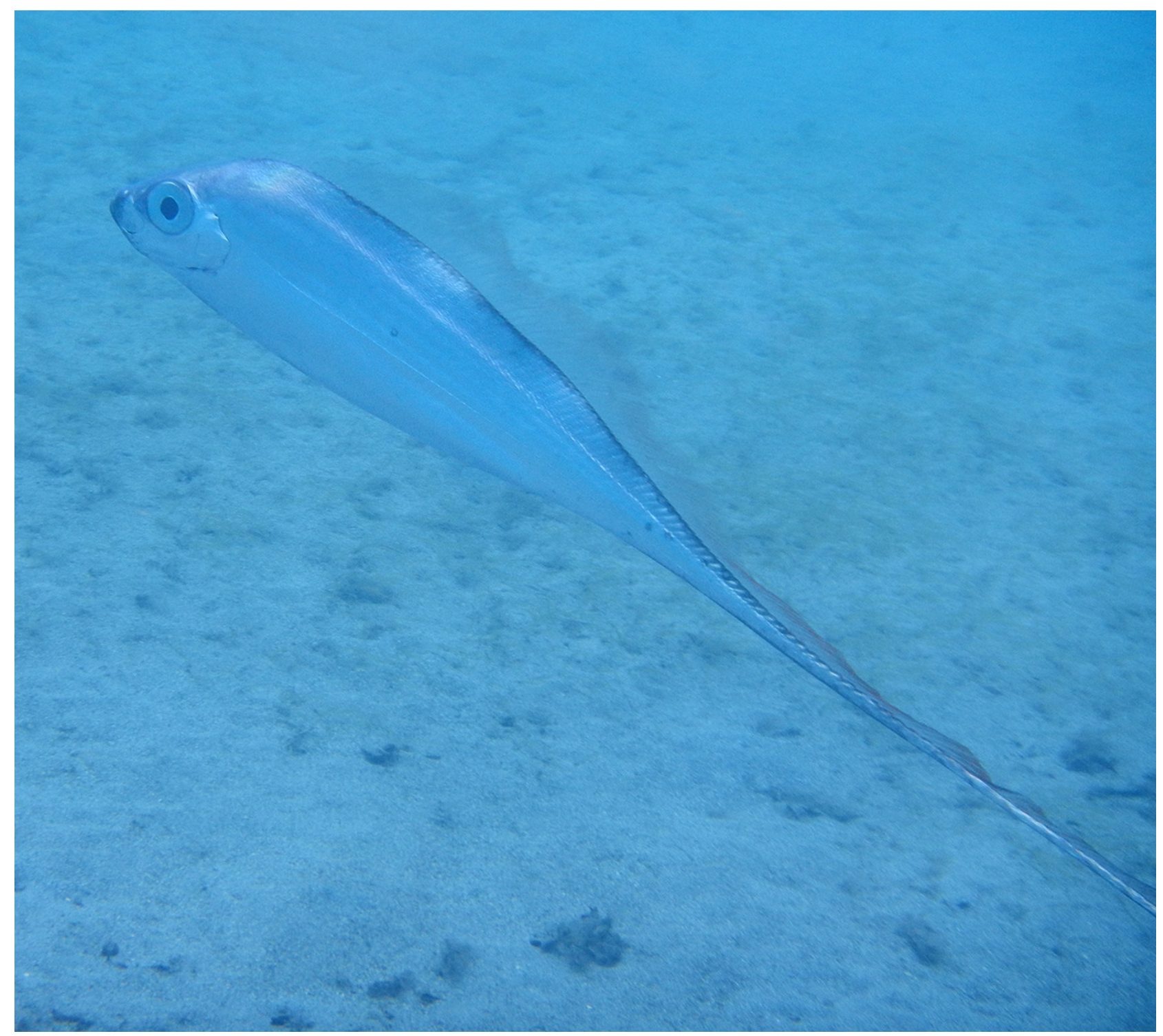

FIGURE 27. Desmodema $\mathrm{sp}$. Live specimen (not collected) approximately $1.2 \mathrm{~m}$ TL photographed in Guadeloupe at 5 to $6 \mathrm{~m}$ depth. (C) Daniel Rabble, used with permission.

In revising the suborder Trachipteroidei, Walters \& Fitch (1960) erected the genus Desmodema for the placement of Trachypterus jacksoniensis polystictus Ogilby 1898. Walters \& Fitch (1960) differentiated the genus Desmodema from $Z u$ based, in part, on 1) the orientation of the ventral profile (straight vs. scalloped) and 2) the lateral line on the caudal region (straight vs. wavy), and from Trachipterus based on 1) the number of vertebrae (104-109 vs. 69-101), 2) the presence vs. absence of scales and 3) orientation of the dorsal caudal-fin rays relative to the caudal peduncle (parallel vs. angled dorsally). Walters and Fitch (1960) referenced an unknown number of specimens presumably ranging from late larvae to adult; neither the ontogenetic nor the geographical variation represented by their generic diagnosis is known.

In review of the trachipterids from the eastern Pacific, Fitch (1964) examined 26 Pacific specimens of $D$. polystictum and based his redescription of the species on 12 individuals from the eastern Pacific (11 mm-1106 mm SL). Although Fitch (1964) acknowledged the morphological changes that occur with ontogeny, his description did not specifically address these changes. However, Fitch recognized both T. misakiensis Tanaka 1908 and T. deltoideus Clark 1938 as conspecifics of $D$. polystictum and synonymized them accordingly.

A second species of Desmodema was described by Rosenblatt \& Butler (1977) with their description of $D$. lorum from the northern Pacific. These authors addressed previous confusion in the literature regarding the presence of scales in the genus. For example, there is no mention of scales by Ogilby (1898) in the original description and 
Tanaka (1908) noted that the body is scaleless and smooth. However, Walters \& Fitch (1960: 446) and Fitch (1964) noted that the body of Desmodema is covered with "...non-imbricated elliptical scales each with two slightly divergent spinose ridges." Rosenblatt \& Butler (1977) described D. polystictum as scaleless at all sizes and the young of $D$. lorum being covered with scales, each with a pair of longitudinal spinous ridges, and adults as scaleless. Confusion regarding the presence of scales continued to persist, as Zacharia \& Kannen (2012) described an adult specimen of $D$. polystictum as scaleless. Examination of new material (this study) reveals the presence of scales in juveniles and adults in both species of Desmodema. Non-overlapping, cycloid scales are located on at the base of the dorsal-fin rays in D. polystictum from the northwestern Atlantic (MCZ $60557355 \mathrm{~mm} \mathrm{SL}$, Fig. 28). However, a northwestern Pacific specimen (NSMT 91459, $94.3 \mathrm{~mm} \mathrm{SVL}$ ) was covered with slightly overlapping scales that bear longitudinal ridges and do not alter the pigmentation pattern when removed (note that these ridges are not the same as those found on the lateral surface of some ctenoid scales, i.e., some spinoid scales; Roberts, 1993: fig. 2C). A second northwestern Pacific specimen of D. polystictum (NSMT 68656, 140.5mm SVL) has large patches of simple (i.e., without ridges) cycloid scales covering the body.

Juvenile and adult specimens of $D$. lorum have cycloid scales; although these are both with and without ridges (NSMT 58740, $404 \mathrm{~mm} \mathrm{SL}$ ) and may be rectangular. Scales may have 1-4 ridges either with or without spines (USNM 164325, $60 \mathrm{~mm}$ SL; HUMZ 113370, $273 \mathrm{~mm} \mathrm{SL}$ ). These differences in scale morphology do not appear to correlate with geography, ontogeny, or morphological placement. No scales with spines were observed in $D$. polystictum in the current study.

Rosenblatt \& Butler (1977) provided a detailed redescription of Desmodema, but nearly all specimens they examined were from the northeastern Pacific Ocean, thereby masking potential geographical variation. Additionally, most specimens were damaged and no material smaller than $18.9 \mathrm{~mm} \mathrm{SV}$ were examined. Although the authors addressed some ontogenetic changes (juvenile to adult), character changes associated with the larva-to-juvenile transition were not discussed.

Species-level diversity. Since the establishment of the genus by Walters \& Fitch (1960), Desmodema has been reviewed by Fitch (1964) from the eastern Pacific, globally by Rosenblatt \& Butler (1977), Heemstra \& Kannemeyer (1984) from South African waters and Ji et al. (2009) from Korean waters. The genus was considered monotypic until the work of Rosenblatt and Butler (1977) in which they described D. lorum; prior work was unknowingly based on both species.

The following summarizes morphological differences between $D$. polystictum and $D$. lorum. Data are synthesized from published work and from new specimens, some of which represent new geographic locations, examined in this study.

\section{Desmodema polystictum (Ogilby 1898)}

Figures 2C, 23, 26, 28

Type species. Trachypterus jacksoniensis polystictus Ogilby 1898

Holotype. lost. 140 mm SL. Beach wash-up, Newcastle, New South Wales, Australia.

Material Examined. AMS I.24154 (Radiograph, 840 mm SL, Pacific, Australia, Nelson Bay); AMS I.24308001 (353 mm SL, Pacific, Indonesia, South Java); AMS I.20098-013 (235 mm SL, Pacific, Australia, New South Wales, Broken Bay); BMNH 1982.10.1.1 (105.9 mm SVL, Indian, off Sumatra); HUMZ 141902 (98.4 mm SL, Pacific, Japan, off Kinkasan Island); HUMZ 199972 (106.9 mm SL, Pacific, East China Sea); MCZ 58907 (cleared and stained, 2 specimens, 11-41 mm SL; Atlantic, western Atlantic, off Brazil); MCZ 58909 (3 specimens, 21-29 mm SL, Atlantic, western Central Atlantic); MCZ 58910 (35 mm SL, Atlantic, western Central Atlantic); MCZ 60557 (355 mm SL, Atlantic, northwestern, off Massachusetts); MCZ 96836 (64.5 mm SL, Atlantic, eastern, off Senegal); MCZ 164725 (Radiograph, 92 mm; Atlantic, northwestern, off Massachusetts); MCZ 165989 (59 mm, Atlantic, northwestern, Bear Seamount); NMNZ P.16409 (240 mm SL, Pacific, Kermedec Islands, Havre Trough); NSMT-P 57647 (145.1 SVL, Pacific, Japan, Western North Pacific); NSMT-P 63975 (271 mm SL, Pacific, Japan, Sea of Japan, Hyogo Prefecture); NSMT-P 65206 (142.4 mm SL, Pacific, Japan, Kagoshima Prefecture); NSMT-P 68656 (140.5 mm SVL, Pacific, Japan, Sea of Japan, Hyogo Prefecture); NSMT-P 91459 (94.3 SVL, Pacific, Japan, off Kagoshima); USNM 287024 (195.4 mm SVL, Pacific, south Pacific Ocean); USNM 215709 (421.17 mm 
SL, Pacific, Hawaii, off Oahu); USNM 112110 (80 mm SL, Pacific, Philippines, Sulu Sea); USNM 164171 (107.9 mm SL, Pacific, Kiribati, near Washington Island); USNM 16552 (366.6 mm SVL, Atlantic, Florida, off Fort Lauderdale); VIMS 42793 (48 mm SVL; Atlantic, Bear Sea Mount); VIMS 42794 (66.1 mm SL, Atlantic, Straits of Florida).

Trachypterus deltoideus (= Desmodema polystictum); CAS:ICH:5552 (Holotype, radiograph only, Pacific, south Pacific, French Polynesia, Austral Islands, Rurutu Island).

Diagnosis. Dorsal-fin rays 115-139; in juveniles first 5 or 6 more stout and elongate than more posterior rays; pectoral-fin rays 1+ 11-14; $\mathrm{P} 2$ absent in adults, 6-10 elongate rays in juveniles, the posteriormost is branched; caudal $7-10$, typically 7 or 8 . Snout length less than eye diameter in adults, eye diameter slightly greater than snout length in juveniles. SVL 1.44-2.61 in SL in adults, 1.21-1.43 in juveniles. Vertebrae: 71-74 total, 18-20 precaudal. Scales present in juveniles and adults.

Remarks. Rosenblatt \& Butler (1977) listed the lack of scales at all sizes as a diagnostic character for D. polystictum. Although present in both species of Desmodema, scales are not obvious in the genus, and are even less obvious in D. polystictum due to their fragility, simplicity, and what appears to be low frequency of occurrence, at least after preservation. However, scales were detected in nearly all juvenile and adult specimens of $D$. polystictum examined in this study.

Distribution. Desmodema polystictum is considered circumtropical but large gaps exist in its confirmed distribution. It is currently known as common throughout the western Pacific and the northeastern and tropical Pacific. Also known from the western North Atlantic (Bear Seamount to Guadeloupe), Eastern Atlantic (south of Mauritania-Senegal border) and Indian Ocean (Oman, India, Pakistan, eastern South Africa, Indonesia). Desmodema polystictum has not been recorded from the northeast Atlantic (north of Senegal) or the Mediterranean (Palmer 1961, Whitehead et al. 1986) and there are no confirmed collections in those regions known to the authors.

Geographic variation. Juveniles from the Atlantic Basin have five or six pelvic-fin rays and Pacific juveniles have nine or ten. Of the two juveniles reported from the southeastern Indian Ocean (Heemstra \& Kannemeyer 1984), one specimen has nine pelvic-fin rays, and the second has seven on the left and eight on the right.

Taxonomic notes. The synonyms provided in Rosenblatt \& Butler (1977), Heemstra \& Kannemeyer (1984) and Quéro et al. (1990) are all considered valid. Additionally, Trachypterus trachyurus Poey 1861 from Cuba, a $112 \mathrm{~mm}$ SL juvenile specimen that, based on the description, was transitioning from juvenile to adult, is considered a synonym of $D$. polystictum as outlined below. The Cuban specimen described by Poey has been referenced as a misspelling of Trachipterus trachyurus (Gmelin 1789) and not an original description. However, after comparison of new material with Poey's (1861) original description, T. trachyurus Poey 1861 is considered a senior synonym of D. polystictum (Ogilby 1898). Rosenblatt \& Butler (1977) synonymized Trachipterus trachyurus, not of Poey, as described by Leapley (1953) with D. polystictum. Those authors stated, however, that T. trachyurus Poey 1861 is not D. polystictum for several reasons: 1) number of pelvic-fin rays (6 in T. trachyurus vs. 8 or 9 in D. polystictum); 2) number of pectoral-fin rays (15 vs. 12-14); and 3) coloration (silvery with a midlateral yellow band vs. polka-dotted). Examination of Atlantic specimens not available to Rosenblatt \& Butler reveal that the number of pelvic-fin rays in this region is 5-6 and several Pacific specimens have pectoral-fin ray counts of 15 (1 exceptionally short fin-ray followed by 14 rays). It also appears that Rosenblatt \& Butler (1977) translated Poey's "une band argentée" as "a yellow band" rather than "a silver band". This midlateral silver band can accompany a "spotless' Desmodema as some specimens do not show spots or lose spots early in development (see Fig. 26).

Poey (1861) described several other characters that actually align his specimen with D. polystictum. First, it had a triangular shape to the body, which is the case in juvenile $D$. polystictum. Second, it had a very large maxilla (Desmodema has the largest maxilla of the three trachipterid genera). Third, in regards to the caudal fin, Poey stated that the fin was barely detectable but the rays were all dorsal and ran parallel to the body. He essentially described the caudal fin of Desmodema, as there is no ventral caudal lobe present and the caudal fin is easily overlooked, which is not the case in Trachipterus or $Z u$. Finally, Poey also stated that the post-anal region was rough because the lower processes of the vertebrae pierced through the ventral body margin. This condition has been observed in Desmodema (for example, NMNZ P.016409 240mm SL; see Remarks) and, to a lesser extent, in Trachipterus.

It is for these reasons that we provisionally recognize Trachypterus trachyurus Poey 1861 as a senior synonym of D. polystictum (Ogilby 1898). In accordance with Article 23.9 of the International Code of Zoological Nomenclature, the younger name, Desmodema polystictum (Ogilby 1898) is here provisionally recognized as valid. The junior synonym has been used as the presumed valid name in more than 25 works by at least 10 authors in the im- 
mediately preceding 50 years, encompassing the minimum 10 year required span, and therefore satisfies the condition of Article 23.9.1.2 (Pertseva-Ostroumova \& Rass 1973, Rosenblatt \& Butler 1977, Bauchot \& Bianchi 1984, Heemstra \& Kannemeyer 1984, Olney 1984, Whitehead et al. 1986, Quéro et al. 1990, Richards 1990, Amaoka et al. 1992, Charter \& Moser 1996, Hutchins 2001, Shinohara et al. 2001, Hayashi 2002, Moore et al. 2003, Nelson et al. 2004, Mundy 2005, Olney \& Richards 2006, Fahay 2007, Ji et al. 2009, Zacharia \& Kannan 2012, Okiyama 2014, Shinohara et al. 2014, Martin 2015, Deshmukh et al. 2017, Rathnasuriya et al. 2019). However, Trachypterus trachyurus Poey 1861 was used as a valid species name by Leapley (1953). As outlined above, both the description of Poey (1861) and the specimen described by Leapley (1953) fit the concept of Desmodema polystictum. Therefore, because the name has been used after 1899, Article 23.9.1.1 for allowing reversal of precedence is not satisfied. Therefore, an application to the International Commission on Zoological Nomenclature to resolve this issue will be submitted.

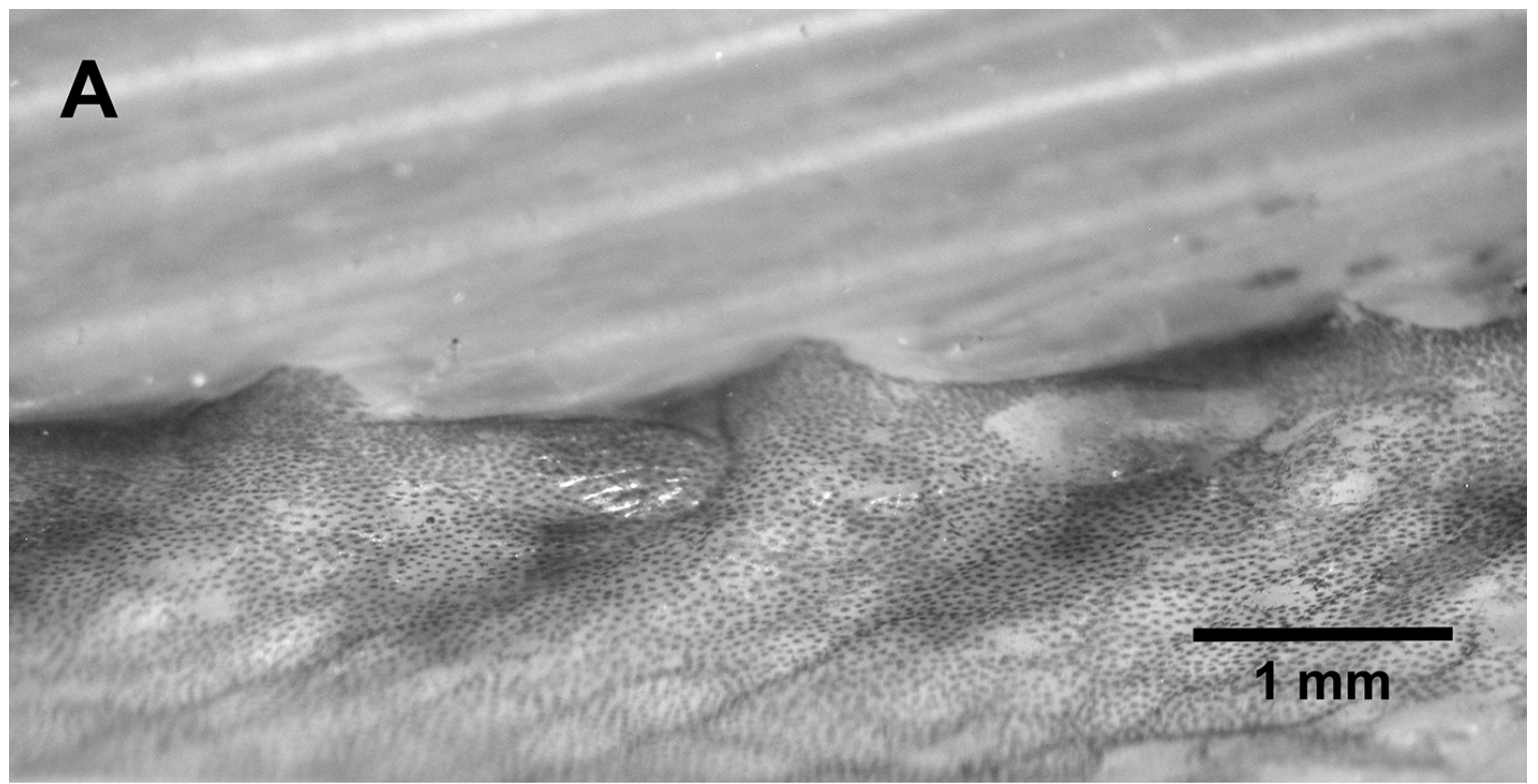

\section{B}

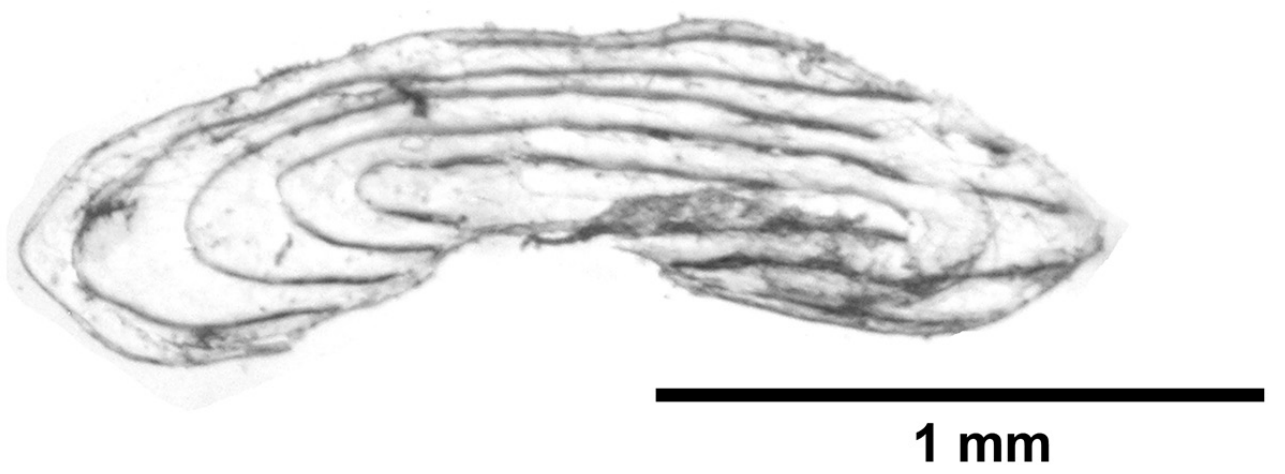

FIGURE 28. Desmodema polystictum (Ogilby 1898). MCZ 60557; $355 \mathrm{~mm}$ SL. A, scales at base of dorsal fin. B, Isolated scale.

\section{Desmodema lorum Rosenblatt \& Butler 1977}

Figure 29

Holotype. USNM 216726. 1098 mm SL. Trawled west of northern Baja California, at 400m fishing depth. (Fig. 29).

Material Examined. HUMZ 186218 (986 mm SL, Pacific, Japan, off Miyagi); KPM-NI0019326 (935 mm TL, Pacific, Japan); NSMT-P 57555 (430 mm SL, Pacific, western north Pacific); NSMT-P 58740 (404 mm SL, Pacific, 
Japan, Honshu); NSMT-P 58741 (2 specimens, 765, 827 mm SL, Pacific, Japan, Honshu); USNM 216726 (Holotype, radiograph, 1098 mm SL, Pacific, eastern North Pacific, Mexico); USNM 164325 (4 specimens, 52.3-100.2 mm SL, Pacific, California, west of Santa Cruz, from Alepisaurus stomach).

Diagnosis. Dorsal-fin rays 197-215; in juveniles first 5 or 6 more stout and elongate than more posterior rays; pectoral 1+ 11-14; pelvic absent in adults, 7-11 elongate rays in juveniles; caudal 4-7, typically 6 . Snout length greater than eye diameter in adults, approximately equal in juveniles. Snout-vent length 3.0-4.1 in SL in adults, 1.4-2.0 in juveniles. Vertebrae: 106-111 total, 21-25 precaudal. Numerous scale types (cycloid, ridged scales both with and without lateral spines) present in juveniles and adults.

Remarks. The caudal region is much more elongate in adult $D$. lorum with the SL of adult $D$. lorum comprised of approximately $3 / 4$ postanal length (vs. $2 / 3$ postanal length in $D$. polystictum). The height of the dorsal fin is proportionately greater in D. lorum than in D. polystictum of similar size (Rosenblatt \& Butler 1977: fig. 8). Additionally, the overall coloration after preservation of juvenile and adult $D$. lorum is darker than $D$. polystictum, particularly along the elongate caudal region. In addition to lateral-line scales, several scale types are present in $D$. lorum, although they are easily overlooked. The most obvious location is the ventral margin between the left and right pectoral girdles, where scales with 1-4 ridges, some possessing 1-5 lateral spines per ridge are present (NSMT 58740). There does not appear to be an ontogenetic or geographic trend regarding placement or morphology of scales based on the available specimens, however examination of more specimens is required.

Distribution. Known only from North Pacific Ocean, from $41^{\circ}$ to $29^{\circ} \mathrm{N}$ in the western Pacific and from $36^{\circ}$ to $22^{\circ} \mathrm{N}$ in the eastern Pacific. Specimens are primarily collected in midwater trawls, with collection depths ranging from depth bins of 0-80 $\mathrm{m}$ to $902-933 \mathrm{~m}$, but adults are most commonly collected from 500-700m.

Geographic variation. Fin-ray counts generally are greater than what has been previously reported for $D$. lorum, and those specimens with numbers corresponding to the higher end of the range were collected from the western Pacific Ocean. An adult specimen captured from 20-30 m depth off Sagami Bay (KPM NI-0019326, 935 mm SL), has seven caudal-fin rays and 30 total $(1+14)$ pectoral-fin rays, a number previously unreported for the genus.

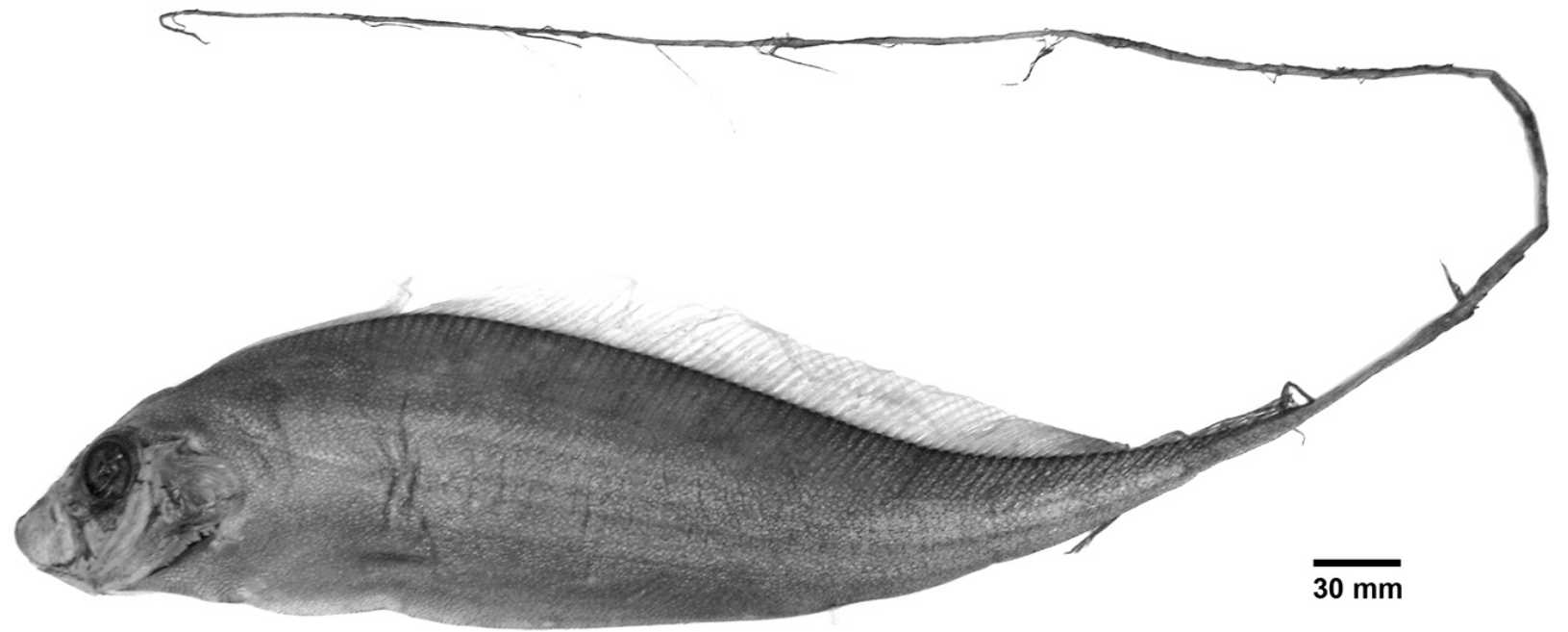

FIGURE 29. Desmodema lorum Rosenblatt \& Butler 1977. Holotype; USNM 216726; 1098 mm SL.

\section{Conclusions}

Despite advances in the understanding of Trachipteridae resulting from tremendous additions to the specimen base, which have allowed for the refinement of the taxonomy and diagnoses within the family, there are still large knowledge gaps associated with the taxonomy of the family. These reflect incomplete understanding of geographic distribution of taxa that may mask unrecognized taxonomic variability. The genus Trachipterus specifically remains problematic and will require greater detailed global study. Early life history stages remain unknown for several taxa, which hinders full interpretation of ontogenetic transitions. Protracted transitions, some of which are clarified here, further confuse stage-based diagnoses and must be considered in future analyses of this family. 


\section{Acknowledgments}

J.M.M. is sincerely grateful for the support and guidance of the late John E. Olney, Sr. This work would not be possible without J. E. Olney and the assistance and enthusiasm of the curators and managers of the collections visited and listed within this manuscript- we thank you. The authors greatly appreciate feedback on earlier drafts of the manuscript from Richard Brill, Tracey Sutton, Pete Van Veld and especially Bill Richards, who generously provided invaluable guidance and expertise throughout this project. We thank Bruce Mundy for his detailed review that greatly improved the final product. We also thank Peter Konstantinidis, Filipe Ribeiro, and Peter Warth for providing translations. J.M.M. was supported by the National Science Foundation East Asia and Pacific Programs Graduate Fellowship, the Chancellor's Faculty Fellowship and the Paul Lee Professional Development Grant from the Virginia Community College System, Women in Scientific Education (WISE) Grant from the National Science Foundation awarded to the College of William \& Mary, The John E. Olney Sr. Ichthyology Award and Student Research Grant from VIMS, and Reves International Center Student Research Grant at William \& Mary. This is contribution number 3998 of the Virginia Institute of Marine Science, William \& Mary.

\section{References}

Amaoka, K., Ama, G., Nakaya, M., Yabe, K., Masuda, K. \& Sasaki, S. (1992) Larval and juvenile fishes collected from the northern Pacific Ocean by T/S Oshoro-Maru. Part I. Salmoniformes, Clupeiformes, Myctophiformes, Cyprinodontiformes, Lophiiformes, and Lampridiformes. Bulletin of the Faculty of Fisheries, Hokkaido University, 43, 1-23.

Angulo, A. \& López-Sánchez, M.I. (2017) New records of lampriform fishes (Teleostei:Lampriformes) from the Pacific coast of lower Central America, with comments on the diversity, taxonomy, and distribution of the Lampriformes in the eastern Pacific Ocean. Zootaxa, 4236 (3), 573-591. https://doi.org/10.11646/zootaxa.4236.3.11

Backus, R.H., Mead, G.W., Haedrich, R.L. \& Ebeling, A.W. (1965) The mesopelagic fishes collected during Cruise 17 of the R/V Chain, with a method for analyzing faunal transects. Bulletin of the Museum of Comparative Zoology, 134 (5), 139-157.

Bauchot, M.L. \& Bianchi, G. (1984) First record of Desmodema polystictum (Ogilby, 1898) in North Indian Ocean. Cybium, 8 (4), 96-98.

Beltrán-León, B.S. \& Herrera, R.R. (2000) Estadios tempranos de peces del Pacifico Colombiano. Tomos 1 \& 2. Republica de Colombia, Ministerio de Agricultura y Desarrollo Rural, Instituto Nacional de Pesca Y Acuicultura (INPA), Buenaventura, Colombia, 726 pp.

Bleeker, P. (1868) Description et figure d'une nouvelle espèce de Trachypterus de l'île d'Amboine. Archives néerlandaises des sciences exactes et naturelles, 3, 279-280, pl. 12.

Bloch, M.E. \& Schneider, J.G. (1801) Gen. 101. Trachypterus. In: Blochii, M.E. (Ed.), Systema Ichthyologiae Iconibus cx Ilustratum. Post obitum auctoris opus inchoatum absolvit, correxit, interpolavit Jo. Gottlob Schneider, Saxo. umtibus Austoris Impressum et Bibliopolio Sanderiano Commissum, Berolini [Berlin], pp. 480-483. https://doi.org/10.5962/bhl.title.5750

Bolin, R.L. (1933) New fish records from southern California. Copeia, 1, 35-36. https://doi.org/10.2307/1436190

Bonelli, F.A. (1820) Description d'une nouvelle espèce de poisson de la Méditerranée appartenant au genre Trachyptère avec des observations sur les caractères de ce même genre. Memorie della Reale Accademia delle Sciene di Torino, 24 (8129), 485-494, pl. 9.

Bounhiol, J.P. (1923) Une espèce nouvelle de Trachypterus Goüan: le Trachypterus Gavardi, Bounhiol. In: Bounhiol, J.P. \& Gavard, A., Bulletin de l'Institut Océanographique, Monaco, 432, pp. 1-4.

Brünnich, M.T. (1788) Om den Islandske Fisk, Vogmeren. Gymnogaster arcticus. Kongelige Danske Videnskabernes Selskab, 3, 408-413.

Charter, S.R. \& Moser, H.G. (1996) Trachipteridae. In: Moser, H.G. (Ed.), The early stages of fishes in the California current region. CalCOFI Atlas, 33, pp. 669-677.

Clark, H.W. (1938) Additional new fishes. The Templeton Crocker Expedition of 1934-35. No. 36. Proceedings of the California Academy of Sciences, Series 4, 22 (7), 179-185.

Clarke, F.E. (1881) Description of a new species of Trachypterus. Transactions of the New Zealand Institute, 13, $195-199$.

Cocco, A. (1838) Osservazioni intorno taluni pesci del mare di Messina. Lettera. Il Faro Anno 6. 4 (15). Tip. M. Nobolo, Messina, 16 pp., 1 pl.

Costa, O.G. (1842) Fauna del regno di Napoli, ossia enumerazione di tutti gli animali che abitano le diverse regioni di questo regno e le acque che le bagnano, etc. Pesci. Fauna del regno di Napoli, 3 (pt 2), 1-148.

Cuvier, G. (1816) Le Règne Animal distribué d'après son organisation pour servir de base à l'histoire naturelle des animaux et 
d'introduction à l'anatomie comparée. Les reptiles, les poissons, les mollusques et les annélides. Vol.2. $1^{\text {st }}$ Edition. xviii + 532 pp., pls. 9-10 in Vol. 4.

Deshmukh, A, Dragičevič, B., Paidi, C. \& Muniraj. K. (2017) New record of Desmodema polystictum from northwestern Indian Ocean, Cybium, 41 (4), 379-381.

Dulčić, J. (2002) First record of scalloped ribbon fish, Zu cristatus (Pisces: Trachipteridae), eggs in the Adriatic Sea. Journal of Plankton Research, 24 (11), 1245-1246. https://doi.org/10.1093/plankt/24.11.1245

Emery, C. (1879) Le metamorfosi del Trachypterus taenia. Atti della Accademia Nazionale dei Lincei, 3 (3), 8.

Fahay, M.P. (2007) Lampridiformes. In: Fahay, M.P. (Ed.), Early stages of fishes in the western North Atlantic Ocean. Vol. I. North Atlantic Fisheries Organization, Dartmouth, Nova Scotia, pp. 824-840.

Ferry, L.A., Paig-Tran, E.W., Summers, A.P. \& Liem, K.F. (2019) Extreme premaxillary protrusion in the king-of-the-salmon, Trachipterus altivelis. Journal of Morphology, 280 (12) 1865-1870. https://doi.org/10.1002/jmor.21071

Fitch, J.E. (1964) The ribbonfishes (family Trachipteridae) of the eastern Pacific Ocean, with a description of a new species. California Fish and Game, 50, 228-240.

Fitch, J.E. \& Schultz, S.A. (1978) Some rare and unusual occurrences of fishes off California and Baja California. California Fish and Game, 64 (2), 74-92.

Fourmanoir, P. (1969) Contents stomacaux d'Alepisaurus (poissons) dans le Sud-Ouest Pacifique. Office de la Recherche Scientifique et Technique d'Outre-mer Séries Océanographie, 7 (4), 51-60.

Fricke, R., Eschmeyer, W.N. \& van der Laan, R. (Eds.) (2020) Eschmeyer's Catalog of Fishes: Genera, Species, References. Electronic version Available from; http://researcharchive.calacademy.org/research/ichthyology/catalog/fishcatmain.asp (accessed 30 November 2020)

Garcia-Barcelona, S, Garcia-Cancela, R., Cayuela, M.S., Fernandez-Peralta, L., de Carlos, A., Baon, R., Macias, D. \& Baez, J.C. (2016) Descripcion de dos ejemplares de Zu cristatus (Bonelli 1820) capturados accidentalmente con un palangre semipelagico en el Mediterraneo occidental. Arxius de Miscel-Iania Zoologica, 14, 91-98. [in Spanish] https://doi.org/10.32800/amz.2016.14.0091

Gmelin, J.F. (1789) Pisces in Caroli a Linné, Systema Naturae per regna tria naturae, secundum classes, ordines, genera, species, cum characteribus, differentiis, synonymis, locis. Vol. 1. Part 3. impensis Georg. Emanuel. Beer, Lipsiae, pp. 1126-1516.

Goodrich, E.S. (1909) Part IX. Vertebrata Craniata (First Fascicle: Cyclostomes and Fishes). In: Lankester, R. (Ed.), A Treatise on Zoology. Adam and Charles Black, London, pp 1-518. https://doi.org/10.5962/bhl.title.13773

Goüan, A. (1770) Historia piscium, sistens ipsorum anatomen externam, internam, atque genera in classes et ordines redacta. Histoire des poissons, contenant la description anatomique de leurs parties externes et internes et le caractère des divers genres rangés par classes et par ordres. Amand König, Argentorati (Strasbourg), xviii + 252 (x2) pp., pl. IIV. [in Latin and French] https://doi.org/10.5962/bhl.title.6764

Günther, A. (1861) Trachypteridae. In: Günther, A. (Ed.), Catalogue of the fishes in the British Museum. Vol. 3. British Museum (Natural History), Department of Zoology, London, pp. 300-312.

Günther, A. (1887) Report on the deep-sea fishes collected by H. M. S. Challenger during the years 1873-76. Report on the Scientific Results of the Voyage of H. M. S. Challenger, 22 (57), i-lxv + 1-268, pls. 1-66. https://doi.org/10.5962/bhl.title.15693

Hamilton, H. (1916) Notes on the occurrence of the genus Trachipterus in New Zealand. Transactions and Proceedings of the Royal Society of New Zealand, 48, 370-382.

Harrisson, C.M.H. \& Palmer, G. (1968) On the neotype of Radiicephalus elongatus Osório with remarks on its biology. Bulletin of the British Museum of Natural History, Zoology, 16, 187-211. https://doi.org/10.5962/p.144463

Hayashi, M. (2002) Trachipteridae. In: Nakabo, T. (Ed.), Fishes of Japan with pictorial keys to the species. English Edition. Tokai University Press, Tokyo, pp. 406-1489.

Heemstra, P.C. \& Kannemeyer, S.X. (1984) The families Trachipteridae and Radiicephalidae (Pisces, Lampridiformes) and a new species of $Z u$ from South Africa. Annals of the South African Museum, 94 (2), 13-39.

Herre, A.W. \& Herald, E.S. (1950) Noteworthy additions to the Philippine fish fauna with descriptions of a new genus and species. Philippine Journal of Science, 79 (3), 309-340.

Hubbs, C.L. (1925) The metamorphosis of the Californian ribbon fish, Trachypterus rex-salmonorum. Papers of the Michigan Academy of Science, Arts and Letters, 5, 469-476.

Hutchins, J.B. (2001) Checklist of the fishes of Western Australia. Records of the Western Australian Museum, Supplement No. $63,9-50$. https://doi.org/10.18195/issn.0313-122x.63.2001.009-050

Hutton, F.W. (1873) Contributions to the ichthyology of New Zealand. Transactions of the New Zealand Institute, $1873,264$. Hutton, F.W. (1876) Contributions to the ichthyology of New Zealand. Transactions of the New Zealand Institute, $1876,214$. Ji, H.W., Yoon, S.C. \& Kim, J.K. (2009) Taxonomic review of the family Trachipteridae (Lampridiformes) from Korea. Korean 
Journal of Ichthyology, 21 (4), 273-282. [in Korean]

Jordan, D.S. \& Gilbert, C.H. (1882) Synopsis of the fishes of North America. Bulletin of the US National Museum, 16, 618-619. https://doi.org/10.5479/si.03629236.16.i

Jordan, D.S. \& Gilbert, C.H. (1894) Description of a new species of ribbon fish Trachypterus rex-salmonorum, from San Francisco. Proceedings of the California Academy of Sciences, 2 (4), 144-146, pl. 9.

Jordan, D.S. \& Snyder, J.O. (1901) Descriptions of nine new species of fishes contained in museums of Japan. Journal of the College of Science, Imperial University of Tokyo, 15 (2), 301-311, pls. 15-17.

Jordan, D.S. \& Snyder, J.O. (1904) On a collection of fishes made by Mr. Alan Owston in the deep waters of Japan. Smithsonian Miscellaneous Collections, 45, 230-240, pls. 58-63.

King, J. E. \& Ikehara, I. I. (1956) Some unusual fishes from the central Pacific.Pacific Science, 10, 17-24.

Kner, R. (1859) Ueber Trachypterus altivelis und Chaetodon truncatus, n. sp. Sitzungsberichte der Kaiserlichen Akademie der Wissenschaften. Mathematisch- Naturwissenschaftliche Classe, 34, 437-445, pls. 1-2.

Leapley, W.T. (1953) First record of the ribbonfish, Trachipterus trachyurus, from the mainland of North America. Copeia, 4 , 236. https://doi.org/10.2307/1440364

Lipej, L., Trkov, D. \& Mavrič, B. (2018) Occurrence of ribbon fish (Trachipterus trachypterus) in Slovenian waters (northern Adriatic Sea). Annales. Series historia naturalis, 28 (2), 129-134. https://doi.org/10.19233/ASHN.2018.16

Lowe, R.T. (1852) An account of fishes discovered or observed in Madeira since the year 1842. Proceedings of the Zoological Society of London, 18 (5), 247. [1850]

Macali, A., Semenov, A., Paladini de Mendoza, F., Dinoi, A., Bergami, E. \& Tiralongo, F. (2020) Relative Influence of Environmental Factors on Biodiversity and Behavioural Traits of a Rare Mesopelagic Fish, Trachipterus trachypterus (Gmelin, 1789), in a Continental Shelf Front of the Mediterranean Sea. Journal of Marine Science and Engineering, 8 (581), 1-13. https://doi.org/10.3390/jmse8080581

Martin, J.M. (2015) Phylogeny, ontogeny, and distribution of the ribbonfishes (Lampridiformes, Trachipteridae). Ph.D. Thesis. The College of William \& Mary, Williamsburg, Virginia, 217 pp.

Masuda, H., Amaoka, A., Araga, C., Uyeno, T. \& Yoshino, T. (1984) The fishes of the Japanese Archipelago. Tokai University Press, Tokyo, 437 pp.

McCoy, F. (1886) Natural history of Victoria. Prodromous of the zoology of Victoria. J. Ferres, Melbourne, 38 pp. https://doi.org/10.5962/bhl.title.4821

Meek, A. (1890) On the structure of Trachypterus arcticus (the modern ribbon-fish). Studies from the Museum of Zoology at University College Dundee, 1 (6), 1-24, pls. I + II.

Mincarone, M.M., Lima, A.T. \& Soto, J.M.R. (2001) Sobre a ocorrência do peixe-fita Trachipterus jacksonensis (Ramsay, 1881) (Lampridiformes, Trachipteridae) na costa Basileria. Mare Magnum, 1 (2), 121-124. [in Portuguese]

Moore, J.A., Hartel, K.E., Craddock, J.E. \& Galbraith, J.K. (2003) An annotated list of deepwater fishes from off the New England region, with new area records. Northeaster Naturalist, 10 (2), 159-248. https://doi.org/10.1656/1092-6194(2003)010[0159:AALODF]2.0.CO;2

Moritz, T., Stumer, D., Jakobsen, K. \& Jakobsen, J. (2015) Observations on two live specimens of Trachipterus arcticus (Lampridiformes: Trachipteridae) from the Azores. Cybium, 39 (1), 78-80.

Mundy, B.C. (2005) Checklist of the fishes of the Hawaiian Archipelago. Bishop Museum Bulletins in Zoology, 6, 1-703.

Nelson, J.S., Crossman, E.J., Espinosa Pérez, Findley, L.T., Gilbert, C. R., Lea, R.N. \& Williams, J.N. (2004) Common and scientific names of fishes from the United States, Canada, and Mexico. American Fisheries Society Special Publication 29. $6^{\text {th }}$ Edition. American Fisheries Society, Bethesda, Maryland, $386 \mathrm{pp}$.

Nishimura, S. (1964) Additional information on the biology of the dealfish Trachipterus ishikawai Jordan \& Snyder. Bulletin of Japan Sea Regional Fisheries Research Laboratory, 13, 127-129.

Norman, J.R. (1922) Two new fishes from New Britain and Japan. Annals and Magazine of Natural History, Series 9, 10 (56), 217-218. https://doi.org/10.1080/00222932308632764

Ogilby, J.D. (1898) On a Trachypterus from New South Wales. Proceedings of the Linnean Society of New South Wales, 3 , 646-659. https://doi.org/10.5962/bhl.part.12736

Okiyama, M. (1988) An atlas of the early stages of fishes in Japan. Tokai University Press, Tokyo, 1154 pp.

Okiyama, M. (2014) An Atlas of Early Stage Fishes in Japan Second Edition. Vols. 1 \& 2. Tokai University Press, Kanagawa, li +976 pp., XX pls.

Olney, J.E. (1984) Lampridiformes: development and relationships. In: Moser, H.G., Richards, W.J., Cohen, D.M., Fahay, M.P., Kendall Jr., A.W. \& Richardson, S.L. (Eds.), Ontogeny and systematics of fishes. American Society of Ichthyologists and Herpetologists Special Publication No. 1. Allen Press, Lawrence, Kansas, pp. 368-379.

Olney, J.E., Johnson, G.D. \& Baldwin, C.C. (1993) Phylogeny of Lampridiform Fishes. Bulletin of Marine Science, 52 (1), 137-169.

Olney, J.E. \& Naplin, A. (1980) Eggs of the scalloped ribbonfish, Zu cristatus (Pisces: Trachipteridae) in the western north 
Atlantic. Copeia, 1, 165-166.

https://doi.org/10.2307/1444156

Olney, J.E. \& Richards, W.J. (2006) Trachipteridae: dealfishes, ribbonfishes. In: Richards, W.J. (Ed.), Early stages of Atlantic Fishes. An identification guide for the western central north Atlantic. Vol. 1. Taylor \& Francis, New York, pp. $1019-1026$. https://doi.org/10.1201/9780203500217

Palmer, G. (1961) The dealfishes (Trachipteridae) of the Mediterranean and north-east Atlantic. Bulletin of the British Museum of Natural History, Zoology, 7, 335-351. https://doi.org/10.5962/p.314163

Pertseva-Ostroumova, T.A. \& Rass, T.S. (1973) Ichthyoplankton of the southeastern Pacific Ocean. Transactions of the Institute of Oceanology Academy, Nauk, SSSR, 94, 7-70. [in Russian, English translation by the Department of the Secretary of State of Canada]

Philippi, R.A. (1874) Ueber eine neue Art Trachypterus aus dem chilenischen Meere. Archiv für Naturgeschichte, 40 (Pt. 1), 117-121, pl. 3.

Poey, F. (1861) Memorias sobra la historia natural de la Isla de Cuba, acompañadas de sumarios Latinos y extractos en Francés. Tomo 2. Imprinta de Barcina, La Habana, 3, 337-442, pls. 1-19. [in Spanish] https://doi.org/10.5962/bhl.title.2485

Purchase, C.F. (2017) First report of Dealfish, Trachipterus arcticus (Lampriformes: Trachipteridae), from Canadian waters. Canadian Field-Naturalist, 131 (4), 325-327. https://doi.org/10.22621/cfn.v131i4.1912

Quéro, J.C., Hureau, J.C., Karrer, C., Post, A. \& Saldanha, L. (1990) Check-list of the fishes of the eastern tropical Atlantic. UNESCO, Lisbon, 1490 pp.

Quigley, D.T.G. \& Henderson, G. (2014) First record of the scalloped ribbonfish Zu cristatus (Bonelli 1819) (Lampriformes: Trachipteridae) from N.W. European waters. The Glasgow Naturalist, 26 (1), 103-104.

Rafinesque-Schmaltz, C.S. (1810) Caratteri di alcuni nuovi generi e nuove specie di animali (principalmente di pesci) e piante della Sicilia, con varie osservazioni sopra i medisimi. Per le stampe di Sanfilippo, Palermo, 105 pp., 20 pls. [reprint, 1967, Asher-Amsterdam] https://doi.org/10.5962/bhl.title.104418

Ramsay, E.P. (1881) On a new species of Regalecus, from Port Jackson. Proceedings of the Linnean Society of New South Wales, 1881, pp. 631-633, pl. xx https://doi.org/10.5962/bhl.part.15897

Ranzani, C. (1818) Descrizione di un pesce, che appartiene ad un nuovo genere della famiglia dei Tenioidi di Cuvier. Opuscoli Scientifici, 133-137, pl. VI. [in Italian]

Rathnasuriya, M.I.G., Mateos-Rivera, A., Bandara, A.G.G.C., Skern-Mauritzen, R., Jayasinghe, R.P.P.K., Krakstad, J.O. \& Dalpadado, J. (2019) DNA barcoding confirms the first record of a Desmodema polystictum (Ogilby, 1898) egg and all-time high adult catches in the Indian Ocean. Marine Biodiversity Records, 12 (22), 1-7. https://doi.org/10.1186/s41200-019-0180-7

Richards, W.J. (1990) List of Fishes of the Western Central Atlantic and the Status of Early Life Stage Information. NOAA Technical Memorandum NMFS-SEFC, 267, 1-88.

Roberts, C.D. (1993) Comparative morphology of spined scales and their phylogenetic significance in the Teleostei. Bulletin of Marine Science, 52 (1), 60-113.

Roberts, T.R. (2012) Systematics, biology and distribution of the species of the oceanic oarfish genus Regalecus. Mémoires du Muséum national d'Histoire naturelle. Tome 202. Muséum National d'Histoire Naturelle, Paris, 268 pp.

Rosenblatt, R.H. \& Butler, J.L. (1977) The ribbonfish genus Desmodema, with the description of a new species (Pisces, Trachipteridae). Fishery Bulletin, 75 (4), 843-855.

Sabaj, M.H. (2020) Codes for Natural History Collections in Ichthyology and Herpetology. Copeia, 108 (3), $593-669$. https://doi.org/10.1643/ASIHCODONS2020

Sanzo, L. (1918) Uova e larve di Trachypterus cristatus. R. Comitato Talassografico Italaliano Memoria, LXIV, 1-16. [in Italian]

Savinykh, V.F. \& Baitalyuk, A.A. (2011) Taxonomic status of ribbonfishes of the genus Trachypterus (Trachipteridae) from the northern part of the Pacific Ocean. Journal of Ichthyology, 51 (8), 581-589. https://doi.org/10.1134/S0032945211040175

Scott, E.O.G. (1983) Observations on some Tasmanian fishes: Part XXIX. Papers and Proceedings of the Royal Society of Tasmania, 117, 167-202. https://doi.org/10.26749/rstpp.117.167

Scott, E.O.G. (1984) Observations on some Tasmanian fishes: Part XXX. Papers and Proceedings of the Royal Society of Tasmania, 118, 187-222. https://doi.org/10.26749/rstpp.118.187

Shinohara, G., Endo, K., Matsuura, K., Machida, Y. \& Honda, H. (2001) Annotated checklist of deepwater fishes from Tosa Bay, Japan. In: Fujita, T.H., Saito, H. \& Takeda, M. (Eds.), Deep-sea fauna and pollutants in Tosa Bay. National Museum of Nature and Science, Monographs No. 20, pp. 283-343.

Shinohara, G., Masanori, N., Ueda, Y., Kojima, S. \& Matsuura, K. (2014) Annotated checklist of deep-sea fishes of the Sea of 
Japan. In: Fujita, T. (Ed.), Deep-sea fauna of the Sea of Japan. National Museum of Nature and Science Monographs, No. 44, 225-291.

Shirke, S.S., Ramachandran, S., Pradeep, H.P., Musaliyarakam, N., Devi, S.M. \& Sinha, M.K. (2017) First record of the Tapertail ribbonfish Zu elongatus Heemstra \& Kannemeyer, 1984 from Indian EEZ. Fishtaxa, 2 (1), 43-47.

Smith, J.L.B. (1953) The Sea Fishes of Southern Africa. Revised enlarged edition. Central News Agency, Johannesburg, 564 pp., 107 pls.

Smith, J.L.B. (1956) A new dealfish from South Africa. Annals and Magazine of Natural History, Series 12, 9, 1 (02), 449-452, pl. 12. https://doi.org/10.1080/00222935608655839

Snyder, J.O. (1908) Description of Trachypterus seleniris, a new species of ribbon-fish from Monterey Bay, California. Proceedings of the Academy of Natural Sciences of Philadelphia, 60, 319-320.

Sparta, A. (1933) Trachypteridae e Regalecidae. In: Faune e flora del Golfo di Napoli: Uova, larvae e stadi giovanii de Teleostei. Pubblicazioni della Stazione Zoologica di Napoli, Monograph 38, pp. 266-279. [in Italian]

Swainson, W. (1839) On the natural history and classification of fishes, amphibians, \& reptiles, or monocardian animals. Vol. II. Spottiswoode \& Co., London, vi +448 pp. https://doi.org/10.5962/bhl.title.62140

Tanaka, S. (1908) Notes on some Japanese fishes, with descriptions of fourteen new species. Journal of the College of Science, Imperial University of Tokyo, 23 (7), 1-54, pls. 1-4.

Tortonese, E. (1958) Cattura di Trachypterus cristatus Bon. e note sui Trachypteridae del mare Ligure. Doriana, II (89), 1-5. [in Italian]

Valenciennes, A. (1835) s.n. In: Cuvier, G. \& Valenciennes, A., Histoire naturelle des poissons. Tome dixième. Suite du livre neuvième. Scombérö̈des. Livre dixième. De la famille des Teuthyes. Livre onzième. De la famille des Taeniö̈des. Livre douzième. Des Athérines. Vol. 10. Chez F. G. Levrault, Paris, pp. i-xxiv + 1-482, 2 pp., pls. 280-306.

Van der Laan, R., Eschmeyer, W.N. \& Fricke, R. (2014) Family-group names of Recent fishes. Zootaxa, 3882 (1), 1-230. https://doi.org/10.11646/zootaxa.3882.1.1

Walbaum, J.J. (1792) Petri Artedi sueci genera piscium. In quibus systema totum ichthyologiae proponitur cum classibus, ordinibus, generum characteribus, specierum differentiis, observationibus plurimis. Redactis speciebus 242 ad genera 52. Ichthyologiae Pars III. Ant. Ferdin. Rose, Grypeswaldiae [Greifswald], [viii] + 723 pp., pls. 1-3.

Walters, V. (1963) The trachipterid integument and a hypothesis on its hydrodynamic function. Copeia, 1963 (2), $260-270$. https://doi.org/10.2307/1441341

Walters, V. \& Fitch, J.E. (1960) The families and genera of the Lampridiform (Allotriognath) suborder Trachipteroidei. California Fish and Game, 46 (4), 441-451. https://doi.org/10.2307/1439670

Whitehead, P.J.P., Bauchot, M.L., Hureau, J.C., Nielsen, J. \& Tortonese E. (1986) Fishes of the North-eastern Atlantic and Mediterranean. UNESCO, Paris, $491 \mathrm{pp}$. https://doi.org/10.2307/1444931

Wiley, E.O. \& Johnson, G.D. (2010) A teleost classification based on monophyletic groups. In: Nelson, J.S., Schultze, H.-P. \& Wilson, M.V.H. (Eds.), Origin and Phylogenetic Interrelationships of Teleosts. Verlag Dr. Friedrich Pfeil, München, pp. $123-182$.

Young, S.S., Shen, S.C. \& Chui, T.S. (1994). First record of trachipterid larvae with description of different stages and adult forms from Taiwan. Acta Zoologica Taiwanica, 5 (2), 85-93.

Zacharia, P.U. \& Kannan, K. (2012) First record of polka-dot ribbonfish Desmodema polystictum (Pisces: Trachipteridae) from Indian waters. Marine Biodiversity Records, 5, 1-4.

https://doi.org/10.1017/S1755267211001151 